University of Tennessee Health Science Center

UTHSC Digital Commons

\title{
Habituation and Dishabituation in the Olfactory Bulb: From Neural Responses to Behavior
}

\author{
Mary Cameron Ogg \\ University of Tennessee Health Science Center
}

Follow this and additional works at: https://dc.uthsc.edu/dissertations

Part of the Biological Factors Commons, Investigative Techniques Commons, and the Neurosciences Commons

\section{Recommended Citation}

Ogg, Mary Cameron (http://orcid.org/0000-0003-4451-871X), "Habituation and Dishabituation in the Olfactory Bulb: From Neural Responses to Behavior" (2017). Theses and Dissertations (ETD). Paper 450. http://dx.doi.org/10.21007/etd.cghs.2017.0444. 


\title{
Habituation and Dishabituation in the Olfactory Bulb: From Neural Responses to Behavior
}

\begin{abstract}
Habituation and dishabituation modulate the neural resources and behavioral significance allocated to incoming stimuli across the sensory systems. The purpose of the research presented in this dissertation was to characterize these processes in the mouse olfactory bulb (OB) and to determine if $\mathrm{OB}$ acetylcholine $(\mathrm{ACh})$ has a role in physiological and behavioral olfactory dishabituation. Calcium imaging was used to determine the timecourse and magnitude of habituation in different parts of the OB during and after a prolonged odor presentation. Widefield imaging of the dendritic, or glomerular, response of $\mathrm{OB}$ output cells demonstrated that prolonged odor input habituates glomerular responses during the presentation as well as to subsequent presentations of the odor. Manipulation of OB ACh release during prolonged odor presentations using electrical stimulation dishabituated these decreased glomerular odor responses. A novel behavioral investigation paradigm was developed to see how prolonged odor input affects odor salience in awake, behaving mice. Optogenetic stimulation of OB cholinergic neurons rapidly modulated odor salience in this paradigm, causing mice to suddenly investigate a previously ignored odor. Non-olfactory sensory stimulation also dishabituated odor investigation and this increase could be blocked pharmacologically with a cholinergic antagonist in the $\mathrm{OB}$, demonstrating the ecological validity of this ACh effect. Two-photon imaging revealed that, unlike the glomerular responses, soma responses of different $\mathrm{OB}$ cell types can be quite different from each other during a prolonged odor presentation. These results highlight the need for future studies that explore the role of different $\mathrm{OB}$ cell types in the representation of olfactory information over time and behavioral dishabituation.
\end{abstract}

\section{Document Type}

Dissertation

\section{Degree Name}

Doctor of Philosophy (PhD)

\section{Program}

Biomedical Sciences

Research Advisor

Max Fletcher, Ph.D.

\section{Keywords}

acetylcholine, calcium imaging, dishabituation, habituation, olfactory bulb

\section{Subject Categories}

Biological Factors | Investigative Techniques | Medical Sciences | Medicine and Health Sciences | Neurosciences 
Habituation and Dishabituation in the Olfactory Bulb: From Neural Responses to Behavior

\author{
A Dissertation \\ Presented for \\ The Graduate Studies Council \\ The University of Tennessee \\ Health Science Center
}

\begin{abstract}
In Partial Fulfillment
Of the Requirements for the Degree

Doctor of Philosophy

From The University of Tennessee
\end{abstract}

By

Mary Cameron Ogg

December 2017 
Chapter 2 (C) 2015 by Mary Cameron Ogg, Mounir Bendahmane, and Max Fletcher. All other material C 2017 by Mary Cameron Ogg. All rights reserved. 


\section{DEDICATION}

To Hadrian,

with love to the moon and back. 


\section{ACKNOWLEDGEMENTS}

It takes a village to (raise a child and) complete a Ph.D. and I would like to thank mine:

Max Fletcher, thank you for helping me complete the marathon of graduate school. I have the utmost respect for your scientific vision and appreciation for the kind and supportive way you run the lab.

The members of the Fletcher lab, past and present, who have become my dearest friends: Eloisa Pavesi, Vivian Guedes, Mounir Bendahmane, Jordan Ross, and Stephanie Staszko. Mounir, you played an integral role in this research and I thank you for your patience and guidance, through every verified glomerulus and every "I" button press.

The members of my committee and other professors in the Anatomy and Neurobiology department, thank you for contributing so much to my neuroscience education and inspiring me to share it with others.

My friends and family, especially my parents, Rob and Susan, my brothers, Alec, Thomas, and Charlie, and my son, Hadrian. Your love and encouragement means the world to me and I could not have done this without you. Dad, thank you for instilling a love of science in me from the very beginning, being my first and best editor, and introducing me to the whole new (data analysis) world of R! 


\begin{abstract}
Habituation and dishabituation modulate the neural resources and behavioral significance allocated to incoming stimuli across the sensory systems. The purpose of the research presented in this dissertation was to characterize these processes in the mouse olfactory bulb (OB) and to determine if $\mathrm{OB}$ acetylcholine (ACh) has a role in physiological and behavioral olfactory dishabituation. Calcium imaging was used to determine the timecourse and magnitude of habituation in different parts of the $\mathrm{OB}$ during and after a prolonged odor presentation. Widefield imaging of the dendritic, or glomerular, response of OB output cells demonstrated that prolonged odor input habituates glomerular responses during the presentation as well as to subsequent presentations of the odor. Manipulation of OB ACh release during prolonged odor presentations using electrical stimulation dishabituated these decreased glomerular odor responses. A novel behavioral investigation paradigm was developed to see how prolonged odor input affects odor salience in awake, behaving mice. Optogenetic stimulation of OB cholinergic neurons rapidly modulated odor salience in this paradigm, causing mice to suddenly investigate a previously ignored odor. Non-olfactory sensory stimulation also dishabituated odor investigation and this increase could be blocked pharmacologically with a cholinergic antagonist in the $\mathrm{OB}$, demonstrating the ecological validity of this ACh effect. Two-photon imaging revealed that, unlike the glomerular responses, soma responses of different OB cell types can be quite different from each other during a prolonged odor presentation. These results highlight the need for future studies that explore the role of different $\mathrm{OB}$ cell types in the representation of olfactory information over time and behavioral dishabituation.
\end{abstract}




\section{TABLE OF CONTENTS}

CHAPTER 1. INTRODUCTION ..................................................................................

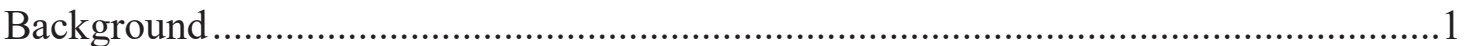

Organization and Specific Aims ........................................................................2

\section{CHAPTER 2. HABITUATION OF GLOMERULAR RESPONSES IN THE OLFACTORY BULB FOLLOWING PROLONGED ODOR STIMULATION}

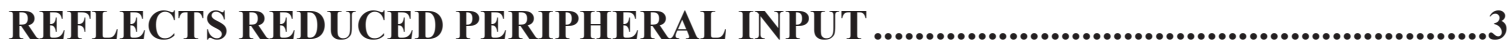

Introduction...

\section{CHAPTER 3. OLFACTORY BULB ACETYLCHOLINE RELEASE DISHABITUATES ODOR RESPONSES AND REINSTATES ODOR INVESTIGATION ........................................................................................................17}

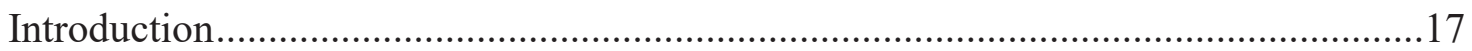

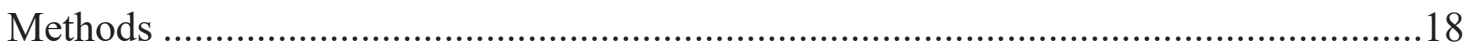

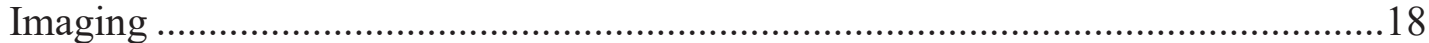

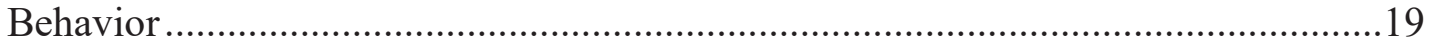

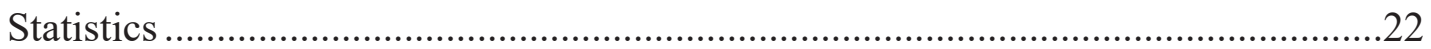

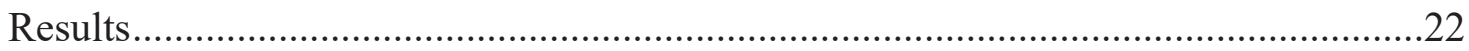

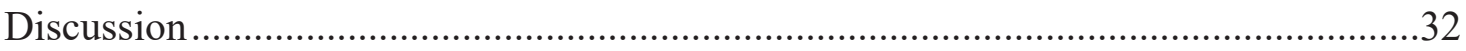

\section{CHAPTER 4. RESPONSE PATTERNS OF MITRAL AND TUFTED CELLS} DIFFER DURING AND AFTER A PROLONGED ODOR STIMULATION..........36

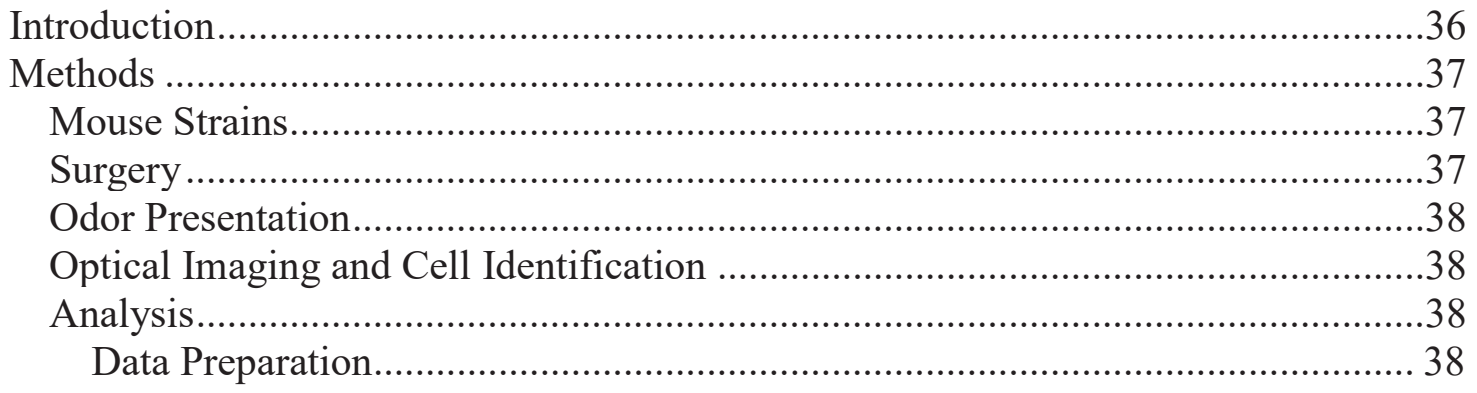




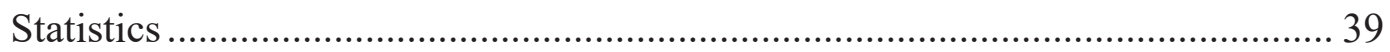

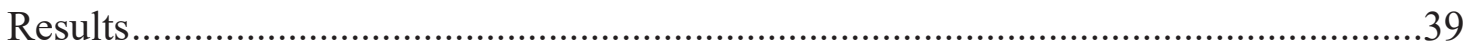

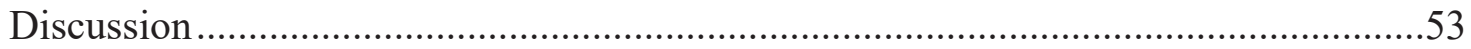

CHAPTER 5. CONCLUSIONS AND FUTURE DIRECTIONS ..................................57

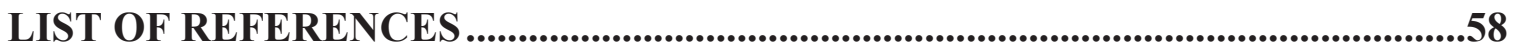

VITA 


\section{LIST OF TABLES}

Table 4-1. P-values from the post-hoc Nemenyi test comparing PC1 values among the different $\mathrm{OB}$ cell types.

Table 4-2. P-values from the post-hoc Nemenyi test comparing PC2 values among the different $\mathrm{OB}$ cell types.

Table 4-3. P-values from the post-hoc Nemenyi test comparing PC1 values among the different $\mathrm{OB}$ cell types and mitral cell groups.

Table 4-4. P-values from the post-hoc Nemenyi test comparing PC2 values among the different $\mathrm{OB}$ cell types and mitral cell groups.

Table 4-5. The percentage (and number) of cell-odor pairs displaying each kind of post-odor response. 


\section{LIST OF FIGURES}

Figure 2-1. 30-s odor exposure decreases subsequent glomerular responses to that odor for several minutes..........................................................................

Figure 2-2. 30-s odor exposure uniformly decreases subsequent glomerular responses, regardless of initial intensity.......................................................

Figure 2-3. 30-s odor exposure decreases subsequent glomerular responses to a structurally similar odor.

Figure 2-4. 30-s odor exposure decreases subsequent glomerular responses to odors, but not to ON electrical stimulation. ..........................................................12

Figure 3-1. Characterization of odor investigation behavior............................................20

Figure 3-2. Glomerular responses to a prolonged odor presentation habituate over time.

Figure 3-3. Electrical basal forebrain stimulation (BFS) dishabituates glomerular odor responses.

Figure 3-4. Olfactory investigation behavior increases with odor onset and habituates over time.

Figure 3-5. Optogenetic light stimulation (OLS) can dishabituate odor investigation behavior.

Figure 3-6. A visual context change (VS) dishabituates odor investigation behavior. ...30

Figure 4-1. Population response patterns of different $\mathrm{OB}$ cell types during a prolonged odor presentation.

Figure 4-2. Individual responses of different $\mathrm{OB}$ cell types during a prolonged odor presentation.

Figure 4-3. Tufted cells are positively correlated with OSN input during a prolonged odor presentation, but mitral cells are not.

Figure 4-4. Principal component analysis (PCA) of individual responses of different OB cell types.

Figure 4-5. Population response patterns of different groups of mitral cell responses during a prolonged odor presentation.

Figure 4-6. Principal component analysis (PCA) of individual responses of different OB cell types and mitral cell groups. 
Figure 4-7. Normalized responses of mitral cells to different odors.

Figure 4-8. Inhibition affects mitral (M) cell responses during and after the odor presentation.

Figure 4-9. Normalized responses of superficial tufted cells to different odors. 54

Figure 4-10. Normalized responses of mitral cells comparing their responses to the same and different odors. 


\section{CHAPTER 1. INTRODUCTION}

\section{Background}

The olfactory bulb (OB) is a unique model system for studying sensory processing in the brain (Shipley and Ennis, 1996; Imai, 2014; Nagayama et al., 2014). While external information makes its way from the periphery to the cortex via the thalamus in other sensory systems, in the olfactory system, odor information is processed in the OBs before projecting to cortical areas. Olfaction begins when odors bind to olfactory receptors on olfactory sensory neurons (OSNs) in the nasal epithelium. Each OSN expresses only one type of olfactory receptor and all the OSNs that express the same receptor type project their axons to a single location in the OB (Mori et al., 1999; Feinstein and Mombaerts, 2004). This site, known as a glomerulus, is a dense collection of the dendrites of OB output (mitral/tufted) cells and interneurons. Because odors bind differentially to the olfactory receptors, each odor generates a unique pattern of glomerular activation (Mori et al., 1999, 2006). Each output cell receives axodendritic OSN odor input from only a single glomerulus, and therefore, reflects the activity of a single type of olfactory receptor. However, far from just passively relaying information about odor features, the activity of output cells is strongly modulated by dendrodendritic connections with excitatory and inhibitory interneurons in the $\mathrm{OB}$ and centrifugal input from the cortex and neuromodulatory areas (Fletcher and Chen, 2010).

Because of its location near the surface of the skull in rodents, the $\mathrm{OB}$ is a tractable part of the olfactory system to study using in vivo optical imaging (Fletcher et al., 2009; Wachowiak et al., 2013; Fletcher and Bendahmane, 2014). OB activity can be visualized in several ways (Homma et al., 2009), but the research described in this dissertation used fluorescent calcium imaging. The fluorescence of GCaMP, a genetically encoded calcium indicator, increases with cytoplasmic calcium concentration, a correlate of neuronal activity. In the time span of the work presented here, the sensitivity, kinetics, and cell-type specificity of GCaMP have continually improved (Fletcher et al., 2009; Chen et al., 2012; Ohkura et al., 2012). This fluorescence can be imaged at different spatial resolutions, to monitor real time changes in $\mathrm{OB}$ activity and to dissect the specific roles of different cell types in odor processing (Homma et al., 2009). Here, one-photon widefield microscopy was used to simultaneously image glomeruli across the entire dorsal surface of the OB. With its higher spatial resolution and deeper recording depth, two-photon microscopy was used to investigate odor dynamics at the single-cell level.

These imaging techniques can be utilized to study a basic, but fundamental question in sensory processing: how do simple forms of learning and experience affect the neural encoding of sensory information? Habituation is a vital sensory process that allows animals to filter out irrelevant stimuli that are being repeated or have been around for a prolonged period and focus selectively on important stimuli. "Although [it] is termed 'the simplest form of learning' and is well studied behaviorally, remarkably little is known about the neural mechanisms underlying habituation" (Rankin et al., 2009). Though work has been done on olfactory habituation of various kinds (Zufall and 
Leinders-Zufall, 2000; Dalton, 2000; Wilson and Linster, 2008; Reisert and Zhao, 2011), it was unknown how the bulb responds to odor exposures of physiologically relevant concentrations and length. The research described in this dissertation utilized in vivo calcium imaging to assess how a prolonged odor presentation (i.e. odor experience) affects odor responses in different parts of the olfactory bulb.

While habituation decreases responses to non-relevant stimuli, the opposing process, dishabituation, reestablishes responsivity to previously filtered stimuli if the sensory environment changes. The neurotransmitter acetylcholine (ACh) is known to be involved in attention and released in situations of environmental change (Inglis and Fibiger, 1995; Giovannini et al., 2001). Studies have demonstrated that OB ACh release increases sensitivity to odor input at both the glomerular and $\mathrm{M} / \mathrm{T}$ cell output levels (Bendahmane et al., 2016; Ma and Luo, 2012; Rothermel et al., 2014). Based on this, it was hypothesized that $\mathrm{ACh}$ release in the $\mathrm{OB}$ could dishabituate glomerular responses during prolonged odors and, as a result, allow the stimuli to be detected and investigated again. ACh levels in the OB were manipulated electrically, optogenetically, and pharmacologically during prolonged odor exposures and the results of these manipulations were tested using OB calcium imaging and a newly developed behavioral paradigm.

\section{Organization and Specific Aims}

The studies presented in Chapters 2-4 address the following specific aims:

1)

a) To characterize the time course and magnitude of glomerular habituation to a subsequent odor exposure following a prolonged presentation of that odor and

b) determine if this habituation reflects OSN adaptation or depression of OB circuitry.

2)

a) To characterize the time course and magnitude of glomerular habituation and behavioral odor salience during a prolonged odor presentation and

b) test the hypothesis that a cholinergic mechanism in the OB could reinstate habituated glomerular odor responses and odor investigation.

3) To characterize and compare the soma response of excitatory cell types in the $\mathrm{OB}$ during and after a prolonged odor presentation.

Chapter 5 contains conclusions and future directions of this work. 


\section{CHAPTER 2. HABITUATION OF GLOMERULAR RESPONSES IN THE OLFACTORY BULB FOLLOWING PROLONGED ODOR STIMULATION REFLECTS REDUCED PERIPHERAL INPUT*}

\section{Introduction}

Olfactory sensory neurons (OSNs) in the nasal epithelium expressing the same type of olfactory receptor project to glomeruli in the olfactory bulb (OB) (Mori et al., 1999; Feinstein and Mombaerts, 2004), a dense cluster of dendrites from interneurons and output mitral/tufted (M/T) cells. Because odors bind differentially to the olfactory receptors, each odor generates a unique pattern of glomerular activation in the bulb (Mori et al., 1999, 2006). These patterns can be visualized at either the presynaptic OSN input level or at the postsynaptic M/T cell level in vivo using various imaging methods (Pain et al., 2011; Fletcher and Bendahmane, 2014) and in some cases can reflect real time changes in responsivity following changes in odor input.

One such change, habituation, is the process by which animals decrease their responses to repeated or continually present stimuli (Wilson and Linster, 2008; Rankin et al., 2009). In the olfactory system, short-term habituation is likely primarily driven by a reduction of neuronal responsivity at several stages along the olfactory pathway from the periphery to the cortex (Zufall and Leinders-Zufall, 2000; Dalton, 2000; Wilson and Linster, 2008; Reisert and Zhao, 2011). Numerous studies have probed adaptation of OSN responses (Zufall and Leinders-Zufall, 2000; Reisert and Zhao, 2011) and M/T cell OB output (Wilson, 2000; Best and Wilson, 2004; Chaudhury et al., 2010). However, olfactory information is processed throughout the layers of the olfactory bulb, including via inhibitory networks within the glomerular layer (Wachowiak and Shipley, 2006; Nagayama et al., 2014). Yet, few studies have addressed the impact of habituating odor stimulation on odor responses in the glomerular layer of the olfactory bulb (Schafer et al., 2005; Lecoq et al., 2009).

Similarly to OSN and M/T cell output responses, these studies found glomerular layer response decreases with prolonged odor exposure or brief, very strong odor stimulations (Schafer et al., 2005; Lecoq et al., 2009). However, these studies both relied on recording methods that reflect the total activity of the glomerular circuit (fMRI (Schafer et al., 2005) and local field potential recordings (Lecoq et al., 2009)) that cannot differentiate excitatory output responses from inhibitory interneuronal responses. Further, the extent to which this reduction reflects decreased input from OSNs, as suggested by a recent study (Lecoq et al., 2009) or a reduction in responsiveness of OB neurons is still unclear.

\footnotetext{
*Reprinted with permission. Ogg, M. C., Bendahamane, M., and Fletcher, M. L. (2015). Habituation of glomerular responses in the olfactory bulb following prolonged odor stimulation reflects reduced peripheral input. Front. Mol. Neurosci. 8, 53.
} 
To address these questions about olfactory habituation in the glomerular layer, we measured glomerular responses before and after prolonged odor exposure in anesthetized transgenic mice expressing the fluorescent calcium indicator GCaMP2 in M/T and excitatory juxtaglomerular (JG) cells (Díez-García et al., 2005; Fletcher et al., 2009). We assessed glomerular responses to the same odorant (self-habituation) and to structurally similar, representationally overlapping odorants (cross-habituation) and compared them to that of M/T cell output responses reported previously (Wilson 2000). To dissect the role of OSN adaptation in post-synaptic glomerular habituation, we also compared posthabituated odor-driven responses to responses driven by olfactory nerve layer (ON) electrical stimulation (Fletcher et al., 2009).

We found that glomerular odor responses to both the habituating odor (selfhabituation) and to an odor that is structurally similar to the habituating odor (crosshabituation) decreased following a 30 second continuous odor pulse. At the moderate odor concentrations used in this study, neural response changes following selfhabituation were relatively uniform across glomeruli regardless of initial response intensity. Therefore, the glomerular representation (spatial map and relative intensity) of the habituated odor was unchanged. In contrast, post habituation ON stimulation-evoked glomerular responses displayed little habituation. The difference in glomerular habituation between odor and electrical stimulation provides evidence that the odor response reductions measured in the OB are most likely the result of OSN adaptation processes taking place in the periphery and not a consequence of adaptation of the OSN$\mathrm{M} / \mathrm{T}$ synapse.

\section{Methods}

\section{Animals and Surgery}

Experiments were performed using 20 adult transgenic male and female mice expressing the green fluorescent $\mathrm{Ca}^{2+}$ indicator GCaMP2 under the Kv3.1 potassium channel promoter (Díez-García et al., 2005). Under this promoter, GCaMP2 is expressed in M/T cells and a subpopulation of JG cells (Fletcher et al., 2009). Mice were anesthetized with urethane $(2 \mathrm{mg} / \mathrm{kg}$, i.p.) and given an injection of methyl scopolamine $(0.05 \mathrm{mg} / \mathrm{kg}$, i.p) to prevent nasal congestion. Mice were secured in a custom stereotaxic apparatus (Narishige) with a heating pad underneath to maintain body temperature. To create an imaging window, a skin incision was made over the dorsal surface of the mouse head and the bone overlying the olfactory bulbs was thinned with a dental drill. In cases in which electrical stimulation was used, part of the bone was removed after thinning. In some cases lidocaine was applied to the bulb through a small incision in the dura. A dental-cement well was built around the olfactory bulbs and filled with Ringer's solution. During imaging sessions, animals were freely breathing and the respiratory rate was monitored from the respiratory oscillation observed in the odor-evoked GCaMP2 odorevoked signal. All animal care protocols were approved by the University of Tennessee Institutional Animal Care and Use Committee. 


\section{Odorant Presentation}

Odors (2-hexanone, 2-heptanone, and ethyl butyrate (Sigma-Aldrich)) were delivered using a flow-dilution olfactometer previously described (Fletcher et al. 2009). Separate flow controllers for the clean air and the pure odorant vapor were used to mix the flow streams at the end of the odor delivery system to achieve an approximate concentration of $0.25 \%, 0.5 \%$, or $0.75 \%$ saturated vapor (s.v.) at a flow rate of $0.7 \mathrm{~L} / \mathrm{min}$. The odor concentration used for each animal was a concentration that activated discrete, stable glomeruli.

\section{Olfactory Nerve Stimulation}

For olfactory nerve layer electrical stimulation (ONS), a single current pulse (2 $\mathrm{ms}, 45-100 \mu \mathrm{A}$ ) was delivered to the olfactory bulb dorsal surface using a bipolar tungsten electrode (World Precision Instruments). This method has been shown previously to evoke increased glomerular GCaMP signals via synaptically driven activity and is not a result of direct electric current stimulating glomerular postsynaptic dendrites (Fletcher et al., 2009). Further, topical application of the $\mathrm{Na}^{+}$channel blocker lidocaine onto the OB completely blocked all ONS driven glomerular activity.

\section{Experimental Protocol}

Experiment 1: Habituation Timeline. For control trials, odor pulse duration was $1 \mathrm{~s}$ with an inter-stimulus interval of at least $2 \mathrm{~min}$. For the habituation trial, odor pulse duration was $30 \mathrm{~s}$. For post-habituation trials, odor pulse duration was $1 \mathrm{~s}$ and the interstimulus interval varied.

Experiment 2: Cross-Habituation. For control trials, odor pulse duration was $1 \mathrm{~s}$ with an inter-stimulus interval of at least 2 min. 2-hexanone (C6) was presented during the 30-s habituation trial. 2-heptanone (C7) was given $30 \mathrm{~s}$ post-habituation and C6 was given 1 minute post-habituation. We waited at least 10 minutes for the animals to recover from the first habituation, established new baseline responses for the two odors, and repeated the experiment with $\mathrm{C} 7$ as the habituating odor.

Experiment 3: ON-Stimulation. For control trials, odor pulse duration was $1 \mathrm{~s}$ and ONS duration was $2 \mathrm{~ms}$ with an inter-stimulus interval of at least $2 \mathrm{~min}$. For the habituation trial, odor pulse duration was $30 \mathrm{~s}$. For post-habituation trials, odor pulse duration was $1 \mathrm{~s}$, ONS duration was $2 \mathrm{~ms}$, and the inter-stimulus interval varied. Posthabituation trials occurred within 1 min following the odor habituation trial. 


\section{Optical Imaging and Analysis}

Imaging was performed using a Scientifica Slicescope equipped with a 10x $(0.3$ NA) Olympus objective. The dorsal olfactory bulb was illuminated with a LED light source centered at $480 \mathrm{~nm}$. GCaMP2 signals were band-pass filtered with a Chroma emission filter (HQ535/50) and collected using a CCD camera at $25 \mathrm{~Hz}$ (NeuroCCDSM256, Redshirt Imaging). Maps of stimulus-evoked spatial activity were generated by first correcting for photo-bleaching and then spatially low-pass filtered as described previously (Fletcher et al., 2009). The stimulus-evoked change in fluorescence $(\Delta \mathrm{F})$ was calculated by subtracting the average of five frames immediately preceding stimulus onset from the average of five frames centered on the peak of the response generated by the first respiration or electrical stimulation. Glomerular response amplitude $(\Delta \mathrm{F} / \mathrm{F})$ was calculated by dividing the stimulus-evoked change in fluorescence by the resting fluorescence. For quantitative analysis, discrete glomeruli were visually identified and the response amplitude was measured from a ROI (2x2 pixel average) at the center of each (Fletcher et al., 2009). The response of each glomerulus was averaged across control trials. A glomerulus was considered to respond if its mean $\Delta \mathrm{F} / \mathrm{F}$ response to a stimulus was greater than the background $\Delta \mathrm{F} / \mathrm{F}$ signal. Background signal was defined as the mean $\pm 2 \mathrm{SD} \Delta \mathrm{F} / \mathrm{F}$ value obtained from adjacent regions containing no glomerular activity (Fletcher, 2011). Habituation was measured by dividing the post-habituation response of each glomerulus by its average control response. To identify overlapping glomeruli in both the cross-habituation and ONS experiments (i.e. glomeruli that respond to both odors or to both odor and ONS), ROIs were placed at the center of all glomeruli activated by either odor delivery or ONS for each animal. Glomeruli that responded significantly, as defined above, to both stimuli were defined as shared and were pooled across animals for analysis (Fletcher, 2011).

\section{Statistical Analysis}

Statistical analyses were performed using Prism 5.0 software (Graphpad). Values are expressed as mean normalized response \pm SEM (unless otherwise indicated). Data were compared using one sample t-test, paired t-test, one-way ANOVA, and repeated measures ANOVA (Dunnett's test and Tukey's test post hoc analyses were performed when appropriate). Statistical significance was defined as $\mathrm{p}<0.05$.

\section{Results}

To determine how a 30-s odor exposure impacts subsequent glomerular responses to that odor, we measured glomerular responses to 1-s odor pulses before and after a single prolonged exposure in 10 animals (Figure 2-1). Following the habituation trial, the mean normalized glomerular responses changed (ANOVA: $F(5,395)=37.03, p<0.0001$ ), and post hoc tests showed significant reduction from baseline responses 1 minute $(70.1 \pm 2.1 \%, \mathrm{n}=95), 2$ minutes $(73.8 \pm 3.3 \%, \mathrm{n}=61)$, and 4 minutes $(85.2 \pm 2.5 \%, \mathrm{n}=49)$ post exposure (Figure 2-1C). Mean responses at $6(94.5 \pm 2.5 \%, \mathrm{n}=61)$ and 11 minutes 

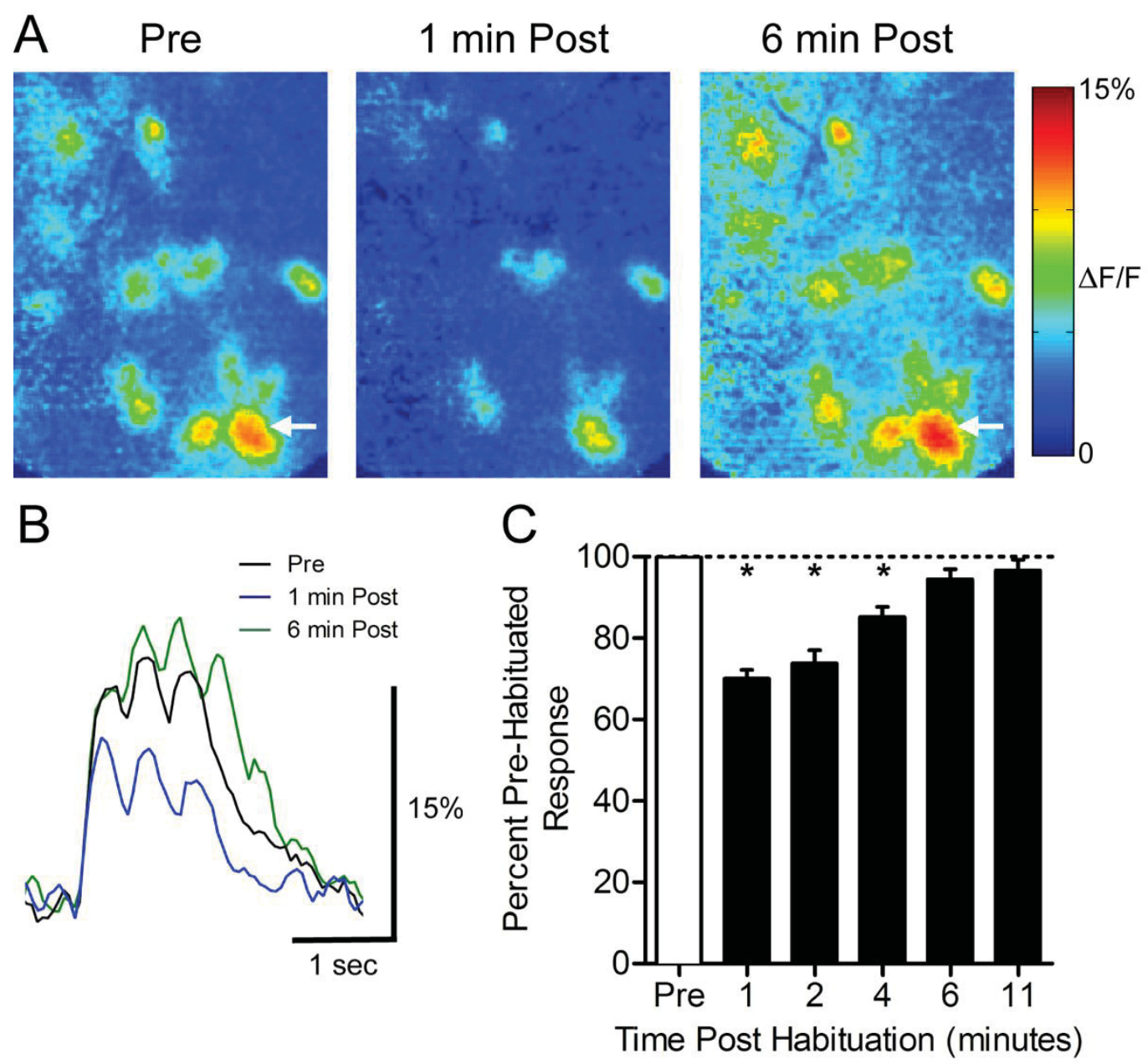

Figure 2-1. 30-s odor exposure decreases subsequent glomerular responses to that odor for several minutes.

(A) Pseudo-color glomerular responses to 2 -heptanone $(0.5 \%$ s.v. $)$ at $10 \mathrm{x}$ magnification. One minute after the habituating odor exposure ( 1 min Post), glomerular responses are decreased from their baseline (Pre). After six minutes, the responses have recovered (6 min Post). (B) GCamp2 fluorescence traces from the glomerulus indicated by arrows in (A). (C) The timeline of recovery from habituation. Mean normalized glomerular responses for all animals were reduced for several minutes post exposure. Error bars indicate SEM. * $\mathrm{p}<0.05$. 
$(96.6 \pm 2.7 \%, \mathrm{n}=40)$ post-habituation were not significantly different from the baseline, indicating that recovery had occurred by six minutes.

To determine if there was an effect of response intensity on the amount of habituation, we compared the responses of each glomerulus before and 1 minute after habituating odor exposure (Figure 2-2A). Linear regression analysis yielded a best-fit line with a slope (1.1 \pm 0.1 , not significant) showing that habituation has a uniform effect regardless of response intensity, and does not disproportionately decrease the response of either strongly or weakly responding glomeruli. The uniform reduction leaves relative glomerular response magnitudes of individual odor representations intact following prolonged odor stimulation. This effect is illustrated in Figure 2-2C, which highlights the similarity of pre- and post-habituation odor maps when they are normalized to the maximally responding glomerulus in each odor representation.

We next evaluated whether prolonged exposure to an odor would affect the subsequent glomerular response to a structurally similar odor, an effect known as crosshabituation (Wilson, 2000). In 5 animals, pre-habituation baseline responses to 2hexanone (C6) and 2-heptanone (C7) were established (Figure 2-3A). These odors differ by only a single carbon and share some activated glomeruli (Figure 2-3B). We assessed the effects of both self- and cross-habituation in shared glomeruli (Figure 2-3C). Pooling all habituation trials, regardless of habituating odor, shared glomeruli showed reduced mean normalized responses to both the habituated odor $(59.1 \pm 2.4 \%$ of baseline $)$ and to the cross-habituated odor $(66.9 \pm 1.8 \%$ of baseline $)$ with responses to the habituated odor significantly lower than those to the cross-habituated odor (paired t-test: $t(61)=2.53$, $\mathrm{p}<0.05, \mathrm{n}=62$ glomeruli) (Figure 2-3D). When the longer carbon chain odorant, C7, was used as the habituating odor, the cross-habituation (response to C6: $64.3 \pm 2.4 \%$ of baseline) was not different from self-habituation (response to C7: $60.1 \pm 3.1 \%$ of baseline) (paired t-test: $\mathrm{t}(40)=0.97, \mathrm{p}=0.33, \mathrm{n}=41$ glomeruli) (Figure 2-3E). However, when the shorter carbon chain odorant, $\mathrm{C} 6$, was used as the habituating odor, the cross-habituation (response to C7: $72.1 \pm 2.7 \%$ of baseline) was significantly less than the self-habituation (response to C6: $57.3 \pm 3.8 \%$ of baseline) (paired t-test: $\mathrm{t}(20)=4.92, \mathrm{p}<0.0001, \mathrm{n}=21$ glomeruli) (Figure 2-3F).

We used olfactory nerve-stimulation (ONS) to assess whether reduced glomerular responses following prolonged odor stimulation reflect synaptic depression of OSN input. To accomplish this, we stimulated the axons of the OSNs within the OB to generate glomerular responses without odorant activation. In 2 animals, responses to ONS were compared before and after OB lidocaine application to verify that ONS was not directly activating glomeruli (Figure 2-4D, gray trace). Following bulbar lidocaine application, glomerular responses to ONS were completely blocked (Pre: $7.0 \pm 0.3 \% \Delta \mathrm{F} / \mathrm{F}$; Post: $0.3 \pm 0.2 \% \Delta \mathrm{F} / \mathrm{F}$ ) (one sample t-test: $\mathrm{t}(21)=1.85, \mathrm{p}=0.09, \mathrm{n}=22$ glomeruli). In 4 animals, pre-habituation baseline responses to one of the odors and to electrical ONS were established (Figure 2-4A). Analysis was performed on overlapping glomeruli that were activated by both the odor and the ON stimulation $(n=28)$ (Figure 2-4B). Glomerular responses changed within one minute following the odor habituation trial (ANOVA: $\mathrm{F}(3,81)=21.25, \mathrm{p}<0.0001)$. Post hoc tests showed significant reduction of the mean 

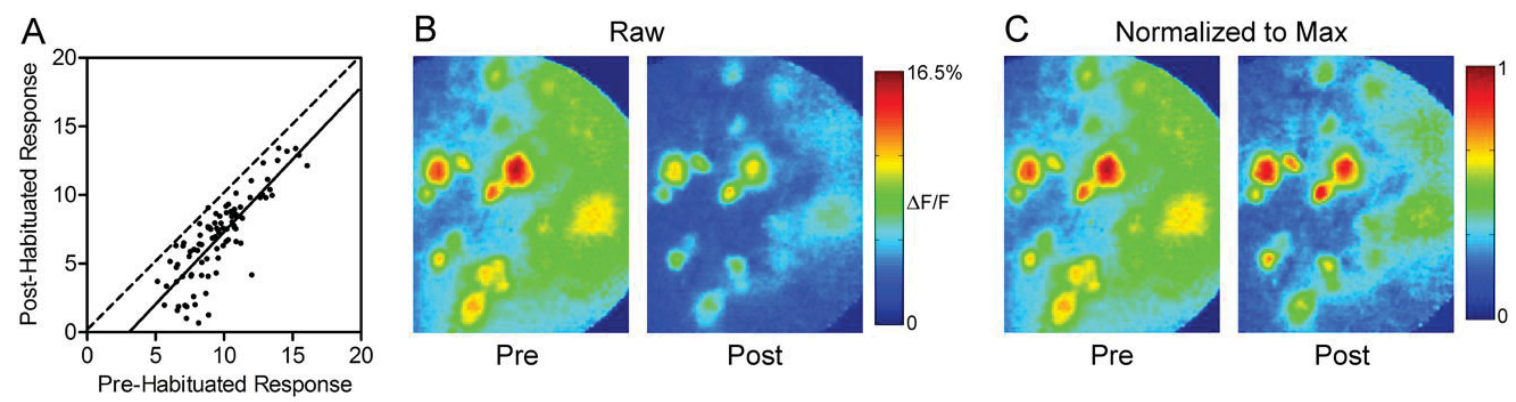

Figure 2-2. 30-s odor exposure uniformly decreases subsequent glomerular responses, regardless of initial intensity.

(A) Responses of each glomerulus before and 1 minute after the habituating odor exposure are plotted against each other. The dashed line has a slope of unity. The solid best-fit line is parallel to the line with a slope of unity, indicating that glomeruli maintain their relative odor responses following habituation. The downward shift of the line reflects the effect of habituation across glomeruli. (B) Psuedo-color glomerular responses to 2 -heptanone $(0.5 \%$ s.v.) at $10 \mathrm{x}$ magnification before (Pre) and after (Post) the habituating odor exposure. (C) The glomerular responses shown in (B), normalized to the maximum glomerulus in each representation, illustrating that glomeruli maintain their relative odor responses following habituation, as discussed in (A). 
Figure 2-3. 30-s odor exposure decreases subsequent glomerular responses to a structurally similar odor.

(A) Baseline glomerular responses to 2-heptanone (C7) and 2-hexanone (C6) in the same animal displayed in different color channels (C7, 0.5\% s.v.: green; $\mathrm{C} 6,0.5 \%$ s.v.: red) at 10x magnification. (B) Overlay of the baseline glomerular responses to $\mathrm{C} 7$ and $\mathrm{C} 6$ shown in (A), highlighting glomeruli (yellow) that respond to both odors. White arrows indicate some examples of these shared glomeruli. (C) Pseudo-color glomerular responses to C7 and $\mathrm{C} 6$ before (Pre Hab) and after (Post C7 Hab) a 30-s exposure to C7. For both odors, glomerular responses are decreased from their baseline following the habituating odor exposure. (D) Mean normalized glomerular responses to both the habituated odor and the cross-habituated odor are reduced. Habituated responses are significantly lower than cross-habituated responses. (E) When $\mathrm{C} 7$ was used as the habituating odor, self- and cross-habituated responses were not significantly different. (F) When C6 was used as the habituating odor, self-habituated responses were significantly lower than cross-habituated responses. Error bars indicate SEM. ${ }^{*} \mathrm{p}<0.05$. 


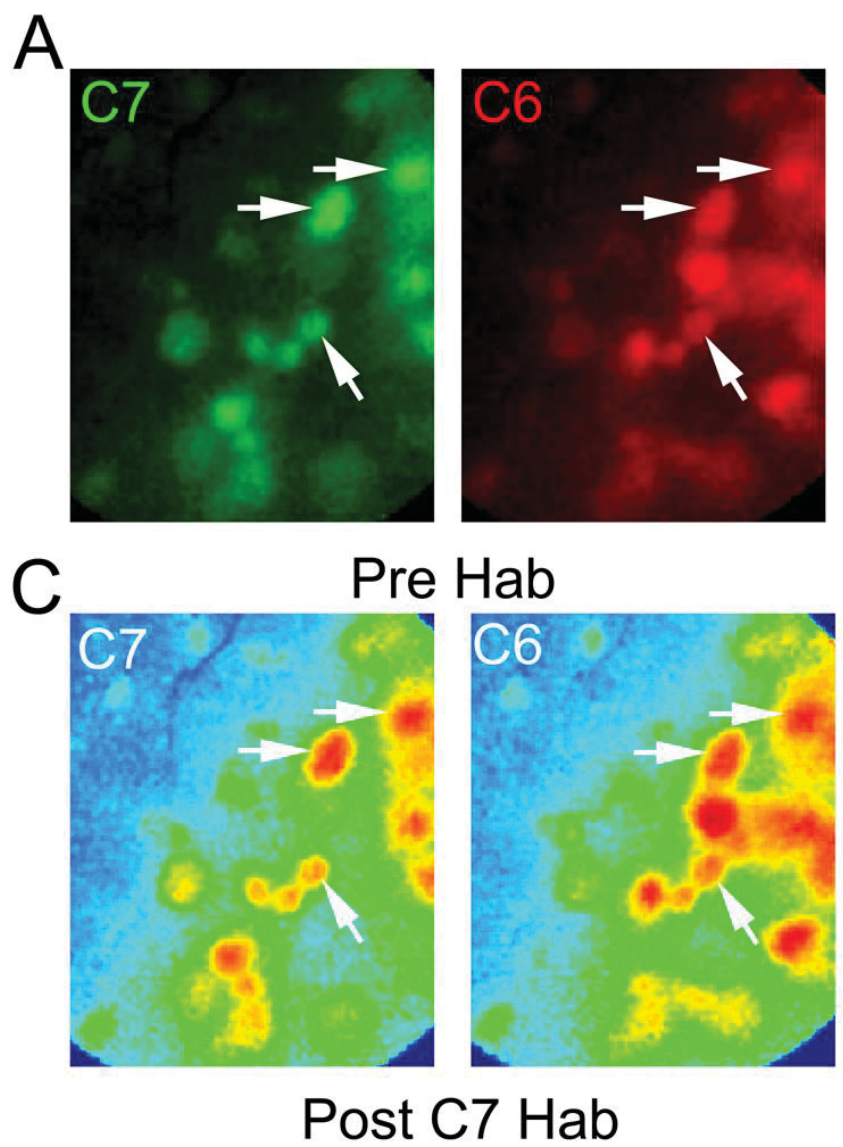

B
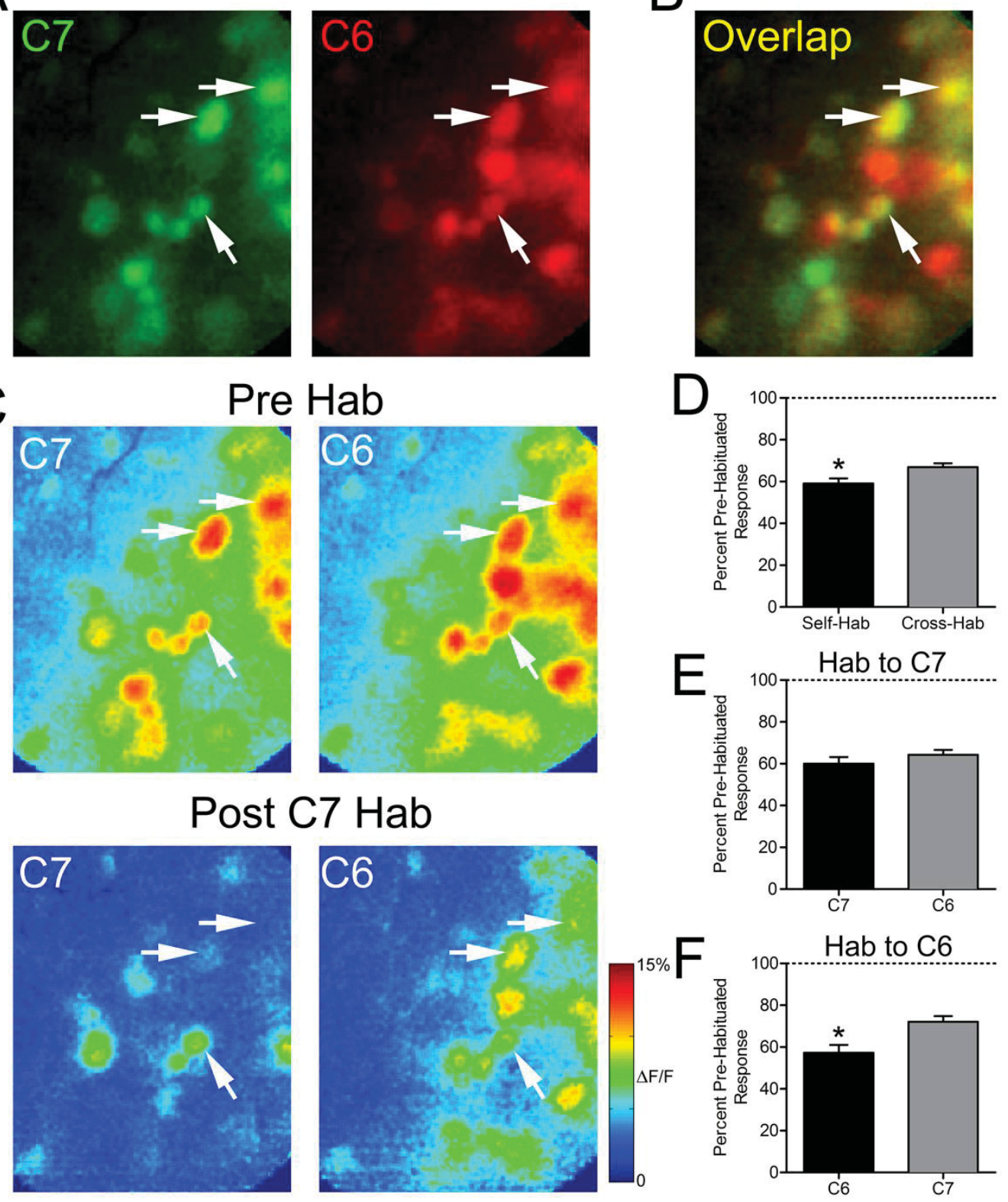
Figure 2-4. 30-s odor exposure decreases subsequent glomerular responses to odors, but not to ON electrical stimulation.

(A) Baseline glomerular responses to an odor presentation and ON electrical stimulation (ONS) in the same animal displayed in different color channels (2-heptanone, $0.5 \%$ s.V.: green; ONS, $100 \mu \mathrm{A}$ : red) at 10x magnification. (B) Overlay of the baseline glomerular responses to odor and ONS shown in (A), highlighting glomeruli (yellow) that respond to both stimuli. White arrows indicate some examples of these shared glomeruli. (C) Pseudo-color glomerular responses to odor and ONS before (Pre Odor Hab) and after (Post Odor Hab) a 30-s exposure to 2-heptanone. Thirty seconds after a habituating odor exposure (bottom panel), glomerular responses to 2-heptanone are significantly decreased compared to control. However, one minute after the habituating odor exposure, glomerular responses to ON stimulation are unchanged. (D) Example fluorescence traces taken from an overlapping glomerulus (A, B, C: middle white arrow) responding to both 2-heptanone (top panel) and ONS (bottom panel) before (black trace) and after (blue trace) odor habituation. The gray trace in the bottom panel shows the response to ONS following bulbar lidocaine application. Black arrows indicate stimulus onset. (D) Population data show glomerular responses to the odor were significantly reduced following odor habituation, while pre and post ONS responses in the same glomeruli were unchanged. Error bars indicate SEM. ${ }^{*} \mathrm{p}<0.05$. 


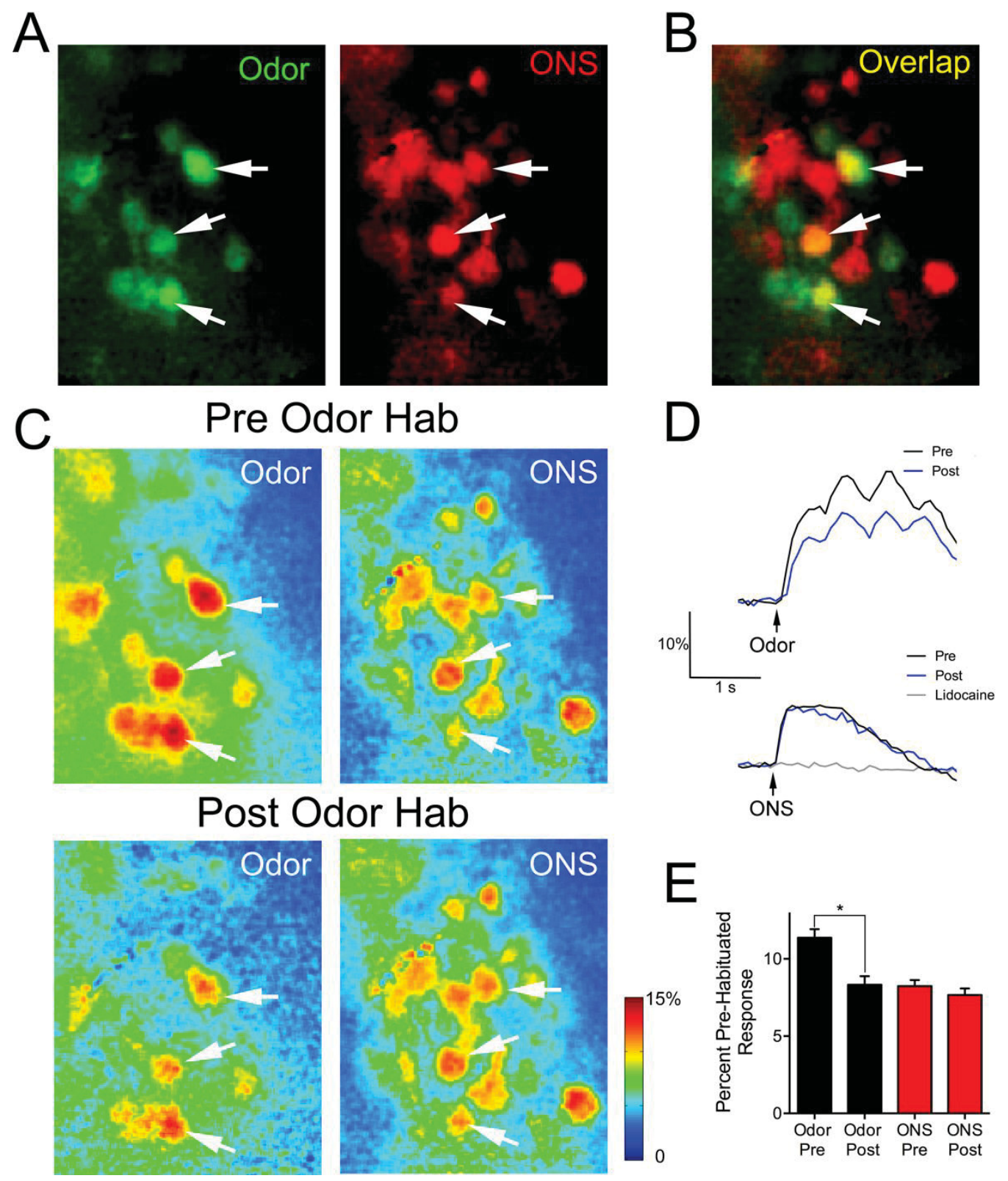


glomerular response to odor (Pre: $11.4 \pm 0.6 \% \Delta \mathrm{F} / \mathrm{F}$; Post: $8.3 \pm 0.5 \% \Delta \mathrm{F} / \mathrm{F}$ ) (Figure 2-4C, $\mathbf{D}$, and $\mathbf{E})$. However, in the same glomeruli, the mean glomerular response to ONS was not significantly reduced following odor habituation (Pre: $8.2 \pm 0.4 \% \Delta \mathrm{F} / \mathrm{F}$; Post: $7.7 \pm 0.4 \% \Delta \mathrm{F} / \mathrm{F}$ ), demonstrating that postsynaptic responses independent of odor input were not depressed.

\section{Discussion}

We imaged excitatory postsynaptic glomerular odor responses and observed reductions in glomerular responsiveness following prolonged odor stimulation. Glomerular responses to an odor were decreased following exposure to both the same odorant (self-habituation) and a structurally similar odorant (cross-habituation). Olfactory nerve layer stimulation following odor habituation showed that these decreases were not a result of OSN-M/T cell synaptic adaptation and suggests that reduced glomerular responses reflect processes taking place in the periphery.

Decreased olfactory bulb activity following prolonged odor stimulation has been observed with multiple recording modalities (Potter and Chorover, 1976; Chaput and Panhuber, 1982; Wilson, 2000; McKeegan and Lippens, 2003; Schafer et al., 2005; Chaudhury et al., 2010). An fMRI study in anesthetized rats found that the glomerular layer showed significantly decreased BOLD signal responses to subsequent odor exposures for up to 5 minutes following a 32-s odor presentation (Schafer et al., 2005). Electrophysiological recordings of single $\mathrm{M} / \mathrm{T}$ cell odor responses in anesthetized rats (Wilson 2000; Fletcher and Wilson 2003) showed a similar amount of habituation and recovery time of several minutes. Our results fit well with these studies and demonstrate that reduced excitatory odor responses following habituation can be seen at the earliest stages of olfactory bulb response and are propagated through the OB relatively unchanged.

Our finding of significant cross-habituation at the glomerular population level is similar to previous electrophysiological studies in anesthetized rats that showed singleunit $\mathrm{M} / \mathrm{T}$ cell responses to other structurally similar odors within their receptive field are also significantly decreased following prolonged exposure to an odor (Wilson, 2000; Fletcher and Wilson, 2003; Chaudhury et al., 2010). Overall, we found that selfhabituation results in a larger reduction of the glomerular response than cross-habituation. However, further analysis showed that the effects of cross-habituation are asymmetrical. While the magnitude of self- and cross-habituation are the same after prolonged exposure to the longer carbon chain odorant, after exposure to the shorter chain odorant the magnitude of cross-habituation is significantly less than that of self-habituation. Asymmetrical effects have been observed in the olfactory bulb (Wilson, 2000), and even perceptually in humans (Cain, 1970). While still unexplained, the asymmetry could reflect the fact that odorants of increasing carbon chain length activate increasing percentages of OSNs (Malnic et al., 1999). In our case, if C6 is unable to activate as many OSNs as C7, then there is a higher likelihood that there will be un-habituated C7 neurons after an exposure to $\mathrm{C} 6$, resulting in less cross-habituation magnitude at the 
glomerular layer.

ON-stimulation allowed us to test whether glomerular habituation still occurs in the absence of epithelial OSN activation. A similar method was used to explore the effects of odor habituation on synaptic efficiency at the M/T cell-aPCX pyramidal neuron synapse (Wilson, 1998b). Interestingly, we found that, after prolonged odor exposure, glomeruli had decreased responses to odor, but showed no significant decreases in their response to $\mathrm{ON}$-stimulation. These results indicate that even though their response to odor is decreased following prolonged odor exposure, postsynaptically, the M/T cell dendrites can still be activated and, presynaptically, glutamate is available and able to be released effectively from the OSN terminals (i.e. adaptation is likely occurring distal to the ONL). Lecoq et al. (2009) found evidence that fast adaptation of the glomerular odor response during high-concentration odor stimulation in anesthetized rats is also peripherally mediated. Together, these results suggest that OB glomerular habituation at the timescale of our experiments is mediated by peripheral OSN adaptation and does not heavily rely on synaptic depression of OSN input or further processing via bulbar circuits.

In contrast to our findings, some studies have demonstrated that recovery from adaptation take places faster in the periphery than in the OB (Potter and Chorover, 1976; Schafer et al., 2005), indicating that additional bulb circuitry was involved. However, in our study M/T glomerular response seems relatively unaffected by bulb processes. This could be due to differences in methodology, since the prior studies used either longer (e.g. 10 minutes) or repeated (e.g. 10 x $30 \mathrm{~s}$ ) odor presentations. Because they utilized more intensive odor stimulation, these studies might reflect bulbar depression mechanisms uncovered by studies which used protocols involving repeated (Chaudhury et al., 2010) or much longer (Larkin et al., 2010; Das et al., 2011; Ramaswami, 2014) odor presentations.

Peripheral olfactory adaptation is complex and still not well understood, however, several possible mechanisms have been outlined (Zufall and Leinders-Zufall, 2000; Reisert and Zhao, 2011). Studies have indicated that the gaseous signaling molecules, carbon monoxide $(\mathrm{CO})$ and nitric oxide $(\mathrm{NO})$, play a role in OSN adaptation that has been shown to last for several minutes (Zufall and Leinders-Zufall, 1997, 1998; Brunert et al., 2009). It has been postulated that these messengers could be important not only for habituation, but for cross-habituation as well, since they are able to diffuse across the nasal epithelium and potentially affect others OSNs (Brunert et al., 2009). While our experiments did not allow us to probe the specific peripheral adaptation processes underlying the decreased glomerular responses, if the OSNs synapsing onto the glomeruli we observed were adapted in this manner, it could explain the relatively subtle, but longer-lasting decrements we recorded.

In conclusion, the present study found that glomerular responses to odors are decreased following a habituation trial, however, our ON-stimulation experiment showed that this reduction seems to reflect uniform distal adaptation of OSNs, rather than transmitter rundown at the glomerular synapse or depression of bulb circuits. 
Intriguingly, this indicates that though input to the glomerular layer has been reduced, it can still be activated, should contingencies change. The olfactory bulb, including the glomerular layer, receives cortical feedback (Brunjes et al., 2005; Boyd et al., 2012; Markopoulos et al., 2012) as well as cholinergic, noradrenergic, and serotonergic input (Fletcher and Chen, 2010), all of which have been shown to modulate olfactory bulb responsivity (Petzold et al., 2009; Ma and Luo, 2012; Eckmeier and Shea, 2014; Rothermel et al., 2014). Future experiments should probe the potential of these centrifugal inputs to affect OB habituation. 


\section{CHAPTER 3. OLFACTORY BULB ACETYLCHOLINE RELEASE DISHABITUATES ODOR RESPONSES AND REINSTATES ODOR INVESTIGATION}

\section{Introduction}

Neuronal and behavioral responses to prolonged stimuli decrease over time as sensory systems habituate to non-relevant stimuli. Yet, if unexpected changes within an environment occur, reestablishing sensory responsivity to previously filtered stimuli can be beneficial for survival. Though these processes, habituation and dishabituation, are ubiquitous across the sensory systems, the mechanisms through which they are mediated are often complex and vary depending on the system (Rankin et al., 2009). The aim of this study was to investigate these two important sensory processing phenomena in the mouse olfactory bulb (OB).

The OBs form the first part of the olfactory central nervous system, where sensory information from the nasal epithelium is processed before projecting to cortical areas. The axons of peripheral olfactory sensory neurons (OSN) synapse onto glomeruli, dense collections of the dendrites of OB output (mitral/tufted) cells and interneurons. Odor information contained in OSN activity is transformed into spatiotemporal patterns of glomerular responses that represent both odor quality and intensity (Fletcher et al., 2009; Wachowiak and Cohen, 2001; Storace and Cohen, 2017).

In a previous study using in vivo calcium imaging, we found that a single, prolonged odor pulse decreases subsequent mitral/tufted $(\mathrm{M} / \mathrm{T})$ cell glomerular odor responses for minutes following the initial presentation (Ogg et al., 2015). However, it is currently unknown the extent to which these responses are reduced during continuous odor presentation. Using calcium imaging and a novel behavioral paradigm, we examined habituation of glomerular odor responses and odor investigation behavior during prolonged odor presentations. In addition, we wanted to determine if, once habituated, glomerular odor responses could be reinstated, what effect this would have on behavioral odor investigation, and whether a cholinergic mechanism could be responsible.

The cholinergic system plays an important role in olfactory learning, processing, and perception (Fletcher and Wilson, 2002; Wilson et al., 2004; Pavesi et al., 2013; Fletcher and Chen, 2010), however, except for a few studies focused on olfactory discrimination (Mandairon et al., 2006; Chaudhury et al., 2009), its role in the OB in modulating olfactory behaviors remains largely unexplored. The OB receives cholinergic input from the basal forebrain (BF) and expresses a variety of cholinergic receptors (Záborszky et al., 1986; Le Jeune et al., 1995; Castillo et al., 1999; Hamamoto et al., 2017; Ojima et al., 1988). Recent work from our lab and others has demonstrated that OB acetylcholine $(\mathrm{ACh})$ release increases sensitivity to odor input at both the glomerular and M/T cell output levels (Bendahmane et al., 2016; Ma and Luo, 2012; Rothermel et al., 2014), mediated by muscarinic receptor activation (Bendahmane et al., 2016). This, together with growing evidence of rapid, phasic ACh modulation in other brain regions 
(Sarter et al., 2016), led us to hypothesize that brief ACh release in the OB could dishabituate glomerular responses during prolonged odors and, as a result, allow the stimuli to be detected and investigated again.

To test this cholinergic dishabituation hypothesis, we manipulated OB ACh release electrically and optogenetically during prolonged odor presentations. We found that $\mathrm{ACh}$ can rapidly modulate habituated glomerular odor responses and increase odor salience. Further, we determined that this change in odor investigation behavior happens naturally in response to contextual changes in the environment, and can be blocked using a cholinergic antagonist in the OB.

\section{Methods}

Adult male and female mice were used for all experiments. Mice were grouphoused and maintained on a 12-h light-dark cycle with ad libitum food and water. All experiments occurred during the light portion of the cycle. All methods were carried out in accordance with relevant and approved guidelines and regulations. All experimental protocols were approved by the University of Tennessee Institutional Animal Care and Use Committee.

\section{Imaging}

Mice were generated by crossing $\mathrm{FVB} / \mathrm{N}$ mice expressing Cre recombinase under the Thy1 promoter (FVB/N-Tg(Thy1-cre)1Vln/J; Jax Stock No: 006143) with B6 mice with a floxed green fluorescent $\mathrm{Ca}^{2+}$ indicator GCaMP3 (Gt(ROSA)26Sortm38(CAGGCaMP3)Hze; Jax Stock No: 014538). In the OBs of these mice, GCaMP3 is expressed in excitatory cells. Mice were anesthetized with urethane $(2 \mathrm{mg} / \mathrm{kg}$, i.p. $)$ and given an injection of methyl scopolamine $(0.05 \mathrm{mg} / \mathrm{kg}$, i.p) to prevent nasal congestion. Mice were secured in a custom stereotaxic apparatus (Narishige) with a heating pad underneath to maintain body temperature. To create an imaging window, a skin incision was made over the dorsal surface of the mouse head and the bone overlying the OBs was thinned with a dental drill. A bipolar tungsten electrode was stereotaxically implanted in the BF (coordinates: $0.5 \mathrm{~mm}$ bregma, $0.6 \mathrm{~mm}$ lateral, $3.5 \mathrm{~mm}$ deep)(Bendahmane et al., 2016) and fixed to the skull with superglue and dental cement. During imaging sessions, animals were freely breathing and the respiratory rate was monitored from the respiratory oscillation observed in the odor-evoked GCaMP3 odor-evoked signal. Imaging was performed using a Scientifica Slicescope equipped with a 4x (0.3 NA) Olympus objective. The dorsal OB was illuminated with a LED light source centered at $480 \mathrm{~nm}$ for $40 \mathrm{~s} /$ trial. GCaMP3 signals were band-pass filtered with a Chroma emission filter (HQ535/50) and collected using a CCD camera at $25 \mathrm{~Hz}$ (NeuroCCD-SM256, Redshirt Imaging).

Odors [2-heptanone and ethyl valerate (Sigma-Aldrich)] were delivered for 30 s/trial using a flow-dilution olfactometer previously described (Fletcher et al., 2009). 
Separate flow controllers for the clean air and the pure odorant vapor were used to mix the flow streams at the end of the odor delivery system to achieve an approximate concentration of $0.25,0.5$, or $0.75 \%$ saturated vapor (s.v.) at a flow rate of $0.7 \mathrm{~L} / \mathrm{min}$. The odor concentration used for each animal was a concentration that activated discrete, stable glomeruli. In cases where there was more than one trial/animal, odor presentations were separated by more than 11 minutes, based on a previously determined recovery rate (Ogg et al., 2015). Basal forebrain electrical stimulation (BFS) consisted of a 1-3 sec, 5 or $50 \mathrm{~Hz}$ train $(100 \mu \mathrm{s}$ pulse) with an amplitude range of 30-120 $\mu \mathrm{A}$ delivered $24 \mathrm{~s}$ into the odor presentation.

Maps of stimulus-evoked spatial activity were analyzed in $\mathrm{R}$ (version 3.3.2; R Core Team, 2016; Hijmans and van Etten, 2010). To correct for photobleaching, an exponential curve with offset (nonlinear least squares, nls) was fit to the fluorescence trace of each pixel and then subtracted. A corrected fluorescence trace was extracted from each discrete, visually identified glomerulus. For both the maps and individual glomerular traces, the initial response was measured by averaging the response during the one second (25 frames) following odor onset. Habituation was measured by averaging the response during the one second preceding the BFS. Dishabituation was measured by averaging the response from the one second following the BFS.

\section{Behavior}

Odor [2-methylpyrazine, 2-heptanone, ethyl butyrate, ethyl valerate, isoamyl acetate (100\% unless otherwise indicated; Sigma Aldrich)] or air was delivered into a standard mouse open field chamber (OFC; $40 \mathrm{~cm} \mathrm{~W} \mathrm{x} 40 \mathrm{~cm} \mathrm{D} \mathrm{x} 35 \mathrm{~cm} \mathrm{H}$; Stoelting) through tubing along a top corner. To ensure that mice would not feel the incoming air, they were placed in a standard mouse cage $(18.4 \mathrm{~cm} \mathrm{~W} \times 29.2 \mathrm{~cm} \mathrm{D} \mathrm{x} 12.7 \mathrm{~cm} \mathrm{H})$ with no bedding in the center of the OFC. This method allows odor delivery without human interference or visual cues, which could result in unintended behavioral effects. To prevent odor build-up, a vacuum pulled air through small holes in the center of the open field chamber and a HEPA filter was run throughout the experiment. Mice were placed into the apparatus and allowed to acclimate to the environment for $\sim 10$ minutes. Odor investigation, described below, was recorded using a video camera positioned at the side of the OFC and and manually scored using ANY-maze (Stoelting) throughout the duration of the trial, including the last two minutes of the acclimation period and the entire odor delivery period. Odor duration lasted 6-9 minutes, depending on the trial. In cases where there was more than one trial per animal, odor presentations were separated by at least one day (Figure 3-1F, G).

Olfactory investigation was defined as active sampling episodes in which the mouse sniffs with its head lifted above the plane of its body. This included three stereotypical behaviors: head-up, stretched, and reared sniffing (Figure 3-1A). Pilot studies and detailed observational analysis of mice exploratory behavior in the absence and presence of odor lead us to combine these behaviors into a single metric of olfactory investigation. Behavior was quantified by pressing and holding a defined key in ANY- 
a
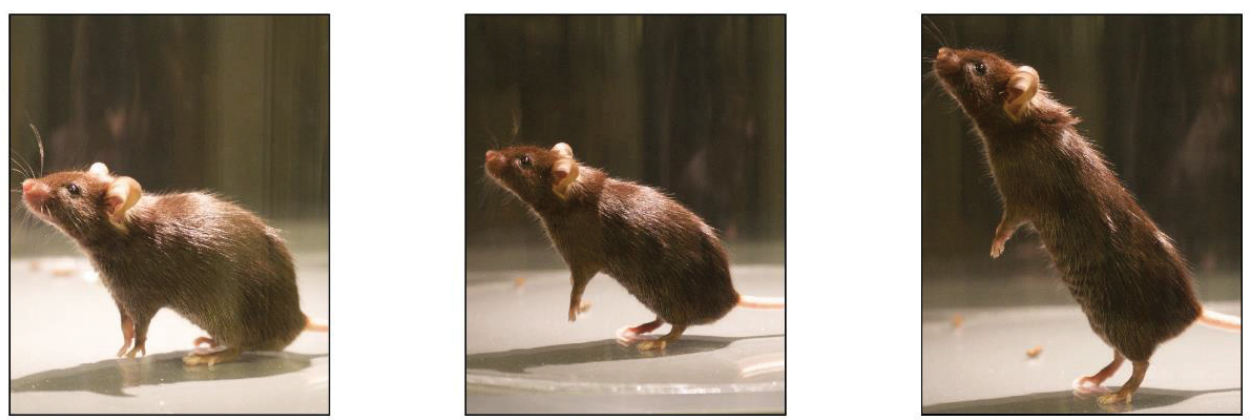

b

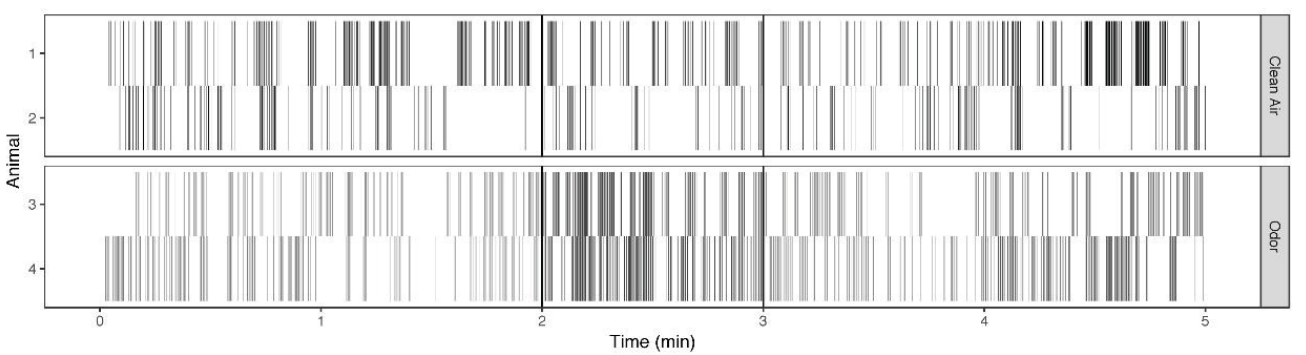

C

d $\square$ No odor $\square$ Clean air
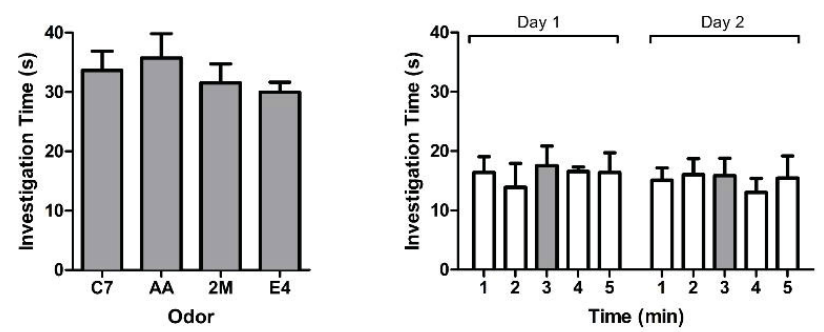

e $\square$ No odor $\square$ Odor

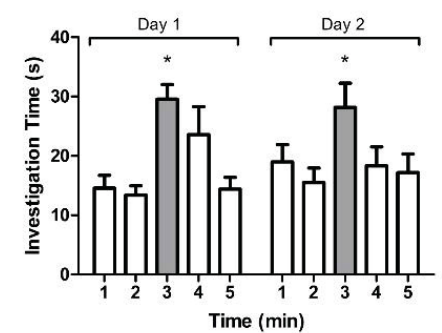

Figure 3-1. Characterization of odor investigation behavior.

(a) Examples of the behaviors included in odor investigation (from right): raised-head sniffing, half-rearing, full rearing. (b) Example raster plots of odor investigation behavior during two minutes of no odor, a minute of clean air or odor, and another two minutes of no odor. (c) Investigation time (seconds $\pm \mathrm{SE}$ ) is similar for different odors tested, including 2-heptanone (C7), isoamyl acetate (AA), 2-methylpyrazine (2M), and ethyl butyrate (E4). (d) If the experiment is repeated one day later, investigation time when odor is not present is not affected, but (e) increases with odor onset on both days. 
maze each time olfactory investigatory behavior was observed. The key remained pressed throughout the behavior and released once the behavior was terminated. This allowed us to quantify the time point and length of each investigatory event throughout the trial. Investigatory behavior was not restricted to a specific zone in the testing apparatus due to the tendency of odors to permeate the space. Rates of baseline and odor-evoked active investigation were consistent across different raters, illustrating the ease of behavioral identification.

For optogenetic experiments, mice expressing channelrhodopsin in cholinergic neurons (B6.Cg-Tg(Chat-COP4*H134R/EYFP,Slc18a3)6Gfng/J; Jax Stock No: 014546) and their wildtype littermates were used. For LED implantation, mice were anesthetized with ketamine $(100 \mathrm{mg} / \mathrm{kg}) / x y l a z i n e ~(10 \mathrm{mg} / \mathrm{kg}$, i.p.) and given a prophylactic injection of carprofen $(5 \mathrm{mg} / \mathrm{kg}$, s.c.). Mice were secured in a stereotaxic apparatus (Kopf Instruments) with a heating pad underneath to maintain body temperature. Miniature blue LEDs (Osram; LBW5SN) were soldered to female miniature electrical connectors and implanted over the OBs(Lepousez et al., 2011). A skin incision was made over the dorsal surface of the mouse head and the bone overlying the OBs was thinned with a dental drill. The LED was attached over the thinned OBs with superglue. The rest of the skull was covered with black nail polish to prevent light diffusion and the LED was covered and secured with a screw and black dental cement. Mice recovered for at least one week before the experiment. Habituation trials were conducted and scored the same as above. Before each trial, the LEDs were plugged into the pulse generator using thin, light-weight wires. Optogenetic light stimulation (OLS), consisted of a $3 \mathrm{sec}, 5,25$ or $50 \mathrm{~Hz}$ train delivered 7 minutes into the odor presentation.

For visual dishabituation experiments, B6 mice (C57BL/6J; Jax Stock No: $000664)$ were used. Mice were anesthetized with ketamine $(100 \mathrm{mg} / \mathrm{kg}) / x y l a z i n e ~(10$ $\mathrm{mg} / \mathrm{kg}$, i.p.) and given a prophylactic injection of carprofen $(5 \mathrm{mg} / \mathrm{kg}$, s.c.) for pain control. Mice were secured in a stereotaxic apparatus (Kopf Instruments) with a heating pad underneath to maintain body temperature. Bilateral stainless steel cannula guides (Plastics One; C235GS-5-2.0/SPC) were implanted in the OBs (coordinates: $4.2 \mathrm{~mm}$ bregma, $1 \mathrm{~mm}$ lateral/each side, $1 \mathrm{~mm}$ deep) and secured with a head screw, superglue, dental cement. A dummy and a cap (Plastics One; C235DCS-5/SPC and $303 \mathrm{DC} / 1 \mathrm{~B})$ covered the cannula guides during the one week recovery period. Before each trial began, $0.5 \mu \mathrm{l}$ of either vehicle (Ringer's solution) or scopolamine ( $1 \mathrm{mM}$, diluted in Ringer's solution; Sigma Aldrich) was bilaterally infused into each olfactory bulb at a rate of $0.125 \mu 1 /$ minute through each cannula using an SP 100i Syringe Pump (World Precison Instruments). After infusion, the mice were placed in the chamber to acclimate and habituation trials were conducted as above. To drive dishabituation, a micro projector (Fugetek; FG-957 DLP) mounted above the chamber displayed thin, black and white lines on the floor of the cage at minute 7 of odor delivery. 


\section{Statistics}

Statistical analyses were performed using Prism software (GraphPad; version 5.03). Data were compared using a $t$-test or an appropriate ANOVA with a post hoc Bonferroni multiple comparisons test. Statistical significance was defined as $\mathrm{p} \leq 0.05$.

\section{Results}

To determine if prolonged odor input leads to decreased or habituated postsynaptic glomerular odor responses, we imaged glomerular odor responses in anesthetized Thy1-GCaMP3 mice before, during, and after 30-second odor presentations (Figure 3-2A). Overall, we found glomerular responses display a rapid rise in response amplitude that quickly reaches a maximum and is followed by a slower, steady decay to approximately $40 \%$ of the peak response by end of the odor presentation $(n=92$ glomeruli from 6 mice; paired $t$-test: $t(91)=32.15, \mathrm{p}=<0.0001$; End $=36.74 \pm 1.97 \%$; Figure 3-2B, C). We did not observe any glomerular responses that maintained maximal responses or increased in amplitude over the course of the odor presentation.

Based on previous work from our lab demonstrating that OB ACh receptor activation enhances glomerular odor responses (Bendahmane et al., 2016), we hypothesized that brief OB ACh release delivered near the end of the odor presentation could reinstate, or dishabituate, reduced OB odor responses. To test whether ACh release could enhance $\mathrm{OB}$ responsivity to adapted stimuli, we again imaged glomerular odor responses in anesthetized Thy1-GCaMP3 mice implanted with a stimulating electrode in the cholinergic BF (Bendahmane et al., 2016). For these experiments, electrical stimulation (BFS) was delivered 24 seconds into the 30 second odor stimulation (Figure 3-3A). As in the control mice, mean glomerular odor responses decreased during the odor presentation. BFS delivered at $50 \mathrm{~Hz}$ rapidly increased these habituated glomerular odor responses (Figure 3-3B, C). To quantify this, we compared the mean normalized fluorescence in the second immediately preceding the BFS to the mean normalized fluorescence in the second following BFS for each glomerulus and found a significant increase in the mean fluorescence following BFS $(n=76$ glomeruli from 5 mice; $R M$ ANOVA: $\mathrm{F}(2,150)=749.8, \mathrm{p}<0.0001 ;$ Pre-BFS $=35.31 \pm 1.13 \%$, Post-BFS $=78.64 \pm$ $1.62 \%$; Figure 3-3D).

In a subset of mice, in addition to $50 \mathrm{~Hz}$ stimulation we also stimulated at $5 \mathrm{~Hz}$, a frequency previously shown to have little effect on OB activity (Ma and Luo, 2012) (Figure 3-3B,C). This allowed us to directly compare response enhancement at two different stimulation frequencies in the same mice. A two-way repeated measures ANOVA revealed a significant interaction between imaging time and BFS stimulation $(\mathrm{n}=32$ glomeruli from 2 mice; $\mathrm{F}(1,62)=1015.43, \mathrm{p}<0.0001)$. Post hoc tests revealed significant increases when BFS was given at $50 \mathrm{~Hz}$ (Pre-BFS $=32.24 \pm 1.51 \%$, Post-BFS $=88.00 \pm 2.33 \%$ ), but no significant changes in fluorescence at $5 \mathrm{~Hz}$ (Pre-BFS $=30.14 \pm$ $1.38 \%$, Post-BFS $=30.15 \pm 1.51 \%$; Figure 3-3E). 
a Initial

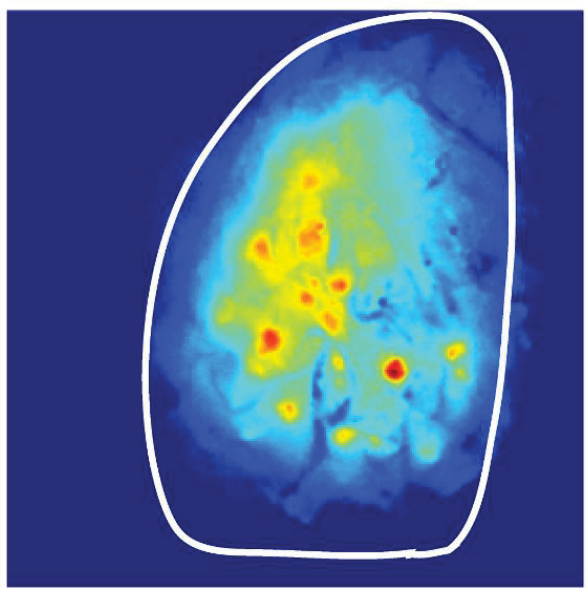

b

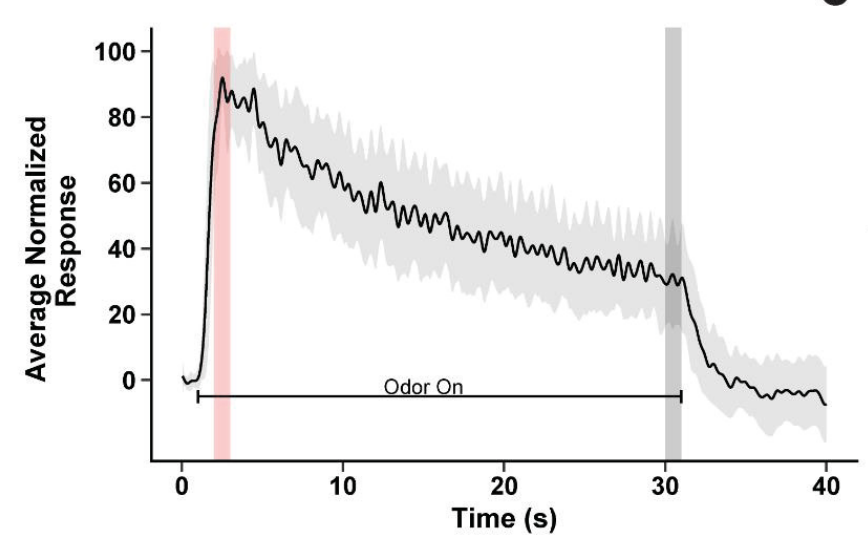

End
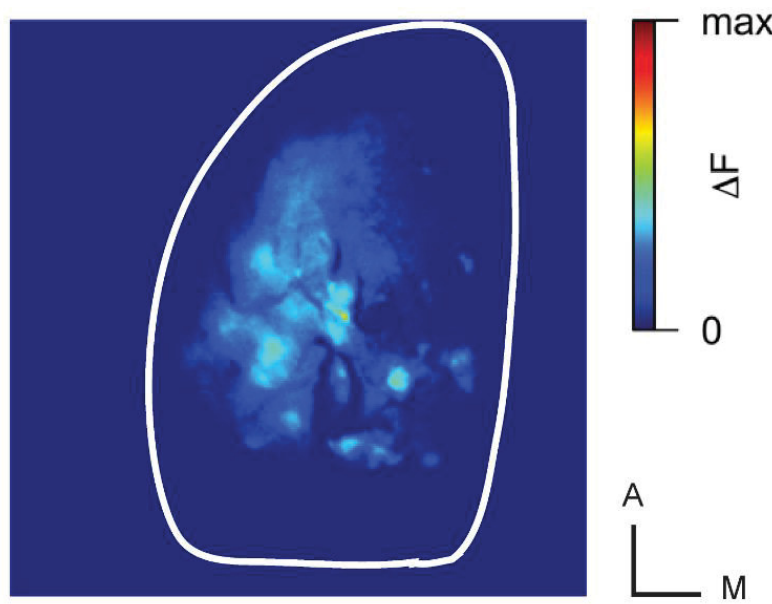

C

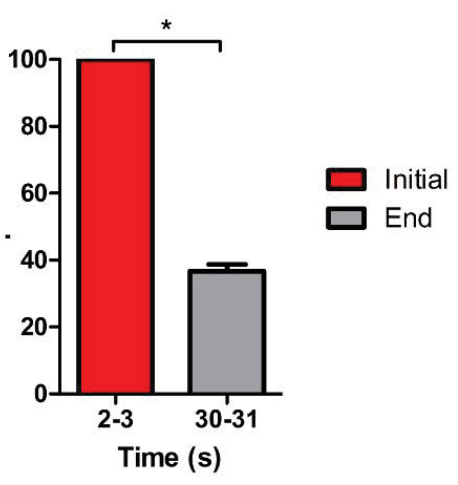

Figure 3-2. Glomerular responses to a prolonged odor presentation habituate over time.

(a) Pseudo-color glomerular responses to 2-heptanone $(0.3 \%$ s.v) initially and after thirty seconds of the odor presentation. (b) The average fluorescence trace ( $\%$ of initial response $\pm \mathrm{SE}$ ) from all recorded glomeruli. (c) The average glomerular odor response ( $\%$ of initial response $\pm \mathrm{SE}$ ) decreases during the odor presentation. $*=\mathrm{p}<0.05$. 

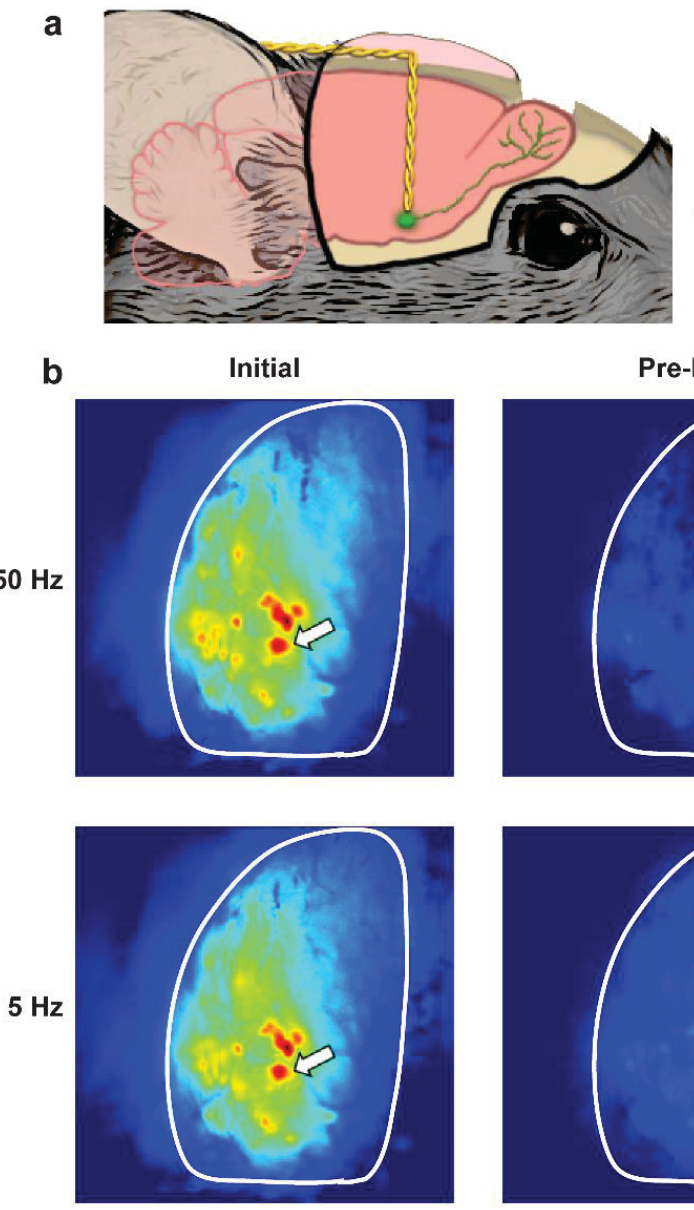

C

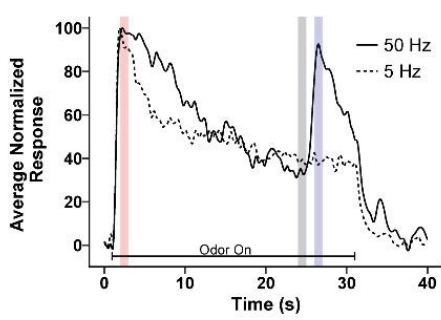

Pre-BFS
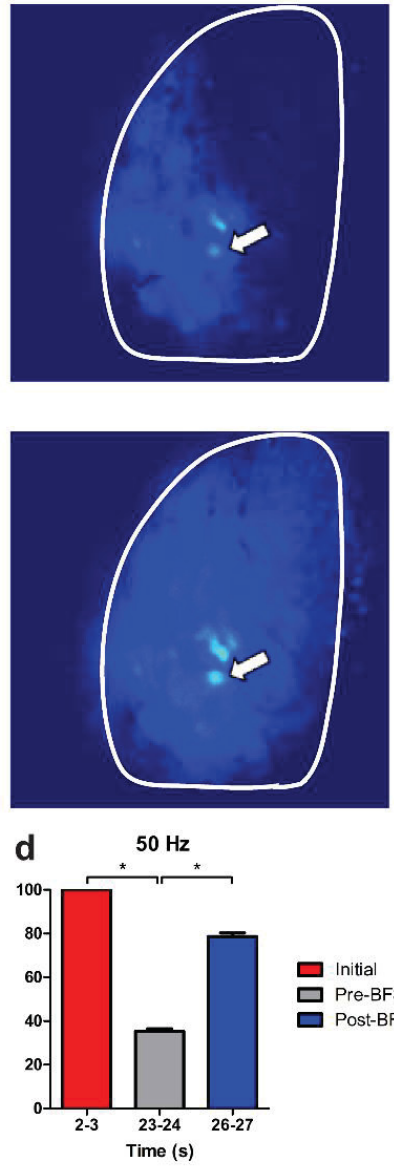

Post-BFS
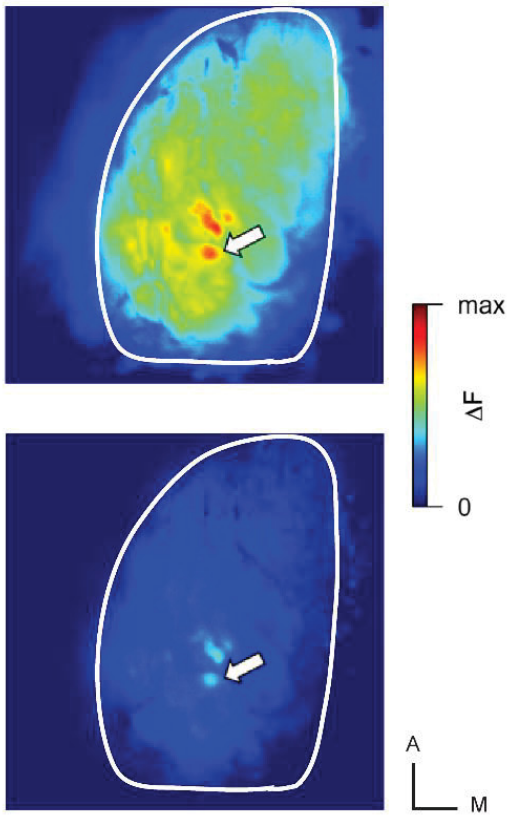

e

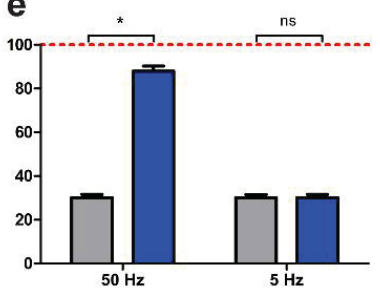

Figure 3-3. Electrical basal forebrain stimulation (BFS) dishabituates glomerular odor responses.

(a) Schematic illustration of the imaging experiment. (b) Pseudo-color glomerular responses to 2-heptanone $(0.5 \%$ S.v) initially and before and after BFS $(50 \mu \mathrm{A}, 3 \mathrm{~s})$ at 50 and $5 \mathrm{~Hz}$. (c) Fluorescence traces (\% of initial response) from the glomerulus indicated by arrows in (b). (d) The average glomerular odor response (\% of initial response \pm SE) decreases during the odor presentation and increases following $50 \mathrm{~Hz}$ BFS. (e) In a subset of mice, $5 \mathrm{~Hz}$ stimulation was given in addition to $50 \mathrm{~Hz}$, and it did not increase the average glomerular odor response. $*=\mathrm{p}<0.05$. 
To investigate these effects in awake, behaving animals, we developed a simple olfactory habituation paradigm to measure mice's natural odor investigation behavior. In this paradigm, the duration of stereotypical investigation behaviors was scored and quantified (Figure 3-1A, B). To demonstrate that the duration of these behaviors is an appropriate measurement of olfactory salience in the mouse, we compared the change in the duration of odor investigation from baseline during clean air $(\mathrm{n}=8$ mice) and odor (ethyl butyrate, $10 \%$ dilution; $n=8$ mice) presentations (Figure 3-4A, $\mathbf{B}$ and Figure 3-1B). Odor investigation behavior was measured for five minutes, with clean air or odor presented for the third minute only. For the clean air group, we found no differences in investigation time per minute (RM ANOVA: $\mathrm{F}(4,28)=2.39, \mathrm{p}=0.07$; Minute $1=18.2 \pm$ $1.7 \mathrm{~s}, 2=13.2 \pm 1.6 \mathrm{~s}, 3=18.2 \pm 1.5 \mathrm{~s}, 4=16.0 \pm 1.9 \mathrm{~s}, 5=18.3 \pm 2.2 \mathrm{~s}$; Figure 3-4A).

There was a significant effect of odor on investigation time (RM ANOVA F(4, $28)=15.73, \mathrm{p}<0.0001 ;$ Minute $1=15.1 \pm 1.8 \mathrm{~s} ; 2=14.8 \pm 1.1 \mathrm{~s} ; 3=30.0 \pm 1.6 \mathrm{~s} ; 4=$ $22.7 \pm 2.3 \mathrm{~s} ; 5=16.9 \pm 1.9 \mathrm{~s}$; Figure 3-4B). The post hoc test revealed that investigation time in the third minute when odor was present was significantly higher than in any other non-odor minute. To demonstrate that this paradigm accurately reflects odor investigation and that investigation times are not dependent upon other factors, we also compared investigation times for one minute presentations of different odors as well as the to the same odor across two days.

We tested whether investigation times vary depending on the odorant presented. To accomplish this we presented mice $(n=5)$ with three different odorants $(10 \%$ dilution, 1 minute duration, 3 minute ISI) in the same session. When comparing investigation times of these three odorants to that of when ethyl butyrate (E4) was presented we found no significant differences (ANOVA F $(3,19)=0.79, \mathrm{p}=0.51 ; 2 \mathrm{M}=31.5 \pm 3.2 ; 2 \mathrm{H}=33.6 \pm$ $3.2 \mathrm{~s} ; \mathrm{AA}=35.7 \pm 4.1 \mathrm{~s} ; \mathrm{E} 4=29.9 \pm 1.6 \mathrm{~s}$; Figure 3-1C).

We next investigated the repeatability of the investigation behavior across time. As previously described, odor investigation behavior was measured for five minutes, with clean air ( $n=3$ mice) or odor (ethyl butyrate, $10 \%$ dilution; $n=4$ mice) presented for the third minute only. The experiment was then repeated twenty-four hours later. A two-way repeated measures ANOVA found no effect of either trial time $(\mathrm{F}(4,16)=0.18, \mathrm{p}=0.95)$ or day $(\mathrm{F}(1,4)=0.18, \mathrm{p}=0.69)$ in the clean air group (Figure 3-1D). In the odor group, there was a significant effect of trial time (i.e odor presence) (2-way RM ANOVA $\mathrm{F}(4,24)=11.81, \mathrm{p}=<0.0001)$, but no effect of day $(\mathrm{F}(1,6)=0.03, \mathrm{p}=0.86$; Figure 3-1E). Further, a paired $t$-test confirmed that Minute 3 odor presentation investigation times $(\mathrm{t}(3)$ $=0.21, \mathrm{p}=0.84$; Day $1=29.55 \pm 2.46 \mathrm{~s}$; Day $2=28.18 \pm 4.09 \mathrm{~s}$ ) were not significantly different from one another across days, suggesting that this behavioral quantification is stable over time.

Next, we sought to determine if our olfactory investigation paradigm could be used for measuring olfactory habituation. We quantified investigation behavior during one baseline minute (Minute 0 ) and six minutes of continuous odor (ethyl butyrate) and found significant differences in investigation time across minutes $(\mathrm{n}=10$; RM ANOVA: $\mathrm{F}(6,9)=17.95, \mathrm{p}<0.0001$; Minute $0=16.66 \pm 1.67 \mathrm{~s}, 1=32.50 \pm 1.59 \mathrm{~s}, 6=16.77 \pm$ 

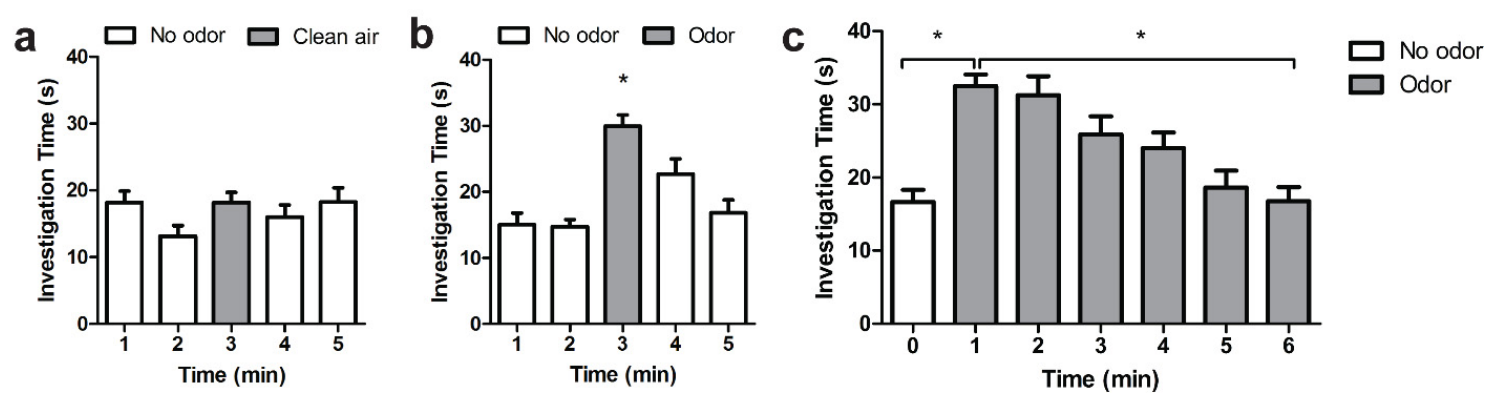

Figure 3-4. Olfactory investigation behavior increases with odor onset and habituates over time.

(a) Investigation time (seconds $\pm \mathrm{SE}$ ) is not affected when odor is not present, but (b) increases with odor ( $10 \%$ ethyl butyrate) onset. (c) Investigation time in control mice increases with odor onset and decreases over the exposure. $*=p<0.05$. 
$1.91 \mathrm{~s}$; Figure 3-4C). The post hoc test revealed that odor investigation increased significantly from baseline when an odor was delivered into the chamber (Minute 0 vs 1). Further, when an odor was continuously delivered into the chamber for several minutes, odor investigation significantly decreased (Minute 1 vs 6 ) demonstrating that this task can effectively measure olfactory habituation.

To directly investigate whether increased ACh release in the $\mathrm{OB}$ can reinstate investigation of habituated odors in awake, behaving animals, we used mice expressing channelrhodopsin in cholinergic neurons (ChAT-ChR2) and their wildtype (WT) littermates in the above the habituation paradigm. In this case, odor (isoamyl acetate) was presented for nine minutes. No effect of genotype was found between WT ( $\mathrm{n}=5$; Minute $0=13.22 \pm 1.46,1=32.16 \pm 1.96,6=7.72 \pm 1.88)$ and $\mathrm{ChR} 2+(\mathrm{n}=5$; Minute $0=11.77$ $\pm 2.88 \mathrm{~s}, 1=25.68 \pm 3.06 \mathrm{~s}, 6=11.38 \pm 1.01 \mathrm{~s})$ mice when comparing investigation duration at key time points in the habituation paradigm (2-way RM ANOVA: $\mathrm{F}(1,8)=$ $0.43, p=0.53$ ). To specifically drive optogenetic OB ACh release, we turned on an LED implanted over the OBs (optogenetic light stimulation, OLS; Figure 3-5A)(Lepousez et al., 2011). OLS ( $3 \mathrm{~s}, 50 \mathrm{~Hz})$ at the beginning of the seventh minute of odor exposure, following habituation, did not increase odor investigation during the seventh minute compared to the previous minute in WT mice (Minute $6=7.72 \pm 1.88,7=9.80 \pm 1.98$; Figure 3-5B). However, in ChR2+ mice, investigation time after the $50 \mathrm{~Hz}$ OLS increased back to the level of initial odor investigation, and stayed increased through the end of the trial (RM ANOVA: $\mathrm{F}(9,36)=4.57, \mathrm{p}=0.0005$; Minute $6=11.38 \pm 1.01 \mathrm{~s}, 7=$ $28.04 \pm 2.56$ s, $9=19.92 \pm 3.88$ s; Figure 3-5D, E).

As found in a previous study (Ma and Luo, 2012) and in our imaging data above, there is an intensity-dependent effect of cholinergic activation and OB response enhancement. Therefore, we repeated the experiment in the same $\mathrm{ChR} 2+$ mice with two additional stimulation frequencies $(5$ and $25 \mathrm{~Hz}$ ). Decreasing the stimulation frequency reduced the extent and duration of subsequent investigation. After $25 \mathrm{~Hz}$ OLS, investigation time increased back to the level of initial odor investigation, but did not remain increased (RM ANOVA: $\mathrm{F}(9,36)=12.02, \mathrm{p}=<0.0001$; Minute 0: $9.95 \pm 2.38 \mathrm{~s}$, 1: $28.46 \pm 4.23 \mathrm{~s}, 6: 13.08 \pm 1.80 \mathrm{~s}, 7: 23.66 \pm 3.07 \mathrm{~s}, 9: 10.24 \pm 2.79 \mathrm{~s})$ and $5 \mathrm{~Hz}$ OLS did not increase investigation time at all (RM ANOVA: $\mathrm{F}(9,36)=4.50, \mathrm{p}=0.0005$; Minute 0: $12.77 \pm 1.77 \mathrm{~s}, 1: 23.50 \pm 2.08 \mathrm{~s}, 6: 11.60 \pm 2.34 \mathrm{~s}, 7: 11.42 \pm 1.64 \mathrm{~s}, 9: 13.94$ $\pm 2.49 \mathrm{~s}$; Figure 3-5D, E). To verify that OLS alone does not increase investigative behavior, we repeated the experiment in an additional cohort of $\mathrm{ChR} 2+(\mathrm{n}=5)$ mice and found no changes in investigation after optogenetic stimulation in the absence of odor (paired $t$-test: $\mathrm{t}(4)=1.17, \mathrm{p}=0.31$; Minute $0: 13.48 \pm 2.76 \mathrm{~s}, 1=10.52 \pm 3.06 \mathrm{~s}$; Figure 3-5C).

To test whether cholinergic dishabituation occurs naturally, we performed the habituation experiment again, but instead of artificially driving ACh release at the beginning of the seventh minute of odor exposure, we abruptly changed the visual context of the chamber (VS; Figure 3-6A). We hypothesized that this novel sensory stimulation would release ACh (Inglis and Fibiger, 1995; Giovannini et al., 2001) and modulate habituation. A previous imaging study in our lab showed that muscarinic ACh 
Figure 3-5. Optogenetic light stimulation (OLS) can dishabituate odor investigation behavior.

(a) Schematic illustration of the OLS experiment. (b) Investigation time (seconds $\pm \mathrm{SE}$ ) does not increase after $50 \mathrm{~Hz}$ OLS in WT (ChR2-) controls, or (c) in ChR2+ mice if odor is not present. (d) Raster plots of the odor investigation behavior comparing OLS at 5, 25, and $50 \mathrm{~Hz}$. (e) Investigation time in $\mathrm{Ch} 2 \mathrm{R}+$ mice after the OLS is stimulation dependent: Following $50 \mathrm{~Hz}$ OLS, investigation time increases and stays increased for at least three minutes. After $25 \mathrm{HZ}$ OLS, investigation time also increases, but does not remain increased. $5 \mathrm{~Hz}$ OLS does not increase investigation time. $*=p<0.05$. 

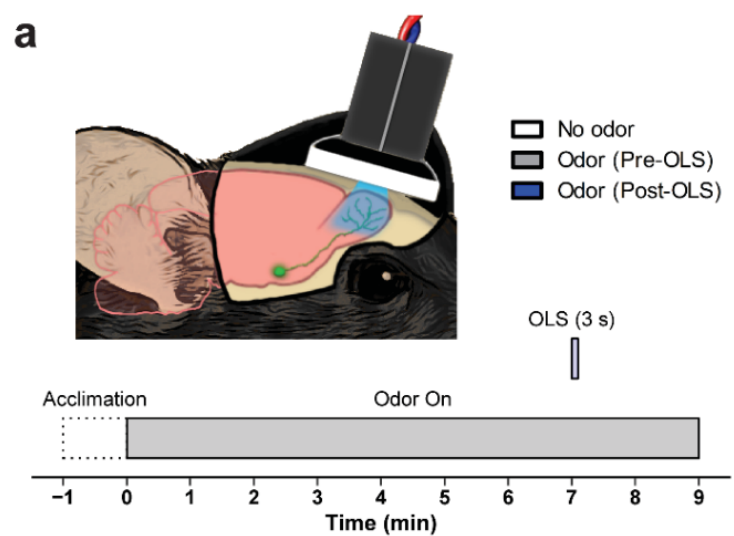

d
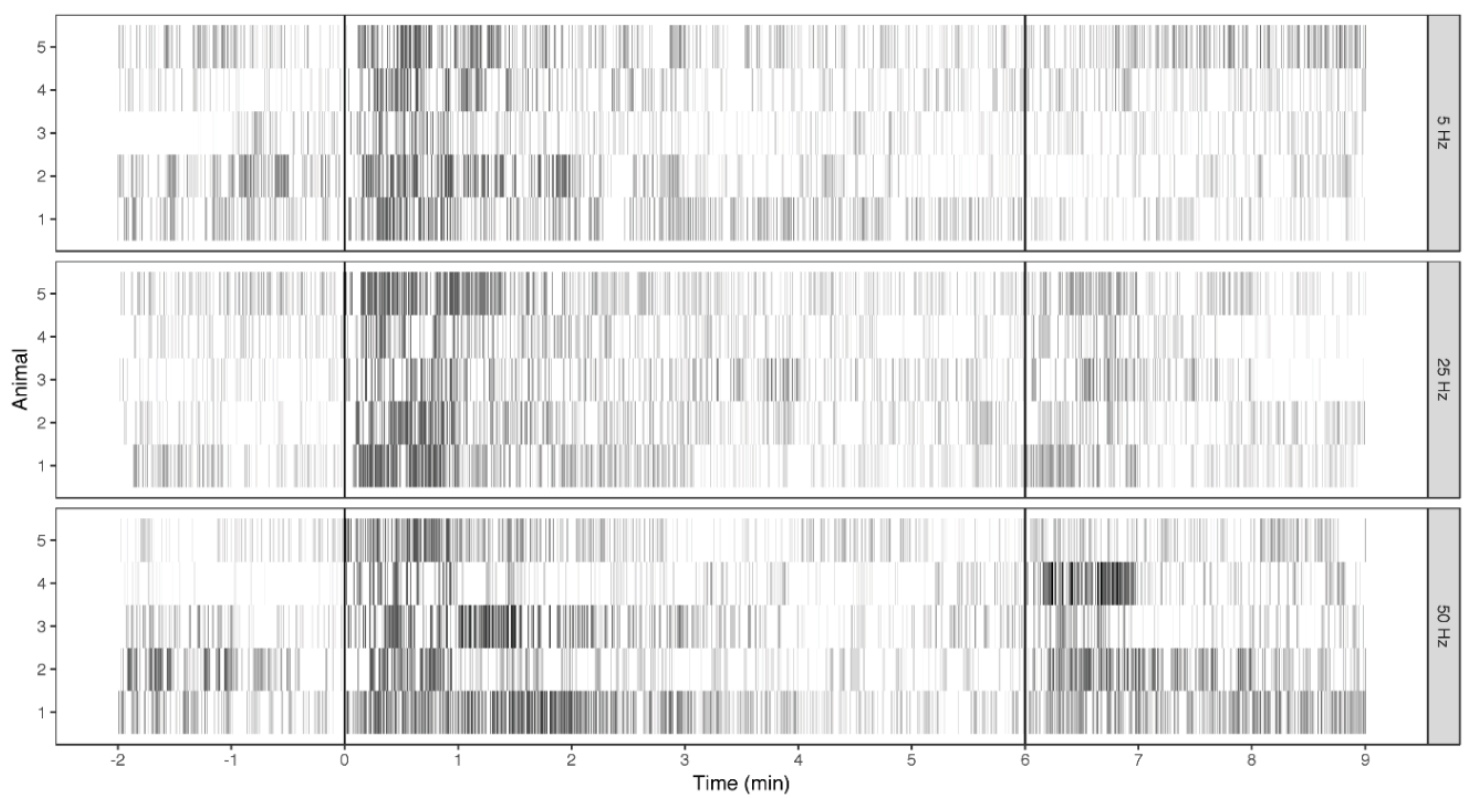

e

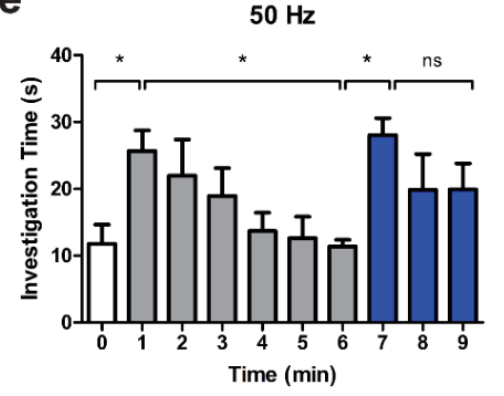

b

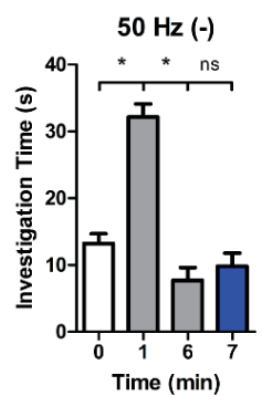

C

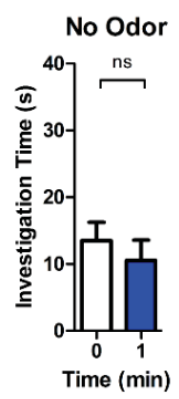

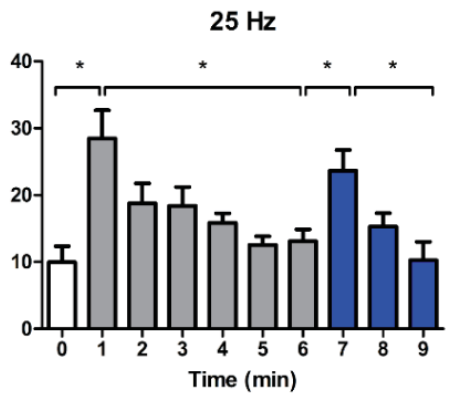

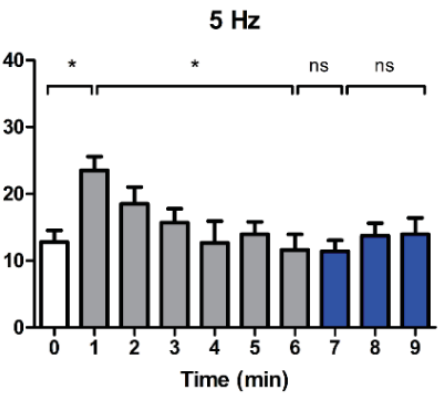


Figure 3-6. A visual context change (VS) dishabituates odor investigation behavior.

(a) Schematic illustration of the VS experiment. (b) Investigation time (seconds $\pm \mathrm{SE}$ ) after the VS does not increase if odor is not present. (c) Raster plots of the odor investigation behavior following olfactory bulb (OB) cannula infusion of vehicle (Ringer's) or the cholinergic antagonist scopolamine. (d) Investigation time after the VS increases when mice receive an OB cannula infusion of Ringer's solution, but does not increase when the mice receive scopolamine. 
a
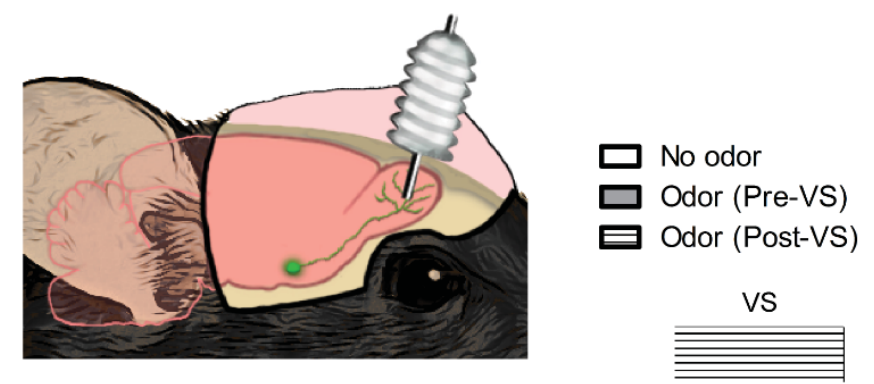

Scopolamine/Ringer's

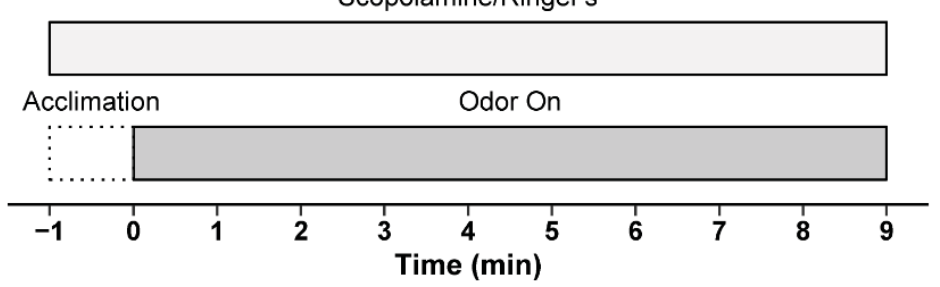

b

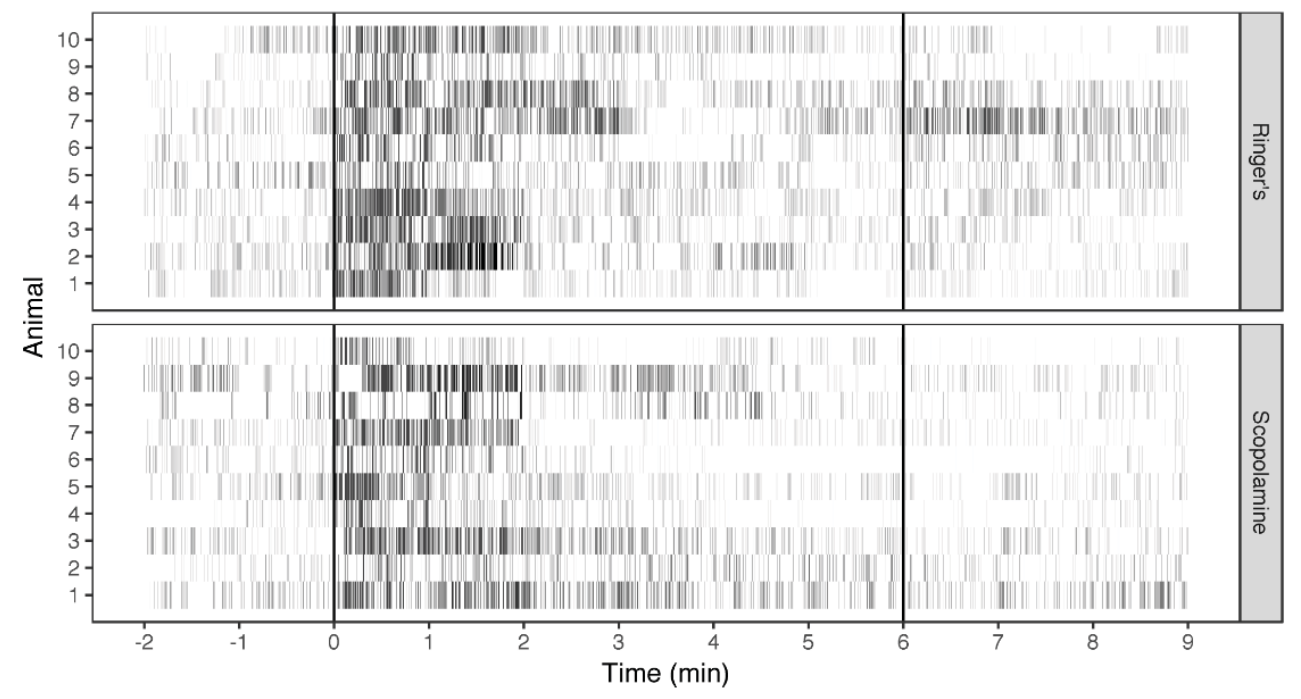

C

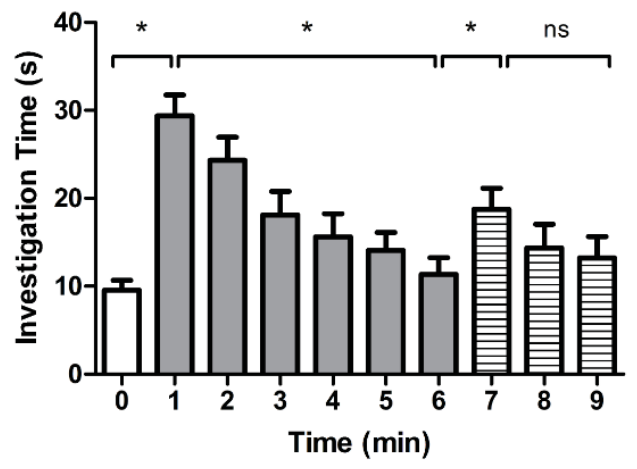

C

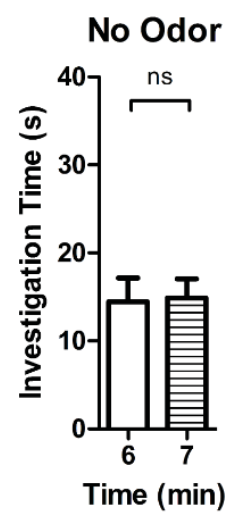

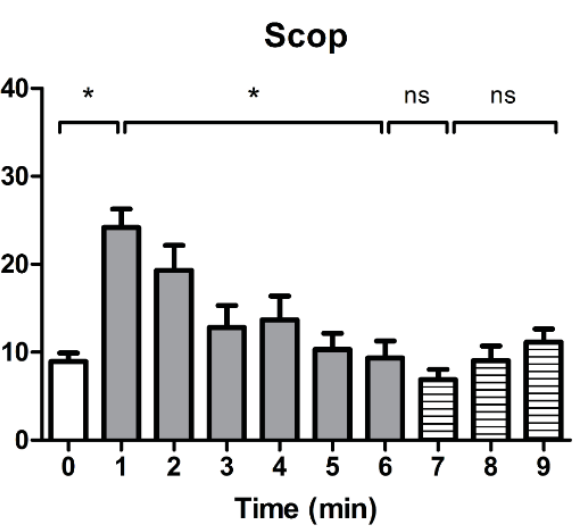


receptor ( $\mathrm{mAChR}$ ) activation in the $\mathrm{OB}$ leads to increased responses at all odor concentrations (Bendahmane et al., 2016), therefore, we further hypothesized that blocking $\mathrm{mAChR}$ activation would prevent any contextual dishabituation. All mice $(n=10)$ were implanted with bilateral olfactory bulb cannula and received infusions of the $\mathrm{mAChR}$ antagonist scopolamine $(1 \mathrm{mM})$ prior to one trial and infusions of vehicle (Ringer's solution) prior to another. Mice were counter balanced so that half received vehicle first and the other half received scopolamine first. No effect of treatment was found when comparing investigation duration at key time points (Minutes 0,1 , and 6) in the habituation paradigm (2-way RM ANOVA: $\mathrm{F}(1,18)=1.86, \mathrm{p}=0.19)$.

Following vehicle infusion, investigation behavior increased with odor (ethyl valerate) onset and decreased throughout the odor presentation (RM ANOVA: $\mathrm{F}(9,81)=10.71, \mathrm{p}=0.0001$; Minute $0=9.55 \pm 1.14 \mathrm{~s}, 1=29.37 \pm 2.38 \mathrm{~s}, 6=11.34 \pm 1.90$ s). Similar to the optogenetic ACh stimulation, changing the visual context in the seventh minute of the odor presentation significantly increased investigation behavior for the next three minutes (Minute $6=11.34 \pm 1.90 \mathrm{~s}, 7=18.75 \pm 2.39 \mathrm{~s}, 9=13.21 \pm 2.43 \mathrm{~s}$; Figure 3-6C, D). When the same mice were treated with OB scopolamine, investigation still significantly increased with the initial odor presentation and decreased by Minute 6 (RM ANOVA: $\mathrm{F}(9,81)=14.26, \mathrm{p}=0.0001$; Minute $0=8.96 \pm 0.96 \mathrm{~s}, 1=24.19 \pm 2.09 \mathrm{~s}, 6=$ $9.36 \pm 1.94 \mathrm{~s}$ ), but the visual stimulation-mediated increase in odor investigation was completely blocked (Minute 6=9.36 \pm 1.94 s, 7: $6.87 \pm 1.19$ s, 9: $11.14 \pm 1.50$; Figure

3-6C, D), indicating this form of dishabituation requires $\mathrm{OB} \mathrm{mAChR}$ activation. To verify that changing the visual context alone does not increase odor investigation behaviors or that the effects seen are not due to changes in general arousal, we also repeated experiment in non-cannulated mice $(n=3)$ in the absence of odor and found no changes in investigation after the context switch (paired $t$-test: $\mathrm{t}(2)=0.09, \mathrm{p}=0.93$; Minute 6: $14.47 \pm 2.67 \mathrm{~s}, 7=14.90 \pm 2.13 \mathrm{~s}$, Figure 3-6B).

\section{Discussion}

While previous studies have focused on the mechanisms underlying cortical habituation and dishabituation of prolonged odor input (Wilson, 1998b, 1998a; Best and Wilson, 2004; Best et al., 2005; Wilson, 2000; Smith et al., 2009), relatively little was known about how the OB responds under these conditions. In this study, we characterized the response pattern of $\mathrm{M} / \mathrm{T}$ cell glomeruli and quantified the amount of habituation that occurs during a continuous odor presentation. On average, glomerular responses rapidly increased with odor onset and then slowly decreased to approximately $40 \%$ of their initial value until odor offset. The timecourse and the relative magnitude of habituation are similar to those measured at both the input (Reisert and Matthews, 2001; Madrid et al., 2003; Schafer et al., 2005) and output (Wilson, 2000) levels of the OB during prolonged odor presentation. Based on this correspondence, and the results from our previous glomerular habituation study (Ogg et al., 2015), it is likely that M/T cell habituation is strongly influenced by reduced odor input from the periphery. However, an fMRI study in rodents found that while OSN and OB habituation followed identical time courses, $\mathrm{OB}$ responses were more reduced, suggesting additional mechanisms within the 
bulb also partially contribute to OB habituation (Schafer et al., 2005). In the insect antennae lobe, this effect is mediated by increasing feedback inhibition from interneurons (Larkin et al., 2010; Das et al., 2011; Ramaswami, 2014). Future studies are needed to determine the extent to which different circuits contribute to OB habituation.

Multiple studies have demonstrated that $\mathrm{OB}$ ACh release and receptor activation can increase both glomerular and M/T cell odor responses (Rothermel et al., 2014; Ma and Luo, 2012; Castillo et al., 1999; Bendahmane et al., 2016). To test whether this effect can reinstate habituated glomerular odor representations, we electrically stimulated the cholinergic BF near the end of the odor presentation. Our imaging experiment showed that $50 \mathrm{~Hz}$ BFS increased the magnitude of glomerular responses, but $5 \mathrm{~Hz}$ BFS had no effect. Although direct optogenetic activation of BF cholinergic neuron soma at frequencies as low as $5 \mathrm{~Hz}$ can elicit action potentials in brain slices, in vivo stimulation at this low frequency had little to no effect on either inhibitory periglomerular or $\mathrm{M} / \mathrm{T}$ cell activity in the $\mathrm{OB}^{8}$.

To determine if this cholinergic effect in the OB could dishabituate odor salience in awake, behaving animals, we used a newly developed olfactory investigation paradigm coupled with OLS of OB cholinergic fibers in transgenic mice. Based on the frequencydependent effect seen in our imaging experiment, mice in the behavioral experiment received OLS at 3 different frequencies: 5, 25, and $50 \mathrm{~Hz} .25$ and $50 \mathrm{~Hz}$ OLS dishabituated odor investigation. Comparing these two higher frequency stimulations revealed a frequency dependence of the duration of the dishabituating effect. However, in both cases, in the minute following the stimulation, the amount of dishabituated odor investigation was not significantly different than the amount of initial odor investigation, possibly indicating that if a salient odor is detected, a stereotypical amount of time will be spent investigating that odor, unaffected by the intensity of the stimulation. In our paradigm, $5 \mathrm{~Hz}$ OLS had no effect on odor investigation. A study in awake rats found BF firing rates during baseline conditions to be approximately $10 \mathrm{~Hz}$ (Devore et al., 2015). In the context of these results, our $5 \mathrm{~Hz}$ stimulation may be below resting $\mathrm{BF}$ firing rates and does not drive cholinergic release above baseline conditions.

These experiments effectively demonstrated that artificially increasing OB ACh can reinstate habituated odor responses and odor investigation, but it was still unclear whether this cholinergic effect in the OB was ecologically valid. Multiple studies have shown that hippocampal and cortical ACh levels rapidly rise in response to various novel sensory stimuli, including contextual changes (Inglis and Fibiger, 1995; Giovannini et al., 2001). Based on this, we performed the behavioral habituation experiment in another group of mice, but instead of driving ACh release optogenetically, we used a more naturalistic paradigm in which the visual context of the chamber was suddenly changed. Visual stimulation increased odor investigation. The effect was not as strong as it was with OLS, however the ACh change that occurs in the OB during the VS is unknown and could be less intense than that driven by OLS. Alternatively, attention could have been divided between exploring the new visual environment and the reinstated odor. 
The dishabituating effect of the sudden visual context change was blocked by administration of scopolamine, a mAChR antagonist. We recently showed that pharmacologically activating OB $\mathrm{mAChR}$ receptors increases glomerular odor responses (Bendahmane et al., 2016). Though we did not address the mechanism underlying these effects in this study, they are potentially mediated through muscarinic-2 ACh receptors on interneurons in the glomerular layer (Liu et al., 2015; Pignatelli and Belluzzi, 2008). A subset of these juxtaglomerular interneurons tonically inhibit OSNs (McGann et al., 2005). This tonic inhibition reduces the gain of OSN excitatory drive onto M/T cells. Following unexpected changes in the environment, we hypothesize that $\mathrm{OB}$ ACh release decreases this presynaptic inhibition, increasing the strength of OSN input and enhancing $\mathrm{M} / \mathrm{T}$ cell responses. In order for an activity-dependent $\mathrm{mAChR}$ effect to play a role in our longer-lasting behavioral experiments, input would still have to be coming into the $\mathrm{OB}$ from the periphery. We only recorded glomerular odor responses for thirty seconds, however prolonged activity was demonstrated by an fMRI study showing that activity in the olfactory nerve and glomerular layers is reduced, but present even after 10 minutes of odor presentation (Schafer et al., 2005). Additionally, none of our cholinergic manipulations were effective at reinstating investigation unless odor was present.

Our experiments showed that ACh can quickly alter glomerular odor responses and shift habituated animals into active investigatory behavior. The BF cholinergic system has been thought to act slowly and globally within the brain (Sarter et al., 2016). However, more recently it has been shown that fast, local ACh release in specific cortical regions can have a major impact on sensory processing (Pinto et al., 2013) and signal detection (Gritton et al., 2016) on a time scale of seconds. Signal detection studies suggest that phasic cholinergic signaling can arise from local excitation of cholinergic terminals within the cortex, independent of direct BF activation (Parikh et al., 2007, 2008; Sarter et al., 2009; Gritton et al., 2016). However, given that our behavioral dishabituation effect can be mediated via novel non-olfactory sensory cues, it is likely that the rapid cholinergic dishabituation we observe in the $\mathrm{OB}$ is driven by excitatory afferent input into the $\mathrm{BF}$ from other brain regions involved in sensory processing or novelty detection.

While the BF receives input from many brain regions (Carnes et al., 1990; Hu et al., 2016), the locus coeruleus (LC) stands out as a region of interest for future studies. The LC projects noradrenergic fibers to the BF (Jones and Moore, 1977; Jones and Cuello, 1989; Carnes et al., 1990; España and Berridge, 2006) and can excite BF cholinergic neurons (Fort et al., 1995). LC neurons are activated by novel objects (Vankov et al., 1995) and sensory stimulation (Foote et al., 1980; Aston-Jones and Bloom, 1981), such as light flashes, and have been hypothesized to drive arousal-induced attentional processing through BF circuits (Berridge and Waterhouse, 2003).

Interestingly, the only other report of olfactory dishabituation in the literature involves a noradrenergic mechanism within the piriform cortex (Smith et al., 2009). It is possible that the dishabituating cholinergic effects we observe represent an additional pathway by which the LC mediates dishabituation in response to novel environmental stimuli. 
In summary, this study revealed a novel dishabituating role for rapid ACh release at the first synapse within the olfactory pathway, which is necessary and sufficient to change the behavioral salience of sensory input. Here we demonstrated, for the first time, that prolonged odor input leads to decreased mitral/tufted (M/T) cell glomerular responses and that these responses can be reinstated following brief activation of the cholinergic BF. This effect can be replicated in awake, behaving mice through optogenetic activation of cholinergic fibers in the OB alone. Furthermore, we showed that this effect is ecologically valid as blocking mAChR activation in the OB blocks visual context change-induced dishabituation. 


\section{CHAPTER 4. RESPONSE PATTERNS OF MITRAL AND TUFTED CELLS DIFFER DURING AND AFTER A PROLONGED ODOR STIMULATION}

\section{Introduction}

The axons of olfactory sensory neurons (OSN) in the nasal epithelium carry odor information into the olfactory bulb (OB), synapsing onto glomeruli, the dendrites of interneurons and output cells of the bulb. In addition to these dendritic clusters, the glomerular layer contains the cell bodies of the juxtaglomerular cells: glutamatergic external tufted (ET) cells and GABAergic periglomerular and short axon cells. These interneurons do not project outside of the olfactory bulb, though some have intrabulbar projections. The cell bodies of the output cells, tufted and mitral (M), are located in the external plexiform layer (EPL) and the mitral cell layer, respectively. In addition to extending apical dendrites into the glomerular layer, both mitral and tufted cells extend lateral dendrites through the EPL where they make synaptic contact with the lateral dendrites of the GABAergic interneurons, granule cells. This diverse range of OB cell types forms a complex, multilayered odor processing network and the response of a given OB cell to odor input is therefore not only determined by axodendritic OSN input, but by its dendrodendritic connections with other excitatory and inhibitory cells in the network.

The excitatory cells of the olfactory bulb, ET interneurons and the output cells, superficial tufted (ST) and M cells, are distributed from superficial to deeper portions of the OB (Shipley and Ennis, 1996; Nagayama et al., 2014). In addition to their physical location, many other characteristics of these cells form a gradient from ET to M, including the presence, length, and location of lateral dendrites, their sensitivity to axodendritic input (e.g. odor sensitivity, response latency, spike threshold), and their sensitivity to excitatory and inhibitory dendrodendritic input (Schneider and Scott, 1983; Nagayama, 2004; De Saint Jan et al., 2009; Igarashi et al., 2012; Kikuta et al., 2013; Vaaga and Westbrook, 2016, 2017)

Our previous study of olfactory bulb glomerular activity during prolonged odor input indicated that the response pattern is relatively stable: odor input causes an initial sharp increase in activity which habituates throughout the presentation and declines rapidly after the odor stops (Chapter 2). Recording in these postsynaptic dendritic tufts, we saw almost no variation from this basic pattern, with only subtle changes in the rate of habituation across trials (Figure 3-2B).

To address how the gradient of functional characteristics among the three excitatory cell types affects their response to a stereotypical pattern of prolonged odor input, we used 2-photon microscopy to record in vivo calcium responses to a thirtysecond odor presentation in OSN axons and ET, ST, and M cell soma. The responses of tufted cells, which are more sensitive to axodendritic than dendrodendritic input, are correlated with OSN input and have a similar pattern, regardless of odor identity. In contrast, the responses of $\mathrm{M}$ cells, which are more sensitive to excitatory and inhibitory dendrodendritic modulation, displayed several different patterns, both during and after 
the odor presentation. We discuss how these response patterns may relate to the functional characteristics of the cell types and what they may mean for odor coding/perception.

\section{Methods}

Adult male and female mice were used for all experiments. Mice were grouphoused and maintained on a 12-h light-dark cycle with ad libitum food and water. All methods were carried out in accordance with relevant and approved guidelines and regulations. All experimental protocols were approved by the University of Tennessee Institutional Animal Care and Use Committee.

\section{Mouse Strains}

To image odor responses in the axons of olfactory sensory neurons, mice were generated by crossing B6 mice expressing Cre recombinase under the olfactory marker protein, Omp, promoter (129P2-Omptm4(cre)Mom/MomJ; Jax Stock No: 006668) with B6 mice with a floxed green fluorescent Ca2+indicator GCaMP3 (129SGt(ROSA)26Sortm38(CAG-GCaMP3)Hze/J; Jax Stock No: 014538). To image odor responses in tufted cells, mice were generated by crossing FVB/N mice expressing Cre recombinase under the Thyl promoter $(\mathrm{FVB} / \mathrm{N}-\mathrm{Tg}(\mathrm{Thy} 1-\mathrm{cre}) 1 \mathrm{~V} \ln / \mathrm{J}$; Jax Stock No: 006143) with B6 mice with a floxed green fluorescent $\mathrm{Ca}^{2+}$ indicator GCaMP3 (129SGt(ROSA)26Sortm38(CAG-GCaMP3)Hze; Jax Stock No: 014538). To image odor responses in mitral cells, we used a transgenic Thy1-GCamp3 line (B6;CBA-Tg(Thy1GCaMP3)6Gfng/J; Jax Stock No: 017893) and a transgenic Thy1-GCamp6 line (C57BL/6J-Tg(Thy1-GCaMP6s)GP4.12Dkim/J; Jax Stock No. 025776).

\section{Surgery}

Mice were anesthetized with urethane ( $2 \mathrm{mg} / \mathrm{kg}$, i.p.) and given an injection of methyl scopolamine $(0.05 \mathrm{mg} / \mathrm{kg}$, i.p) to prevent nasal congestion. Mice were secured in a custom stereotaxic apparatus (Narishige) with a heating pad underneath to maintain body temperature. To create an imaging window, a skin incision was made over the dorsal surface of the mouse head and the bone overlying the OBs was removed using a dental drill. The surface of the brain was covered with a 1\% agarose solution and topped with a glass coverslip to limit movement artifact. The coverslip was fixed into place with dental cement to create a well for imaging. During imaging sessions, animals were freely breathing and the respiratory rate was monitored from the respiratory oscillation observed in the odor-evoked GCaMP3/6 odor-evoked signal. 


\section{Odor Presentation}

Odors [amyl acetate, benzaldehyde, ethyl tiglate, ethyl valerate, 2-heptanone, 2hexanone, and methyl valerate (Sigma-Aldrich)] were delivered for $30 \mathrm{~s} /$ trial using a flow-dilution olfactometer previously described (Fletcher et al., 2009). Separate flow controllers for the clean air and the pure odorant vapor were used to mix the flow streams at the end of the odor delivery system to achieve an approximate concentration of $1 \%$ saturated vapor (s.v.) at a flow rate of $0.7 \mathrm{~L} / \mathrm{min}$. In cases where there was more than one trial/animal, odor presentations were separated by more than 11 minutes, based on a previously determined recovery rate (Ogg et al., 2015).

\section{Optical Imaging and Cell Identification}

Imaging was performed on a Zeiss 7MP 2-photon microscope equipped with a Zeiss 20x objective. Individual cells could easily be identified in resting fluorescence images. ROIs were manually drawn around all cells within an imaging region and raw fluorescence traces for the entire duration of each trial were collected offline using ImageJ.

Imaging depth and cell diameter were used to identify cell type (references). If a cell was in the glomerular layer and had a diameter $<15 \mu \mathrm{m}$, it was classified as an external tufted cell. We cannot rule out the possibility that a small subset of these cells are periglomerular or short axon cells that expressed the Thyl marker. If a cell was in the outer EPL and had a diameter $\geq 15 \mu \mathrm{m}$, it was classified as a superficial tufted cell. In the literature, these cells are sometimes referred to as external tufted cells with lateral dendrites or middle tufted cells (Nagayama et al., 2014). Cells in the mitral cell layer were classified as mitral cells.

\section{Analysis}

All analysis was performed in R (version 3.3.2; R Core Team, 2016).

Data Preparation. All raw fluorescence traces were compiled, interpolated to the fastest frame rate $(t=0.125 \mathrm{~s})$ using the spline function, and smoothed using the features function. Cells were selected for analysis if they responded above the mean $\pm 6 \mathrm{SD}$ of the pre-odor resting fluorescence value. Cells with highly erratic responses by visual inspection were excluded. For equivalent comparison across animals and trials, a custom algorithm was written and used to determine the earliest response in each trial and all trials were aligned by the frame before the earliest determined response. The relative change in fluorescence $(\Delta \mathrm{F} / \mathrm{F})$ was calculated by dividing each trace by its mean pre-odor resting fluorescence. The absolute value of the minimum value and the maximum value were compared, and responses were classified as excitatory and inhibitory based on which value was larger. Traces were normalized by dividing by the maximum or minimum value for excitatory and inhibitory responses respectively. 
Statistics. Statistical significance was defined as $p \leq 0.05$.

\section{Results}

To establish the pattern of prolonged odor input into the bulb, we imaged 30-s odor responses in OMP-GCaMP3+ mice. Regions of interest included all the labeled OSN axons in each glomerulus, so each recorded signal/trace is an average of the response of many input cells. The response pattern of OSN glomeruli $(n=7)$ is very similar to the pattern we recorded previously in postsynaptic glomeruli (Figure 4-1A and Figure 3-2B).

To determine if this prolonged odor pattern is conserved or transformed in other OB cell types, we imaged 30-s odor responses in Thy1-GCaMP3/6+ mice from the soma of ET $(n=83)$, ST $(n=62)$, and M $(n=381)$ cell-odor pairs. As illustrated in the population averages of Figure 4-1, the OSN odor pattern (Figure 4-1A) is conserved in the tufted cell population response patterns (Figure 4-1B, C) and transformed in the $\mathrm{M}$ cell pattern (Figure 4-1D). Individual responses are shown in Figure 4-2. Electrophysiological studies in rat and mouse OSNs indicate that individual input cells respond to thirty seconds of odor in a tonic or phasic manner (Reisert and Matthews, 2001; Madrid et al., 2003), and the variation seen across individual tufted cell responses (Figure 4-2A) corresponds well to a hypothetical mixture of tonic and phasic OSN input. Individual $\mathrm{M}$ cell responses (Figure 4-2B) show a much wider range of variation.

To quantify the relationship between OSN input and the other cell type responses, the correlation coefficient (r) between each OSN response and each ET, ST, and M response was calculated. The correlation matrices for each cell type group are represented in Figure 4-3. For analysis, all of the $r$ values in each matrix were transformed to zscores and the mean for each population was transformed back to an $r$ value. This correlation analysis revealed strong positive correlation between OSN input and ET $(r=$ 0.67 , Figure 4-3A $)$ and ST $(r=0.62$, Figure 4-3B $)$ responses. In contrast, OSN responses were not correlated with $\mathrm{M}$ cell responses $(\mathrm{r}=0.07$; Figure 4-3C).

To further characterize responses, we analyzed all of the individual responses using PCA (Figure 4-4). The first two components account for over $85 \%$ of the total variation in response patterns and were used for further comparison. The first component (PC1) represents the overall breadth of the response (from broadly inhibited to transiently activated to broadly activated) and the second component (PC2) indicates whether a response is strongest at its beginning or end. Shapiro-Wilk normality tests demonstrate that neither PC1 $(\mathrm{W}=0.85, \mathrm{p}<0.05)$ nor $\mathrm{PC} 2(\mathrm{~W}=0.97, \mathrm{p}<0.05)$ are normally distributed, therefore non-parametric analyses were used. Krukal-Wallis tests on PC1 $(\mathrm{H}(2)=31.20, \mathrm{p}<0.05)$ and $\mathrm{PC} 2(\mathrm{H}(2)=205.46, \mathrm{p}<0.05)$ detected significant variation of cellular responses. Post-hoc Nemenyi tests showed that mitral cells differed from both tufted cell populations along both component axes (Table 4-1 and Table 4-2). 


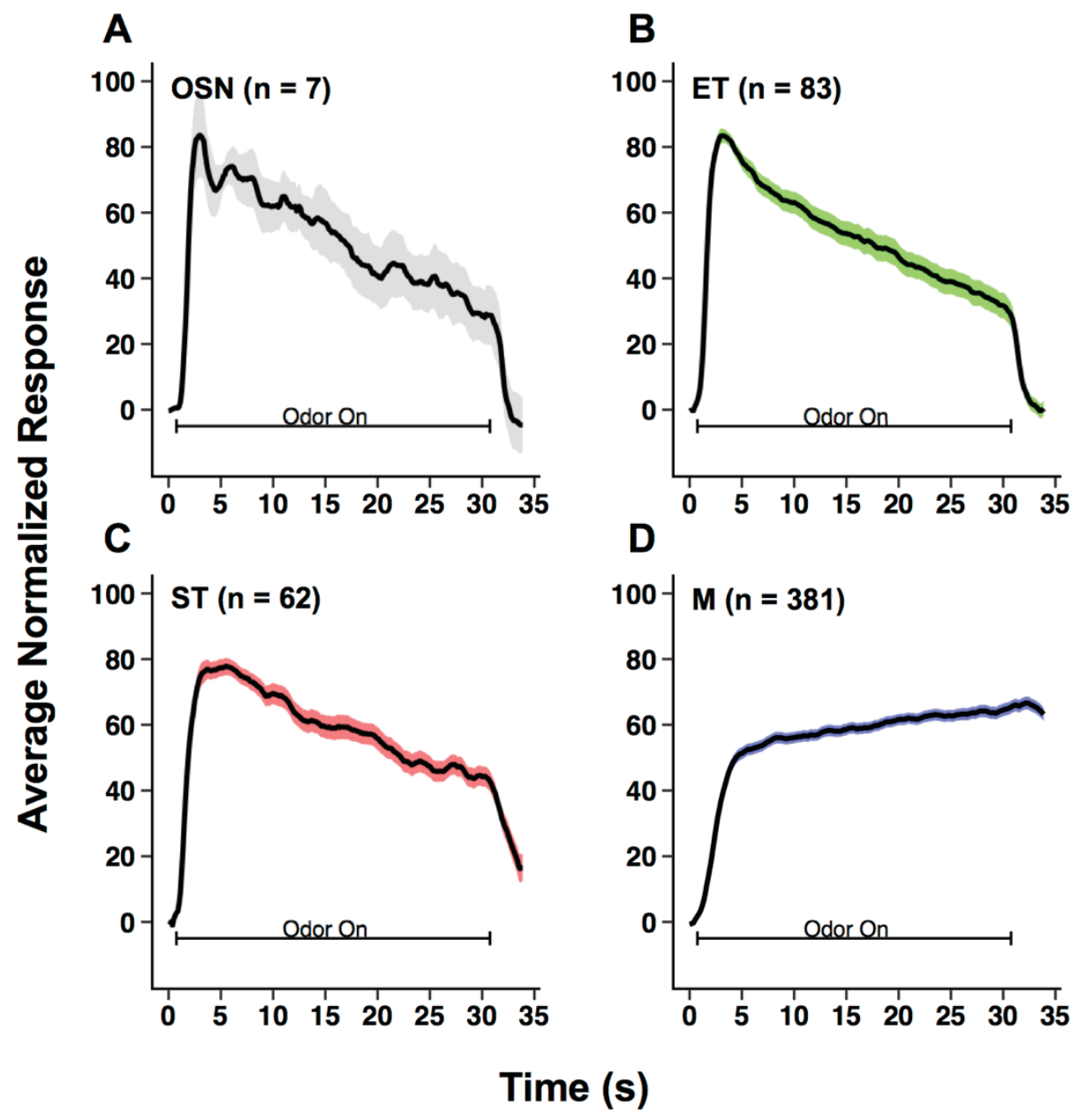

Figure 4-1. Population response patterns of different $O B$ cell types during a prolonged odor presentation.

The average fluorescence trace ( $\%$ of maximum/minimum response \pm SE) during a $30-\mathrm{s}$ odor presentation recorded in (A) olfactory sensory neuron (OSN), (B) external tufted (ET), (C) superficial tufted (ST), and (D) mitral (M) cell-odor pairs. Responses were normalized by their maximum or minimum value for excitatory and inhibitory responses respectively. 

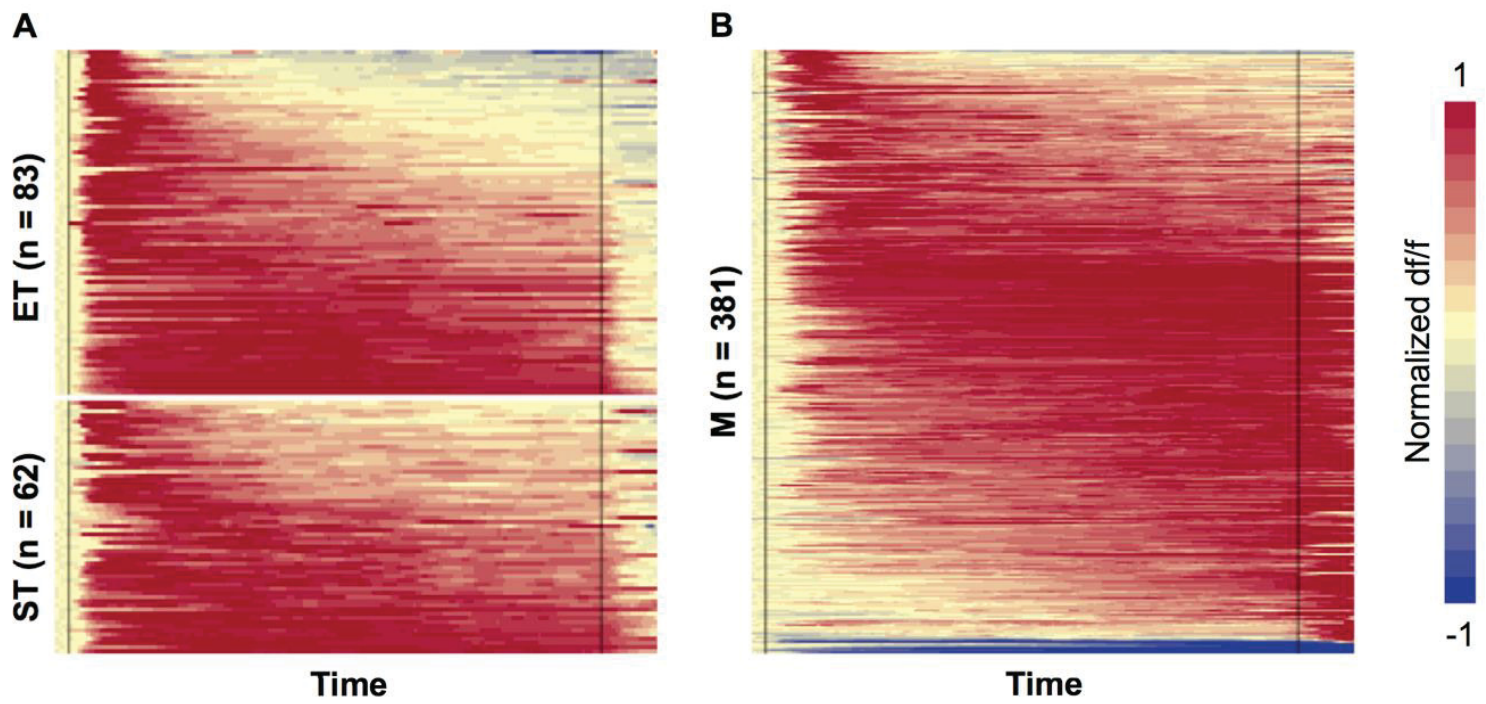

Figure 4-2. Individual responses of different $\mathrm{OB}$ cell types during a prolonged odor presentation.

Individual normalized odor responses sorted by mean response value recorded from A) external tufted (ET; top panel), superficial tufted (ST; bottom panel), and (B) mitral (M) cell-odor pairs. Responses were normalized by their maximum or minimum value for excitatory and inhibitory responses respectively. Each row represents one cell-odor pair, with time along the horizontal axis. The vertical black lines indicate odor on- and offset. 


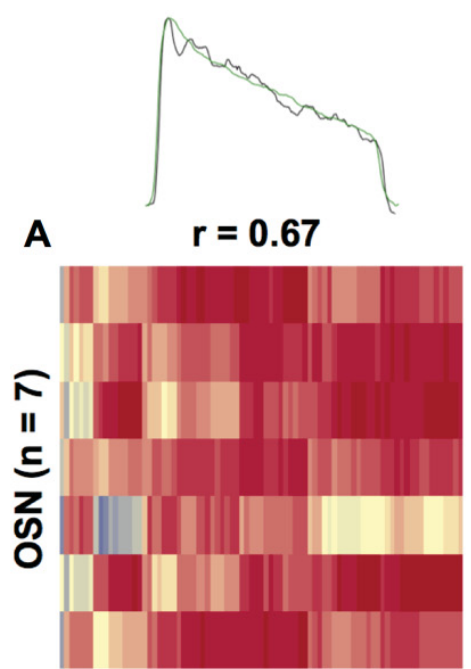

ET $(n=83)$

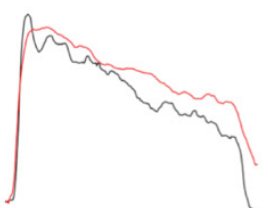

$r=0.62$

B

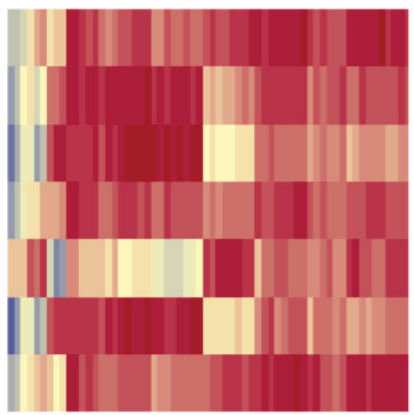

ST $(n=62)$

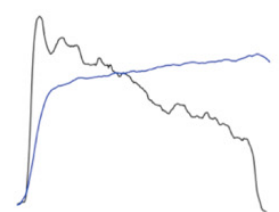

$r=0.07$

C

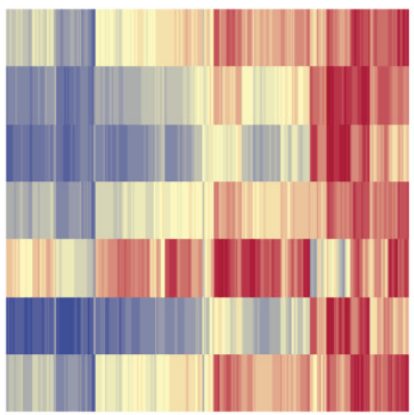

$M(n=381)$

Figure 4-3. Tufted cells are positively correlated with OSN input during a prolonged odor presentation, but mitral cells are not.

Correlation matrices illustrating the relationship between olfactory sensory neuron (OSN) responses and (A) external tufted (ET), (B) superficial tufted (ST), and (C) mitral (M) cell responses. The color of each cell represents the correlation coefficient (r) between the response of an individual OSN and the response of an individual cell of another type.

Above each matrix is displayed the mean of all the correlation coefficients in each matrix and the mean response of the groups being compared. 


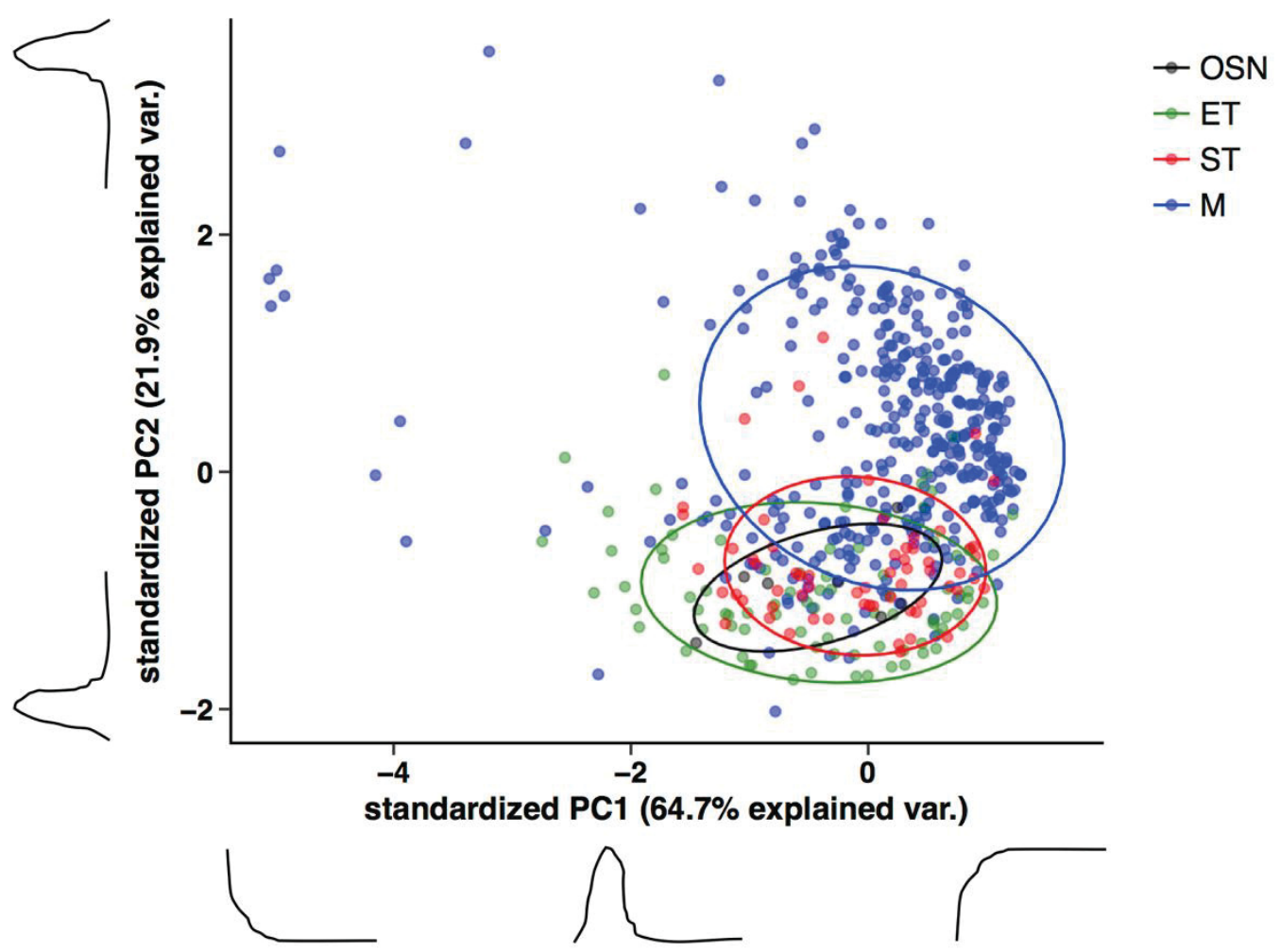

Figure 4-4. Principal component analysis (PCA) of individual responses of different $O B$ cell types. 
Table 4-1. P-values from the post-hoc Nemenyi test comparing PC1 values among the different $O B$ cell types.

\begin{tabular}{ccc}
\hline Cell Type & ET & M \\
\hline M & $<0.05$ & - \\
ST & 0.49 & $<0.05$ \\
\hline
\end{tabular}

Table 4-2. P-values from the post-hoc Nemenyi test comparing PC2 values among the different $O B$ cell types.

\begin{tabular}{ccc}
\hline Cell Type & ET & M \\
\hline M & $<0.05$ & - \\
ST & 0.38 & $<0.05$ \\
\hline
\end{tabular}


The general pattern of the tufted cells (Figure 4-1B, C), with a transient response profile and a strong beginning-to-end ratio, likely reflects the sensitivity of these cell types to axodendritic OSN input. Compared to M cells, ET and ST cells have a lower firing threshold and more OSN synaptic contacts, which results in a larger fast excitatory postsynaptic current over a range of stimulations in slice experiments and causes tufted cells to fire more rapidly earlier and over a wider range of concentrations than mitral cells in vivo (Schneider and Scott, 1983; Nagayama, 2004; De Saint Jan et al., 2009; Najac et al., 2011; Igarashi et al., 2012; Kikuta et al., 2013; Vaaga and Westbrook, 2016, 2017).

Inspection of the response heatmaps (Figure 4-2), correlation plots (Figure 4-3) and PCA plot (Figure 4-4) indicate that while some M cell responses seem to be highly correlated with OSN input and have a similar pattern to that of the tufted cells, there is additional variation in this population. To resolve this variation, we used k-means cluster analysis on the PCA components to sort $\mathrm{M}$ cell responses into commonly occurring patterns. We found three main groups of responses: decreasing $(\mathrm{dM}, \mathrm{n}=80$; Figure 4-5A), increasing (iM, $n=99$; Figure 4-5B), and sustained ( $\mathrm{sM}, \mathrm{n}=192$; Figure 4-5C). In addition, a small group of $\mathrm{M}$ cells were inhibited (hM, $\mathrm{n}=10$; Figure 4-5D). KruskalWallis $(\mathrm{PC} 1(\mathrm{H}(5)=268.17, \mathrm{p}<0.05)$; $\mathrm{PC} 2(\mathrm{H}(5)=396.93, \mathrm{p}<0.05))$ and post-hoc Nemenyi (Table 4-3 and Table 4-4) tests were run with the new groups and indicate significant differences from the other cell types. The $\mathrm{M}$ responses, organized by pattern, are plotted in PCA space for comparison (Figure 4-6).

Different response patterns can be found among mitral cells in the same imaging window to the same odor (Figure 4-7A, B, and C). Differences like these have been shown previously for sister mitral cells, which share glomerular input (Dhawale et al., 2010). Furthermore, individual mitral cells can have different response patterns to different odors (Figure 4-7). These findings imply that the differences among mitral cell responses reflect the sensitivity of mitral cells to network processing, both excitatory and inhibitory, rather than individual properties of the mitral cells themselves.

Like those of ET and ST cells, dMC responses (Figure 4-5A) emerged quickly, peaked early, and then decreased throughout the odor presentation. Post-hoc Nemenyi tests indicate that $\mathrm{dMC}$ responses are as transient (Table 4-3) as tufted cell responses and have the same strong beginning to end ratio (Table 4-4). Najac et al. found that stimulation of OSN axons close to a cell's glomerulus evoke a fast, monosynaptic OSN EPSC in both ET and M cells (2011). With more distant stimulation, this fast component is still present in ET cells, but is missing in M cell responses, which instead display only slow-rising EPSCs at varying latencies. Perhaps $\mathrm{dMC}$ responses, with faster onset than the other response types, are recorded from mitral cells whose glomeruli are being strongly activated by OSN input.

The most common response pattern in $\mathrm{M}$ cells are the sustained responses (Figure 4-5C). The sM pattern is significantly broader than that of the other cell types (Table 4-3). $M$ cells cannot evoke EPSCs in ET cells, but ET, ST, and even other mitral cells have been shown to evoke EPSCs in M cells (De Saint Jan et al., 2009; Najac et al., 2011). Westbrook et al. have demonstrated that $\mathrm{M}$ cells respond to brief afferent 

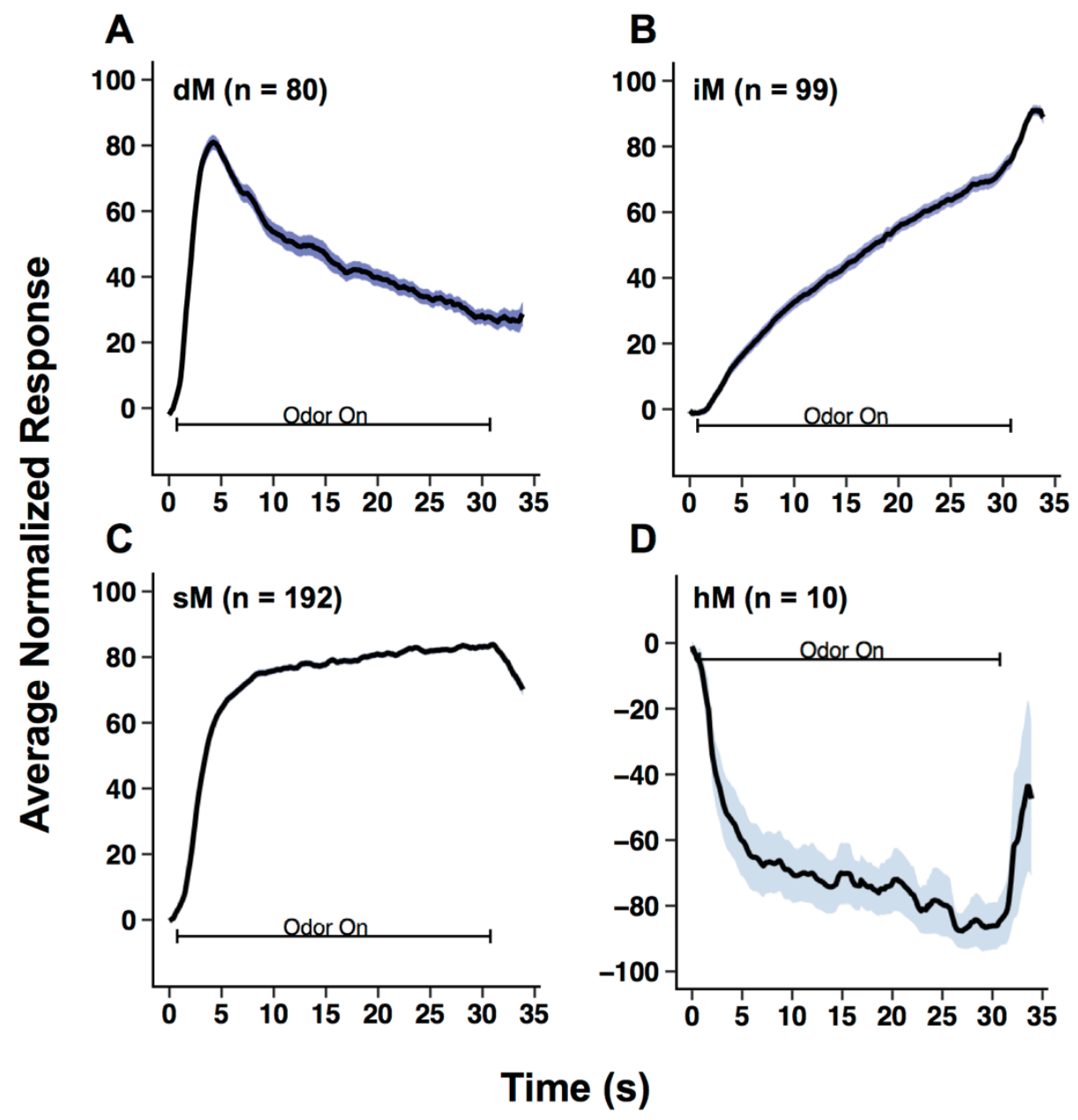

Figure 4-5. Population response patterns of different groups of mitral cell responses during a prolonged odor presentation.

The average fluorescence trace ( $\%$ of maximum/minimum response \pm SE) during a $30-\mathrm{S}$ odor presentation recorded in (A) decreasing (dM), (B) increasing (iM), (C) sustained $(\mathrm{sM})$, and (D) inhibited (hM) mitral cell-odor pairs. Responses were normalized by their maximum or minimum value for excitatory and inhibitory responses respectively. 
Table 4-3. P-values from the post-hoc Nemenyi test comparing PC1 values among the different $\mathrm{OB}$ cell types and mitral cell groups.

\begin{tabular}{cccccc}
\hline Cell Type & dM & hM & iM & sM & ET \\
\hline hM & 0.22 & - & - & - & - \\
iM & 0.08 & $<0.05$ & - & - & - \\
SM & $<0.05$ & $<0.05$ & $<0.05$ & - & - \\
ET & 0.46 & $<0.05$ & 0.98 & $<0.05$ & - \\
ST & 0.07 & $<0.05$ & 1.0 & $<0.05$ & 0.92 \\
\hline
\end{tabular}

Table 4-4. P-values from the post-hoc Nemenyi test comparing PC2 values among the different $O B$ cell types and mitral cell groups.

\begin{tabular}{cccccc}
\hline Cell Type & dM & hM & iM & sM & ET \\
\hline hM & $<0.05$ & - & - & - & - \\
iM & $<0.05$ & 0.99 & - & - & - \\
SM & $<0.05$ & 0.29 & $<0.05$ & - & - \\
ET & 0.21 & $<0.05$ & $<0.05$ & $<0.05$ & - \\
ST & 0.95 & $<0.05$ & $<0.05$ & $<0.05$ & 0.86 \\
\hline
\end{tabular}




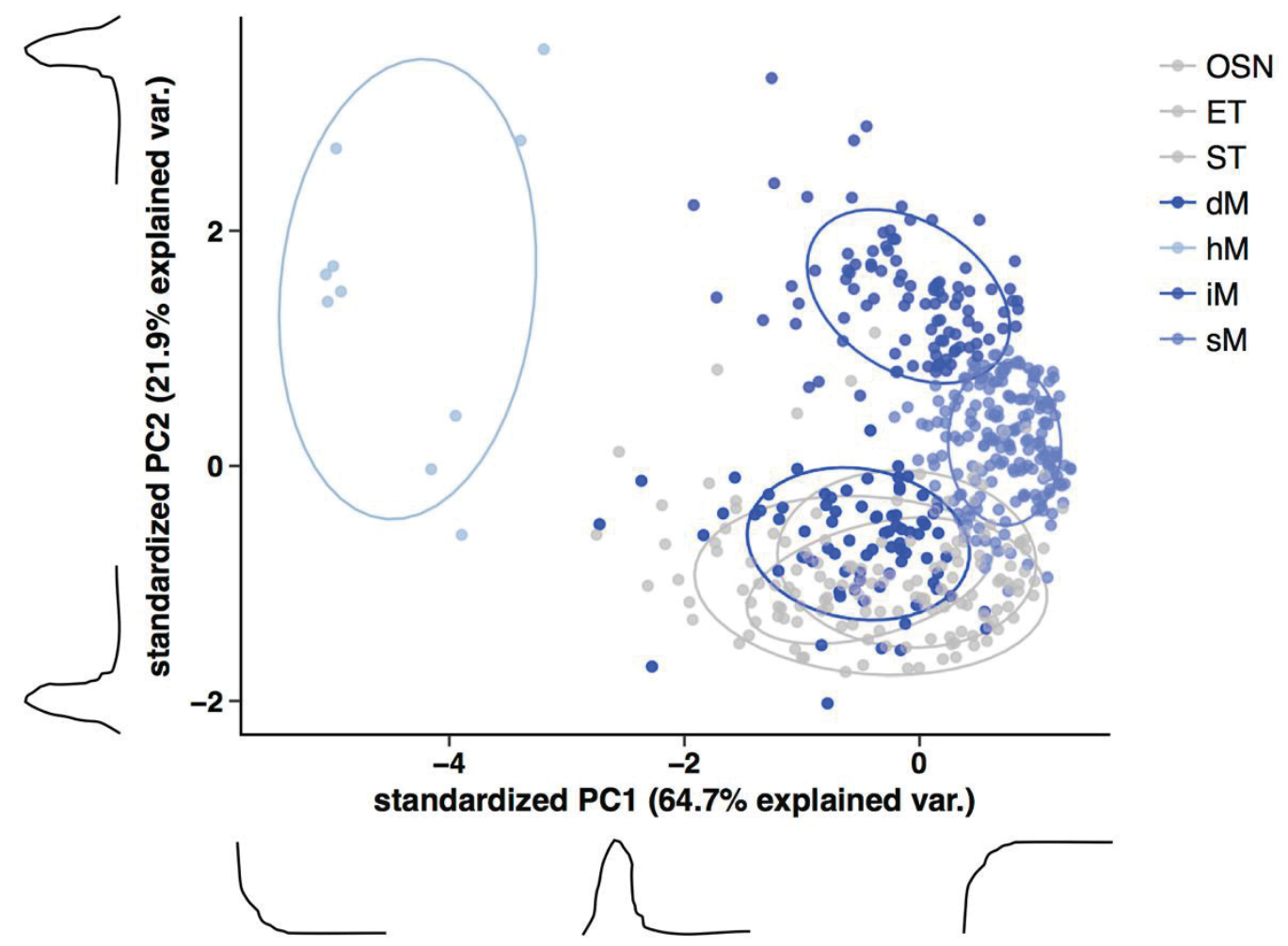

Figure 4-6. Principal component analysis (PCA) of individual responses of different $\mathrm{OB}$ cell types and mitral cell groups.

The PCA is the same as in Figure 4-4 with differences among the mitral cell groups highlighted. 


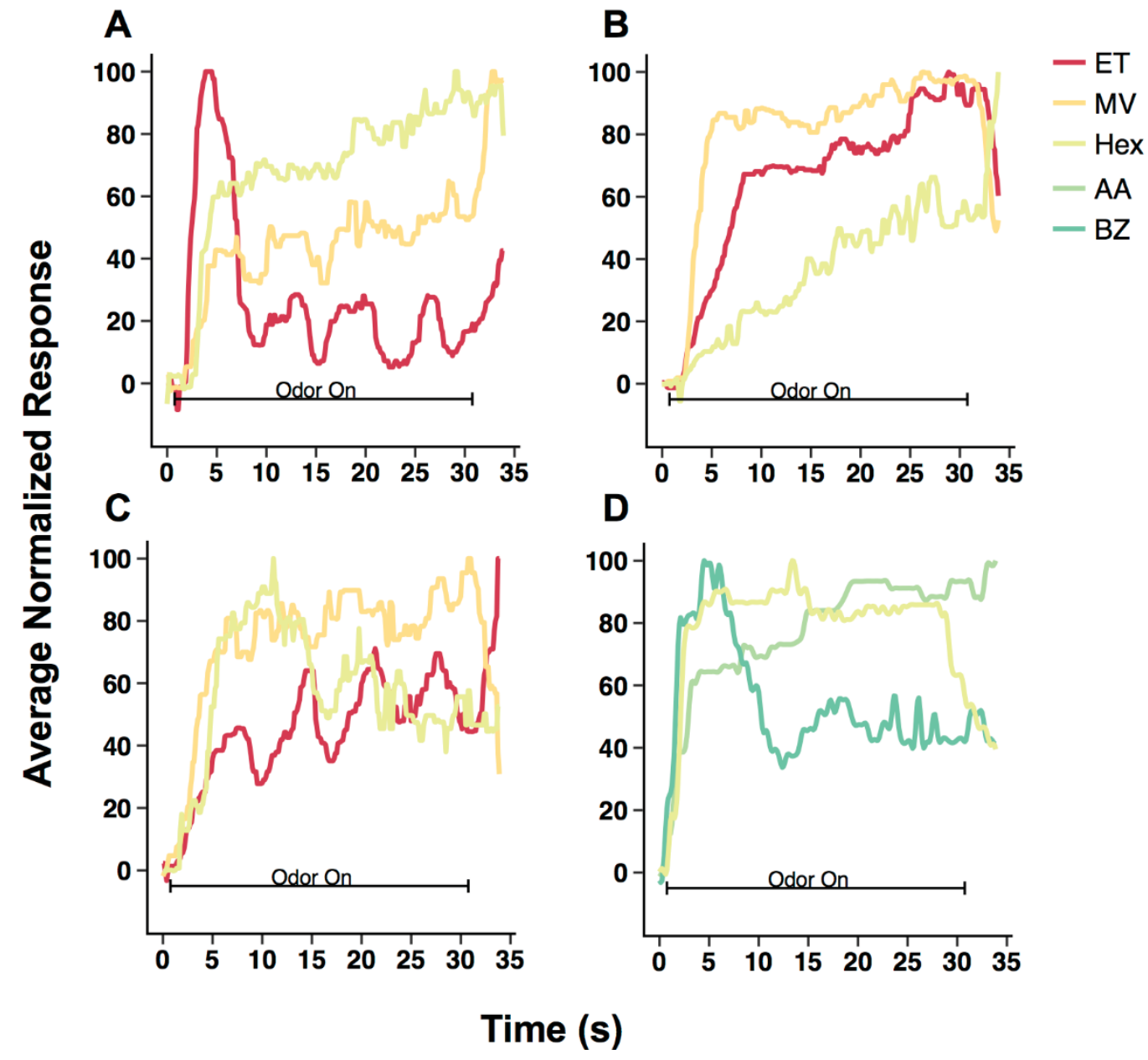

Figure 4-7. Normalized responses of mitral cells to different odors.

(A-C) Cells in the same field of view. (D) Cell from a different animal. Odor identity is represented by color (ethyl tiglate, ET; methyl valerate, MV; 2-hexanone, Hex; amyl acetate, AA; benzaldehyde, BZ). 
stimulation with more sustained responses than ET cells, due to a longer and stronger mGluR1 current from dendrodendritic input (2016, 2017).

In addition to measuring activity during the 30 -s odor presentation, we also measured activity for three seconds after the odor presentation was complete. We used the Mann-Kendall test for monotonic trends, as well as visual inspection, to determine if a response began to decrease, increase, or stay the same after the odor presentation ended (Table 4-5). The majority of ET $(n=79)$ and ST $(n=49)$ cell-odor responses were already off or began to decrease once the odor went off. Of these responses, $75 \%$ and $77 \%$ of cells had returned to baseline $(\leq 0.1)$ by the final recording time point. However, less than half of $M$ responses $(n=176)$ displayed this decreasing behavior and a much smaller proportion of these responses $(18 \%)$ returned to baseline $(\leq 0.1)$ by the final recording time point.

Continued activity after the odor presentation has been recorded previously in the OB (Matsumoto et al., 2009; Patterson et al., 2013; Adam et al., 2014; Economo et al., 2016). The same mGluR1 current found to sustain the MC response during the odor response (Vaaga and Westbrook, 2016, 2017), has also been implicated in prolonging the response of $\mathrm{M} / \mathrm{T}$ cells after the odor presentation, in a phenomenon termed persistent afterdischarge (PAD; Matsumoto et al., 2009). PAD was almost nonexistent in ET responses $(\mathrm{n}=1)$, but was present in equivalent proportions in the ST $(\mathrm{n}=8)$ and MC (n $=63$ ) populations $\left(\mathrm{X}^{2}(1)=0.62, \mathrm{p}=0.43\right)$, both of which extend lateral dendrites and have more potential for dendrodendritic input than ET cells.

Increased activity, or OFF responses, after the odor presentation have also been observed (Matsumoto et al., 2009; Patterson et al., 2013; Adam et al., 2014; Economo et al., 2016). Less than $10 \%$ of ET $(n=3)$ and ST $(n=5)$ cells displayed OFF responses, but OFF responses were much more common in M cells $(n=142)$. This could reflect the sensitivity of $\mathrm{M}$ cells to the inhibitory networks of the bulb (Nagayama, 2004; Kikuta et al., 2013; Adam et al., 2014; Economo et al., 2016). M cells with OFF responses are most likely inhibited throughout the odor presentation and then released from inhibition once the cells inhibiting them go off. Indeed, M cells with OFF responses have a significantly lower response throughout the odor presentation than $\mathrm{M}$ cells without OFF responses (Figure 4-8A).

In addition to having more OFF responses, $\mathrm{M}$ cells also display patterns not seen in the ET and ST responses: the hM pattern (Figure 4-5D), in which responses are inhibited throughout the odor presentation, and the iM pattern (Figure 4-5B), in which responses are increasing throughout the odor presentation and peaking late or even after the odor ends. These patterns may also be due to the influence of the inhibitory networks on $\mathrm{M}$ cells. During the odor presentation, hM responses are inversely correlated with sM responses $(r=-0.72$; Figure 4-8B), and could reflect $M$-excited granule inhibition (Nagayama et al., 2014). Ramping cells are most likely inhibited at the beginning of the odor presentation by ET-excited PG inhibition (Hayar et al., 2004; Adam et al., 2014) which habituates throughout the odor presentation, eventually allowing excitation to overcome the inhibition. In our data, following the average peak of the ET response, the 
Table 4-5. The percentage (and number) of cell-odor pairs displaying each kind of post-odor response.

\begin{tabular}{cccc}
\hline & \multicolumn{3}{c}{ Post-Odor Response } \\
\cline { 2 - 4 } Cell Type & Decrease & Steady (PAD) & Increase (OFF) \\
\hline ET & $95 \%(79)$ & $1 \%(1)$ & $4 \%(3)$ \\
ST & $79 \%(49)$ & $13 \%(8)$ & $8 \%(5)$ \\
dM & $49 \%(39)$ & $11 \%(9)$ & $40 \%(32)$ \\
hM & $80 \%(8)$ & $0 \%(0)$ & $20 \%(2)$ \\
iM & $12 \%(12)$ & $23 \%(23)$ & $65 \%(64)$ \\
sM & $61 \%(117)$ & $16 \%(31)$ & $23 \%(44)$ \\
\hline
\end{tabular}



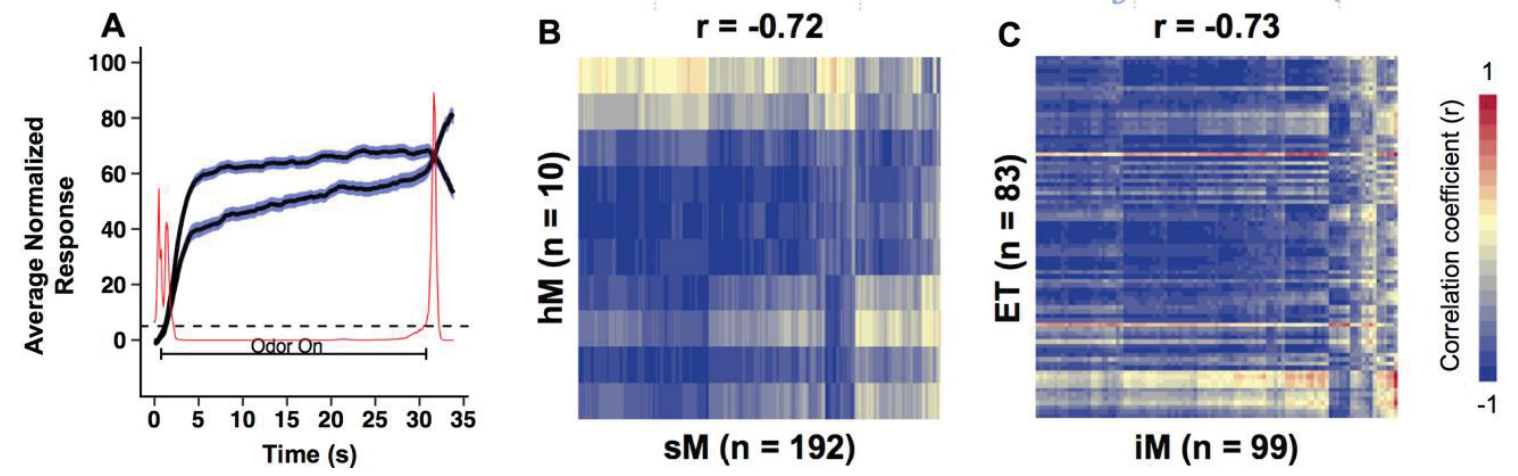

Figure 4-8. Inhibition affects mitral (M) cell responses during and after the odor presentation.

(A) The average fluorescence traces ( $\%$ of maximum/minimum response $\pm \mathrm{SE}$ ) of mitral (M) cells that have OFF responses and those that do not. The response of all the cells was compared at each time point with an ANOVA and the thin red line represents the p-value (x 100). The dashed black line represents significance. The responses of $\mathrm{M}$ cells that have OFF responses are significantly lower during the odor presentation and significantly higher after the odor presentation than the responses of cells that do not have OFF responses. (B-C) Correlation matrices illustrating the relationship between (B) inhibited $\mathrm{M}(\mathrm{hM})$ and sustained $\mathrm{M}(\mathrm{sM})$ cell responses and (C) external tufted (ET) and increasing $\mathrm{M}$ (iM) cell responses as in Figure 4-3. The correlation was assessed only across the time points represented between the dotted black lines above each matrix. 
negative correlation between ET and iM responses $(\mathrm{r}=-0.73)$ is very strong (Figure 4-8C).

To find out more about what these temporal patterns might mean for odor coding, we investigated the behavior of several cells which responded to more than one odor in an imaging session $(\mathrm{n}=1 \mathrm{ET}, 11 \mathrm{ST}, 44 \mathrm{MC})$. Because tufted cells tend to respond in a similar way both during and after the odor presentation, correlation tests indicate that even the response of individual tufted cells to different odors is highly correlated $(\mathrm{r}=$ $0.81, \mathrm{n}=14$ correlations; Figure 4-9). In contrast, while the response of individual mitral cells to the same odor $(\mathrm{r}=0.85, \mathrm{n}=7$ correlations; Figure 4-10 $)$ is also highly correlated, their response to different odors $(r=0.59, \mathrm{n}=73$ correlations; Figure 4-10) is significantly less correlated (Welch $\mathrm{t}(11)=3.8, \mathrm{p}<0.05)$.

\section{Discussion}

In summary, 2P imaging of prolonged odor responses revealed major differences between mitral and tufted cells. In general, the OSN input signal was conserved in the tufted cell response patterns. Information from tufted cells clearly delineated when an odor began and ended, but provided less information about odor identity. Mitral cell responses had more variation, and while some $M$ responses adapted like those of tufted cells, others amplified OSN input throughout and even after the odor presentation. Mitral cell patterning reflects differential activation of the excitatory and inhibitory networks of the OB for each odor and different connections with these networks for each cell. Such differences have also been observed in imaging studies with shorter odor presentations (Adam et al., 2014; Economo et al., 2016) and many have suggested that mitral and tufted cells serve as "distinct, but parallel, input pathways" (Vaaga and Westbrook, 2016).

The ET cells we recorded from do not project out of the OB (Nagayama et al., 2014), but their activity strongly affects mitral patterns, prolonging some responses through dendrodendritic mGluR1 activation (Vaaga and Westbrook, 2016, 2017) and altering the shape of others through activation of intraglomerular inhibition (Hayar et al., 2004; Adam et al., 2014; Economo et al., 2016). Most ST cells project to focal targets in the olfactory tubercle (Nagayama, 2010) and olfactory peduncle areas (anterior olfactory nucleus and tenia tecta) (Igarashi et al., 2012). Both the tubercle (Wesson and Wilson, 2011) and the peduncle (Brunjes et al., 2011) are connected to areas associated with attentional modulation. The tufted cell response pattern to prolonged input, which is strong at the beginning and habituates throughout the presentation, could be a neural correlate to odor attention. Nagayama suggested that "the tufted cell pathway may have a critical function in monitoring the odor environment and changing animal behavioral states in response to external environmental changes" (2010). Further, through association fibers from the peduncle to the piriform cortex $(\mathrm{pCx})$ short-latency tufted cell responses could be priming the $\mathrm{pCx}$ for incoming information from mitral cell responses (Mori et al., 2013). 

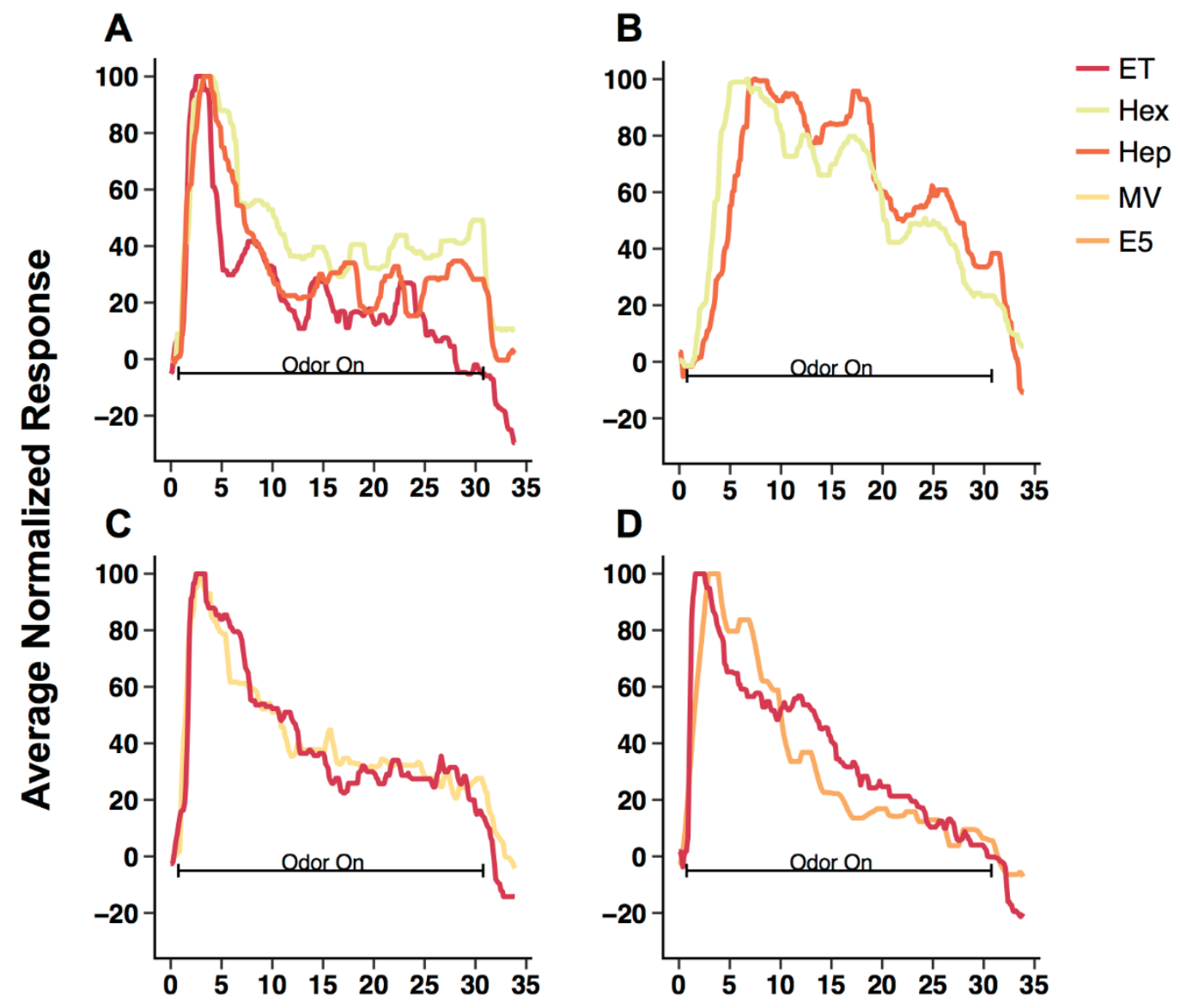

\section{Time (s)}

Figure 4-9. Normalized responses of superficial tufted cells to different odors. (A-B) Cells in the same animal and different fields of view. (C-D) Cells from different animals. Odor identity is represented by color (ethyl tiglate, ET; 2-hexanone, Hex; 2heptanone, Hep; methyl valerate, MV; ethyl valerate, E5). 


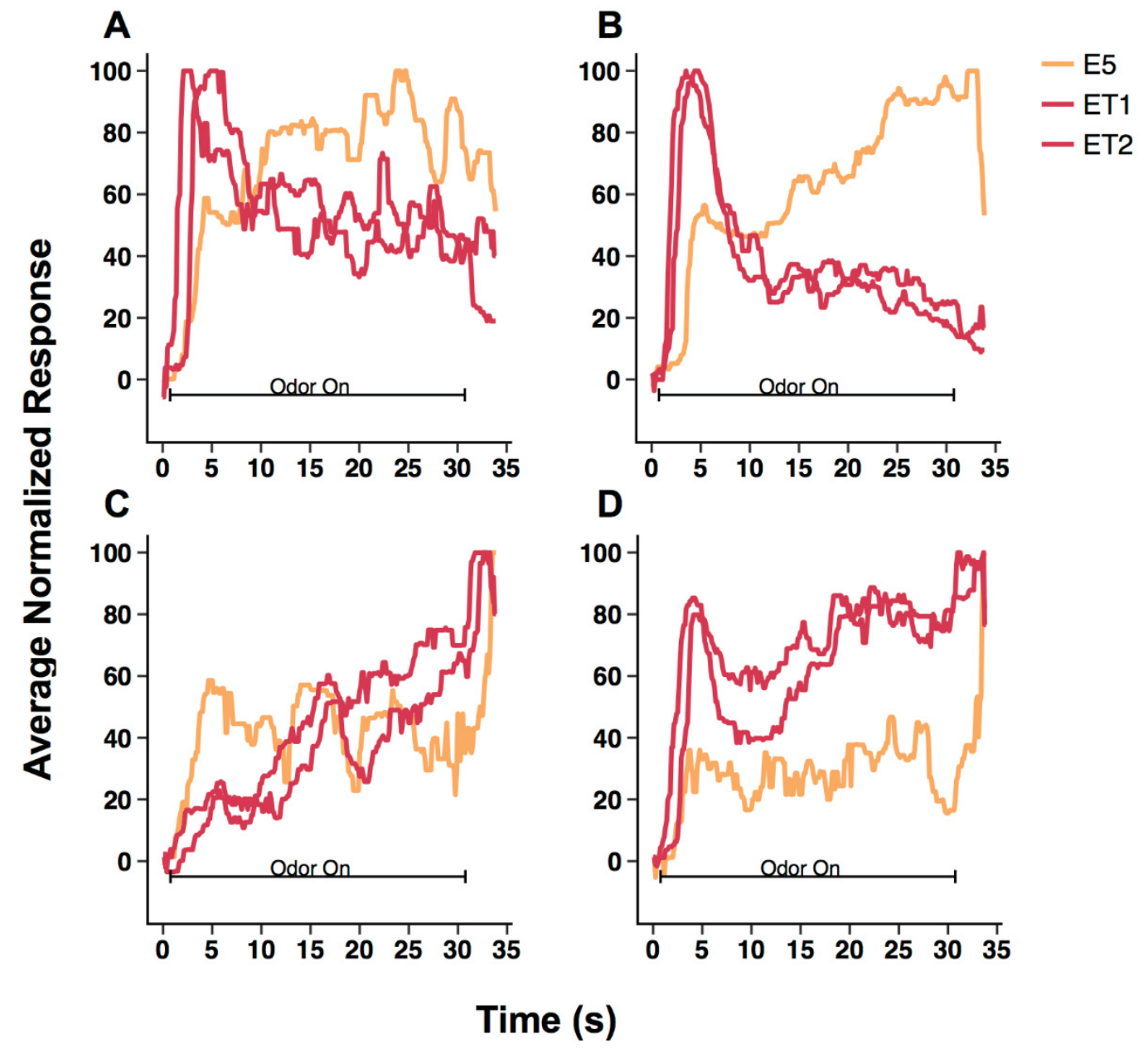

Figure 4-10. Normalized responses of mitral cells comparing their responses to the same and different odors.

(A-D) All cells are in the same field of view. Odor identity is represented by color (ethyl valerate, E5; ethyl tiglate, ET). 
Individual mitral cells project widely across the $\mathrm{pCx}$ (citations) and individual pyramidal cells in the $\mathrm{pCx}$ receive input from $\mathrm{M}$ cells all over the $\mathrm{OB}$ (citations). $\mathrm{pCx}$ cells could be integrating or comparing the various mitral cell patterns we observed to create an "accurate odor image" (Nagayama, 2010). In addition to aiding in odor discrimination, variable mitral cell patterns may contribute to the maintenance of odor information across the prolonged odor presentation. Wilson and colleagues have identified a presynaptic inhibitory feedback mechanism that emerges after at least $10 \mathrm{~s}$ of odor stimulation and silences the M-pCx synapse (Best and Wilson, 2004). The different M patterns we observed shift which cells in an odor ensemble are active at a given time, potentially extending the amount of time that the $\mathrm{pCx}$ can "listen" to odor information. 


\section{CHAPTER 5. CONCLUSIONS AND FUTURE DIRECTIONS}

In the study presented in Chapter 2, calcium imaging showed that a prolonged odor presentation habituates $\mathrm{OB}$ glomerular responses to both the same and structurally similar odors for minutes. Experiments using olfactory nerve stimulation demonstrated that, postsynaptically, M/T dendrites can still be activated and, presynaptically, glutamate is available and able to be released effectively from the OSN terminals, indicating that the glomerular response decreases were most likely the result of adaptation processes taking place in the periphery. The imaging results in Chapter 3 demonstrated that prolonged odor input not only habituates subsequent odor responses, but leads to decreased $\mathrm{M} / \mathrm{T}$ glomerular responses during the presentation as well. Widefield imaging was used in these chapters and the results reflect the mean response of dendrites from both mitral and tufted cells. The work from Chapter 4, using 2-photon imaging, revealed that, unlike the glomerular responses, the soma responses of mitral and tufted cells can be quite different from each other during a prolonged odor presentation. These results indicate that the neural encoding of odor experience in the $\mathrm{OB}$ is more complex than progressive filtering of odor information over time.

The imaging and behavioral experiments in Chapter 3 confirmed the hypothesis that $\mathrm{ACh}$ release in the $\mathrm{OB}$ could dishabituate glomerular responses during prolonged odors and, as a result, allow the stimuli to be detected and investigated again. Further, these experiments demonstrated that this cholinergic dishabituation mechanism in the $\mathrm{OB}$ occurs naturally in response to non-olfactory sensory stimulation. Together, these results indicate that the neural encoding of odor experience in the OB and its manipulations can have a strong effect on the perceptual salience of an odor.

The findings from Chapter 4 highlight the differences between mitral and tufted cell responses to prolonged odor exposure and raise interesting questions about how the responses of these cell types might differ in their recovery from habituation (as in Chapter 2) and in their response to acetylcholine during an odor presentation (as in Chapter 3). Further, with their projections to different parts of the olfactory cortex, is the neural dishabituation of one cell type more important for behavioral dishabituation than the other, or do both play a role?

All of the imaging results presented in this dissertation were recorded in anesthetized animals. The development of awake head-fixed OB imaging (Kato et al., 2012; Kollo et al., 2014; Economo et al., 2016) and fluorescent miniscopes (Ghosh et al., 2011; Cai et al., 2016), which allow animals to move freely while imaging is taking place at a cellular level and can access deeper brain regions, provide a clear future direction for this work. The odor investigation paradigm developed in Chapter 3 can be coupled with these newer imaging techniques to further explore habituation and dishabituation, not only in the olfactory bulb, but in places to which the OB projects, like the olfactory tubercle, and areas which may be involved in dishabituation, such as the basal forebrain and the locus coeruleus. 


\section{LIST OF REFERENCES}

Adam, Y., Livneh, Y., Miyamichi, K., Groysman, M., Luo, L., and Mizrahi, A. (2014). Functional transformations of odor inputs in the mouse olfactory bulb. Front. Neural Circuits 8, 129. doi:10.3389/fncir.2014.00129.

Aston-Jones, G., and Bloom, F. E. (1981). Norepinephrine-containing locus coeruleus neurons in behaving rats exhibit pronounced responses to non-noxious environmental stimuli. J. Neurosci. 1, 887-900.

Bendahmane, M., Ogg, M. C., Ennis, M., and Fletcher, M. L. (2016). Increased olfactory bulb acetylcholine bi-directionally modulates glomerular odor sensitivity. Sci. Rep. 6, 25808. doi:10.1038/srep25808.

Berridge, C. W., and Waterhouse, B. D. (2003). The locus coeruleus-noradrenergic system: modulation of behavioral state and state-dependent cognitive processes. Brain Res. Rev. 42, 33-84. doi:10.1016/S0165-0173(03)00143-7.

Best, A. R., Thompson, J. V, Fletcher, M. L., and Wilson, D. A. (2005). Cortical metabotropic glutamate receptors contribute to habituation of a simple odorevoked behavior. J. Neurosci. 25, 2513-7. doi:10.1523/JNEUROSCI.529804.2005 .

Best, A. R., and Wilson, D. A. (2004). Coordinate synaptic mechanisms contributing to olfactory cortical adaptation. J. Neurosci. 24, 652-60. doi:10.1523/JNEUROSCI.4220-03.2004.

Boyd, A. M., Sturgill, J. F., Poo, C., and Isaacson, J. S. (2012). Cortical feedback control of olfactory bulb circuits. Neuron 76, 1161-74. doi:10.1016/j.neuron.2012.10.020.

Brunert, D., Kurtenbach, S., Isik, S., Benecke, H., Gisselmann, G., Schuhmann, W., Hatt, H., and Wetzel, C. H. (2009). Odorant-dependent generation of nitric oxide in mammalian olfactory sensory neurons. PLoS One 4, e5499. doi:10.1371/journal.pone.0005499.

Brunjes, P. C., Illig, K. R., and Meyer, E. A. (2005). A field guide to the anterior olfactory nucleus (cortex). Brain Res. Brain Res. Rev. 50, 305-35. doi:10.1016/j.brainresrev.2005.08.005.

Brunjes, P. C., Kay, R. B., and Arrivillaga, J. P. (2011). The mouse olfactory peduncle. J. Comp. Neurol. 519, 2870-86. doi:10.1002/cne.22662.

Cai, D. J., Aharoni, D., Shuman, T., Shobe, J., Biane, J., Song, W., Wei, B., Veshkini, M., La-Vu, M., Lou, J., et al. (2016). A shared neural ensemble links distinct contextual memories encoded close in time. Nature 534, 115-118. doi:10.1038/nature17955.

Cain, W. S. (1970). Odor intensity after self-adaptation and cross-adaptation. Percept. Psychophys. 7, 271-275. doi:10.3758/BF03210163.

Carnes, K. M., Fuller, T. A., and Price, J. L. (1990). Sources of presumptive glutamatergic/aspartatergic afferents to the magnocellular basal forebrain in the rat. J. Comp. Neurol. 302, 824-852. doi:10.1002/cne.903020413.

Castillo, P. E., Carleton, a, Vincent, J. D., and Lledo, P. M. (1999). Multiple and opposing roles of cholinergic transmission in the main olfactory bulb. J. Neurosci. 19, 9180-91. 
Chaput, M. A., and Panhuber, H. (1982). Effects of long duration odor exposure on the unit activity of olfactory bulb cells in awake rabbits. Brain Res. 250, 41-52. doi:10.1016/0006-8993(82)90951-9.

Chaudhury, D., Escanilla, O., and Linster, C. (2009). Bulbar acetylcholine enhances neural and perceptual odor discrimination. J. Neurosci. 29, 52-60. doi:10.1523/JNEUROSCI.4036-08.2009.

Chaudhury, D., Manella, L., Arellanos, A., Escanilla, O., Cleland, T. A., and Linster, C. (2010). Olfactory bulb habituation to odor stimuli. Behav. Neurosci. 124, 490499. doi:10.1037/a0020293.

Chen, Q., Cichon, J., Wang, W., Qiu, L., Lee, S.-J. R., Campbell, N. R., Destefino, N., Goard, M. J., Fu, Z., Yasuda, R., et al. (2012). Imaging neural activity using Thy1-GCaMP transgenic mice. Neuron 76, 297-308. doi:10.1016/j.neuron.2012.07.011.

Dalton, P. (2000). Psychophysical and behavioral characteristics of olfactory adaptation. Chem. Senses 25, 487-492. doi:10.1093/chemse/25.4.487.

Das, S., Sadanandappa, M. K., Dervan, A., Larkin, A., Lee, J. A., Sudhakaran, I. P., Priya, R., Heidari, R., Holohan, E. E., Pimentel, A., et al. (2011). Plasticity of local GABAergic interneurons drives olfactory habituation. Proc. Natl. Acad. Sci. U. S. A. 108, E646-54. doi:10.1073/pnas.1106411108.

Devore, S., Pender-Morris, N., Dean, O., Smith, D., and Linster, C. (2015). Basal forebrain dynamics during non-associative and associative olfactory learning. $J$. Neurophysiol. 14853, 423-433. doi:10.1152/jn.00572.2015.

Dhawale, A. K., Hagiwara, A., Bhalla, U. S., Murthy, V. N., and Albeanu, D. F. (2010). Non-redundant odor coding by sister mitral cells revealed by light addressable glomeruli in the mouse. Nat. Neurosci. 13, 1404-12. doi:10.1038/nn.2673.

Díez-García, J., Matsushita, S., Mutoh, H., Nakai, J., Ohkura, M., Yokoyama, J., Dimitrov, D., and Knöpfel, T. (2005). Activation of cerebellar parallel fibers monitored in transgenic mice expressing a fluorescent $\mathrm{Ca} 2+$ indicator protein. Eur. J. Neurosci. 22, 627-35. doi:10.1111/j.1460-9568.2005.04250.x.

Eckmeier, D., and Shea, S. D. (2014). Noradrenergic plasticity of olfactory sensory neuron inputs to the main olfactory bulb. J. Neurosci. 34, 15234-43. doi:10.1523/JNEUROSCI.0551-14.2014.

Economo, M. N., Hansen, K. R., and Wachowiak, M. (2016). Control of mitral/tufted cell output by selective inhibition among olfactory bulb glomeruli. Neuron 91 , 397411. doi:10.1016/j.neuron.2016.06.001.

España, R. A., and Berridge, C. W. (2006). Organization of noradrenergic efferents to arousal-related basal forebrain structures. J. Comp. Neurol. 496, 668-683. doi:10.1002/cne.20946.

Feinstein, P., and Mombaerts, P. (2004). A contextual model for axonal sorting into glomeruli in the mouse olfactory system. Cell 117, 817-831. doi:10.1016/j.cell.2004.05.011.

Fletcher, M. L. (2011). Analytical processing of binary mixture information by olfactory bulb glomeruli. PLoS One 6, e29360. doi:10.1371/journal.pone.0029360.

Fletcher, M. L., and Bendahmane, M. (2014). Visualizing olfactory learning functional imaging of experience-induced olfactory bulb changes. Prog. Brain Res. 208, 89113. doi:10.1016/B978-0-444-63350-7.00004-8. 
Fletcher, M. L., and Chen, W. R. (2010). Neural correlates of olfactory learning: Critical role of centrifugal neuromodulation. Learn. Mem. 17, 561-570. doi:10.1101/lm.941510.

Fletcher, M. L., Masurkar, A. V., Xing, J., Imamura, F., Xiong, W., Nagayama, S., Mutoh, H., Greer, C. A., Knöpfel, T., and Chen, W. R. (2009). Optical imaging of postsynaptic odor representation in the glomerular layer of the mouse olfactory bulb. J. Neurophysiol. 102, 817-30. doi:10.1152/jn.00020.2009.

Fletcher, M. L., and Wilson, D. A. (2002). Experience modifies olfactory acuity: acetylcholine-dependent learning decreases behavioral generalization between similar odorants. J. Neurosci. 22, RC201. doi:20026013 [pii].

Fletcher, M. L., and Wilson, D. A. (2003). Olfactory bulb mitral-tufted cell plasticity: odorant-specific tuning reflects previous odorant exposure. J. Neurosci. 23, 69466955. doi:12890789.

Foote, S. L., Aston-Jones, G., and Bloom, F. E. (1980). Impulse activity of locus coeruleus neurons in awake rats and monkeys is a function of sensory stimulation and arousal. Proc. Natl. Acad. Sci. U. S. A. 77, 3033-7. doi:10.1073/pnas.77.5.3033.

Fort, P., Khateb, A., Pegna, A., Mühlethaler, M., and Jones, B. E. (1995). Noradrenergic modulation of cholinergic nucleus basalis neurons demonstrated by in vitro pharmacological and immunohistochemical evidence in the guinea-pig brain. Eur. J. Neurosci. 7, 1502-1511. doi:10.1111/j.1460-9568.1995.tb01145.x.

Ghosh, K. K., Burns, L. D., Cocker, E. D., Nimmerjahn, A., Ziv, Y., Gamal, A. El, and Schnitzer, M. J. (2011). Miniaturized integration of a fluorescence microscope. Nat. Methods 8, 871-878. doi:10.1038/nmeth.1694.

Giovannini, M. G., Rakovska, A., Benton, R. S., Pazzagli, M., Bianchi, L., and Pepeu, G. (2001). Effects of novelty and habituation on acetylcholine, GABA, and glutamate release from the frontal cortex and hippocampus of freely moving rats. Neuroscience 106, 43-53.

Gritton, H. J., Howe, W. M., Mallory, C. S., Hetrick, V. L., Berke, J. D., and Sarter, M. (2016). Cortical cholinergic signaling controls the detection of cues. Proc. Natl. Acad. Sci. U. S. A. 113, E1089-97. doi:10.1073/pnas.1516134113.

Hamamoto, M., Kiyokage, E., Sohn, J., Hioki, H., Harada, T., and Toida, K. (2017). Structural basis for cholinergic regulation of neural circuits in the mouse olfactory bulb. J. Comp. Neurol. 525, 574-591. doi:10.1002/cne.24088.

Hayar, A., Karnup, S., Ennis, M., and Shipley, M. T. (2004). External tufted cells: a major excitatory element that coordinates glomerular activity. J. Neurosci. 24, 6676-85. doi:10.1523/JNEUROSCI.1367-04.2004.

Hijmans, R. J. (2016). Raster: geographic data analysis and modeling. R package version 2.5-8.

Homma, R., Baker, B. J., Jin, L., Garaschuk, O., Konnerth, A., Cohen, L. B., and Zecevic, D. (2009). Wide-field and two-photon imaging of brain activity with voltage- and calcium-sensitive dyes. Philos. Trans. R. Soc. Lond. B. Biol. Sci. 364, 2453-67. doi:10.1098/rstb.2009.0084.

Hu, R., Jin, S., He, X., Xu, F., and Hu, J. (2016). Whole-brain monosynaptic afferent inputs to basal forebrain cholinergic system. Front. Neuroanat. 10, 98. doi:10.3389/fnana.2016.00098. 
Igarashi, K. M., Ieki, N., An, M., Yamaguchi, Y., Nagayama, S., Kobayakawa, K., Kobayakawa, R., Tanifuji, M., Sakano, H., Chen, W. R., and Mori, K. (2012). Parallel mitral and tufted cell pathways route distinct odor information to different targets in the olfactory cortex. J. Neurosci. 32, 7970-7985. doi:10.1523/JNEUROSCI.0154-12.2012.

Imai, T. (2014). Construction of functional neuronal circuitry in the olfactory bulb. Semin. Cell Dev. Biol. 35, 180-8. doi:10.1016/j.semcdb.2014.07.012.

Inglis, F. M., and Fibiger, H. C. (1995). Increases in hippocampal and frontal cortical acetylcholine release associated with presentation of sensory stimuli. Neuroscience 66, 81-86. doi:10.1016/0306-4522(94)00578-S.

Le Jeune, H., Aubert, I., Jourdan, F., and Quirion, R. (1995). Comparative laminar distribution of various autoradiographic cholinergic markers in adult rat main olfactory bulb. J. Chem. Neuroanat. 9, 99-112. doi:10.1016/08910618(95)00070-N.

Jones, B. E., and Cuello, A. C. (1989). Afferents to the basal forebrain cholinergic cell area from pontomesencephalic-catecholamine, serotonin, and acetylcholineneurons. Neuroscience 31, 37-61. doi:10.1016/0306-4522(89)90029-8.

Jones, B. E., and Moore, R. Y. (1977). Ascending projections of the locus coeruleus in the rat. II. Autoradiographic study. Brain Res. 127, 23-53. doi:10.1016/00068993(77)90378-X.

Kato, H. K., Chu, M. W., Isaacson, J. S., and Komiyama, T. (2012). Dynamic sensory representations in the olfactory bulb: modulation by wakefulness and experience. Neuron 76, 962-75. doi:10.1016/j.neuron.2012.09.037.

Kikuta, S., Fletcher, M. L., Homma, R., Yamasoba, T., and Nagayama, S. (2013). Odorant response properties of individual neurons in an olfactory glomerular module. Neuron 77, 1122-1135. doi:10.1016/j.neuron.2013.01.022.

Kollo, M., Schmaltz, A., Abdelhamid, M., Fukunaga, I., and Schaefer, A. T. (2014). "Silent" mitral cells dominate odor responses in the olfactory bulb of awake mice. Nat. Neurosci. 17, 1313-1315. doi:10.1038/nn.3768.

Larkin, A., Karak, S., Priya, R., Das, A., Ayyub, C., Ito, K., Rodrigues, V., and Ramaswami, M. (2010). Central synaptic mechanisms underlie short-term olfactory habituation in Drosophila larvae. Learn. Mem. 17, 645-53. doi:10.1101/lm.1839010.

Lecoq, J., Tiret, P., and Charpak, S. (2009). Peripheral adaptation codes for high odor concentration in glomeruli. J. Neurosci. 29, 3067-72. doi:10.1523/JNEUROSCI.6187-08.2009.

Lepousez, G., Alonso, M., Wagner, S., Gallarda, B. W., and Lledo, P.-M. (2011). Selective viral transduction of adult-born olfactory neurons for chronic in vivo optogenetic stimulation. J. Vis. Exp., e3380. doi:10.3791/3380.

Liu, S., Shao, Z., Puche, A., Wachowiak, M., Rothermel, M., and Shipley, M. T. (2015). Muscarinic receptors modulate dendrodendritic inhibitory synapses to sculpt glomerular output. J. Neurosci. 35, 5680-92. doi:10.1523/JNEUROSCI.495314.2015. 
Ma, M., and Luo, M. (2012). Optogenetic activation of basal forebrain cholinergic neurons modulates neuronal excitability and sensory responses in the main olfactory bulb. J. Neurosci. 32, 10105-16. doi:10.1523/JNEUROSCI.005812.2012 .

Madrid, R., Sanhueza, M., Alvarez, O., and Bacigalupo, J. (2003). Tonic and phasic receptor neurons in the vertebrate olfactory epithelium. Biophys. J. 84, 4167-81. doi:10.1016/S0006-3495(03)75141-8.

Malnic, B., Hirono, J., Sato, T., and Buck, L. B. (1999). Combinatorial receptor codes for odors. Cell 96, 713-23. doi:10.1016/S0092-8674(00)80581-4.

Mandairon, N., Ferretti, C. J., Stack, C. M., Rubin, D. B., Cleland, T. A., and Linster, C. (2006). Cholinergic modulation in the olfactory bulb influences spontaneous olfactory discrimination in adult rats. Eur. J. Neurosci. 24, 3234-44. doi:10.1111/j.1460-9568.2006.05212.x.

Markopoulos, F., Rokni, D., Gire, D. H., and Murthy, V. N. (2012). Functional properties of cortical feedback projections to the olfactory bulb. Neuron 76, 1175-88. doi:10.1016/j.neuron.2012.10.028.

Matsumoto, H., Kashiwadani, H., Nagao, H., Aiba, A., and Mori, K. (2009). Odorinduced persistent discharge of mitral cells in the mouse olfactory bulb. $J$. Neurophysiol. 101, 1890-900. doi:10.1152/jn.91019.2008.

McGann, J. P., Pírez, N., Gainey, M. a, Muratore, C., Elias, A. S., and Wachowiak, M. (2005). Odorant representations are modulated by intra- but not interglomerular presynaptic inhibition of olfactory sensory neurons. Neuron 48, 1039-53. doi:10.1016/j.neuron.2005.10.031.

McKeegan, D. E. F., and Lippens, N. (2003). Adaptation responses of single avian olfactory bulb neurones. Neurosci. Lett. 344, 83-86. doi:10.1016/S03043940(03)00449-X.

Mori, K., Manabe, H., Narikiyo, K., and Onisawa, N. (2013). Olfactory consciousness and gamma oscillation couplings across the olfactory bulb, olfactory cortex, and orbitofrontal cortex. Front. Psychol. 4, 743. doi:10.3389/fpsyg.2013.00743.

Mori, K., Nagao, H., and Yoshihara, Y. (1999). The olfactory bulb: coding and processing of odor molecule information. Science 286, 711-715. doi:10.1126/science.286.5440.711.

Mori, K., Takahashi, Y. K., Igarashi, K. M., and Yamaguchi, M. (2006). Maps of odorant molecular features in the mammalian olfactory bulb. Physiol. Rev. 86, 409-33. doi:10.1152/physrev.00021.2005.

Nagayama, S. (2010). Differential axonal projection of mitral and tufted cells in the mouse main olfactory system. Front. Neural Circuits 4. doi:10.3389/fncir.2010.00120.

Nagayama, S. (2004). Mitral and tufted cells differ in the decoding manner of odor maps in the rat olfactory bulb. J. Neurophysiol. 91, 2532-2540. doi:10.1152/jn.01266.2003.

Nagayama, S., Homma, R., and Imamura, F. (2014). Neuronal organization of olfactory bulb circuits. Front. Neural Circuits 8. doi:10.3389/fncir.2014.00098. 
Najac, M., De Saint Jan, D., Reguero, L., Grandes, P., and Charpak, S. (2011). Monosynaptic and polysynaptic feed-forward inputs to mitral cells from olfactory sensory neurons. J. Neurosci. 31, 8722-8729. doi:10.1523/JNEUROSCI.052711.2011.

Ogg, M. C., Bendahamane, M., and Fletcher, M. L. (2015). Habituation of glomerular responses in the olfactory bulb following prolonged odor stimulation reflects reduced peripheral input. Front. Mol. Neurosci. 8, 53. doi:10.3389/fnmol.2015.00053.

Ohkura, M., Sasaki, T., Sadakari, J., Gengyo-Ando, K., Kagawa-Nagamura, Y., Kobayashi, C., Ikegaya, Y., and Nakai, J. (2012). Genetically encoded green fluorescent $\mathrm{Ca} 2+$ indicators with improved detectability for neuronal $\mathrm{Ca} 2+$ signals. PLoS One 7, e51286. doi:10.1371/journal.pone.0051286.

Ojima, H., Yamasaki, T., Kojima, H., and Akashi, A. (1988). Cholinergic innervation of the main and the accessory olfactory bulbs of the rat as revealed by a monoclonal antibody against choline acetyltransferase. Anat. Embryol. (Berl). 178, 481-488. doi:10.1007/BF00305035.

Pain, F., L'Heureux, B., and Gurden, H. (2011). Visualizing odor representation in the brain: a review of imaging techniques for the mapping of sensory activity in the olfactory glomeruli. Cell. Mol. Life Sci. 68, 2689-2709. doi:10.1007/s00018-0110708-4.

Parikh, V., Kozak, R., Martinez, V., and Sarter, M. (2007). Prefrontal acetylcholine release controls cue detection on multiple timescales. Neuron 56, 141-154. doi:10.1016/j.neuron.2007.08.025.

Parikh, V., Man, K., Decker, M. W., and Sarter, M. (2008). Glutamatergic contributions to nicotinic acetylcholine receptor agonist-evoked cholinergic transients in the prefrontal cortex. J. Neurosci. 28, 3769-3780. doi:10.1523/JNEUROSCI.525107.2008 .

Patterson, M. A., Lagier, S., and Carleton, A. (2013). Odor representations in the olfactory bulb evolve after the first breath and persist as an odor afterimage. Proc. Natl. Acad. Sci. U. S. A. 110, E3340-9. doi:10.1073/pnas.1303873110.

Pavesi, E., Gooch, A., Lee, E., and Fletcher, M. L. (2013). Cholinergic modulation during acquisition of olfactory fear conditioning alters learning and stimulus generalization in mice. Learn. Mem. 20, 6-10. doi:10.1101/lm.028324.112.

Petzold, G. C., Hagiwara, A., and Murthy, V. N. (2009). Serotonergic modulation of odor input to the mammalian olfactory bulb. Nat. Neurosci. 12, 784-791. doi:10.1038/nn.2335.

Pignatelli, A., and Belluzzi, O. (2008). Cholinergic modulation of dopaminergic neurons in the mouse olfactory bulb. Chem. Senses 33, 331-8. doi:10.1093/chemse/bjm091.

Pinto, L., Goard, M. J., Estandian, D., Xu, M., Kwan, A. C., Lee, S.-H., Harrison, T. C., Feng, G., and Dan, Y. (2013). Fast modulation of visual perception by basal forebrain cholinergic neurons. Nat. Neurosci. 16, 1857-63. doi:10.1038/nn.3552.

Potter, H., and Chorover, S. L. (1976). Response plasticity in hamster olfactory bulb: peripheral and central processes. Brain Res. 116, 417-29. doi:10.1016/00068993(76)90490-X. 
Ramaswami, M. (2014). Network plasticity in adaptive filtering and behavioral habituation. Neuron 82, 1216-29. doi:10.1016/j.neuron.2014.04.035.

Rankin, C. H., Abrams, T., Barry, R. J., Bhatnagar, S., Clayton, D. F., Colombo, J., Coppola, G., Geyer, M. A., Glanzman, D. L., Marsland, S., McSweeney, F. K., Wilson, D. A., Wu, C. F., and Thompson, R. F. (2009). Habituation revisited: an updated and revised description of the behavioral characteristics of habituation.

Neurobiol. Learn. Mem. 92, 135-8. doi:10.1016/j.nlm.2008.09.012.

R Core Team. (2016). R: a language and environment for statistical computing. $\mathrm{R}$ Foundation for Statistical Computing.

Reisert, J., and Matthews, H. R. (2001). Response properties of isolated mouse olfactory receptor cells. J. Physiol. 530, 113-122. doi:10.1111/j.1469-7793.2001.0113m.x.

Reisert, J., and Zhao, H. (2011). Perspectives on: information and coding in mammalian sensory physiology: response kinetics of olfactory receptor neurons and the implications in olfactory coding. J. Gen. Physiol. 138, 303-10. doi:10.1085/jgp.201110645.

Rothermel, M., Carey, R. M., Puche, A., Shipley, M. T., and Wachowiak, M. (2014). Cholinergic inputs from basal forebrain add an excitatory bias to odor coding in the olfactory bulb. J. Neurosci. 34, 4654-64. doi:10.1523/JNEUROSCI.502613.2014.

De Saint Jan, D., Hirnet, D., Westbrook, G. L., and Charpak, S. (2009). External tufted cells drive the output of olfactory bulb glomeruli. J. Neurosci. 29, 2043-52. doi:10.1523/JNEUROSCI.5317-08.2009.

Sarter, M., Lustig, C., Berry, A. S., Gritton, H., Howe, W. M., and Parikh, V. (2016). What do phasic cholinergic signals do? Neurobiol. Learn. Mem. 130, 135-141. doi:10.1016/j.nlm.2016.02.008.

Sarter, M., Parikh, V., and Howe, W. M. (2009). Phasic acetylcholine release and the volume transmission hypothesis: time to move on. Nat. Rev. Neurosci. 10, 383390. doi:10.1038/nrn2635.

Schafer, J. R., Kida, I., Rothman, D. L., Hyder, F., and Xu, F. (2005). Adaptation in the rodent olfactory bulb measured by fMRI. Magn. Reson. Med. 54, 443-448. doi: $10.1002 / \mathrm{mrm} .20588$.

Schneider, S. P., and Scott, J. W. (1983). Orthodromic response properties of rat olfactory bulb mitral and tufted cells correlate with their projection patterns. $J$. Neurophysiol. 50, 358-78.

Shipley, M. T., and Ennis, M. (1996). Functional organization of olfactory system. $J$. Neurobiol. 30, 123-76. doi:10.1002/(SICI)1097-4695(199605)30:1\&lt;123::AIDNEU11\&gt;3.0.CO;2-N.

Smith, J. J., Shionoya, K., Sullivan, R. M., and Wilson, D. A. (2009). Auditory stimulation dishabituates olfactory responses via noradrenergic cortical modulation. Neural Plast. 2009. doi:10.1155/2009/754014.

Storace, D. A., and Cohen, L. B. (2017). Measuring the olfactory bulb input-output transformation reveals a contribution to the perception of odorant concentration invariance. Nat. Commun. 8, 81. doi:10.1038/s41467-017-00036-2.

Vaaga, C. E., and Westbrook, G. L. (2017). Distinct temporal filters in mitral cells and external tufted cells of the olfactory bulb. J. Physiol. 595, 6349-6362.

doi:10.1113/JP274608. 
Vaaga, C. E., and Westbrook, G. L. (2016). Parallel processing of afferent olfactory sensory information. J. Physiol. 594, 6715-6732. doi:10.1113/JP272755.

Vankov, A., Hervé-Minvielle, A., and Sara, S. J. (1995). Response to novelty and its rapid habituation in locus coeruleus neurons of the freely exploring rat. Eur. J. Neurosci. 7, 1180-1187. doi:10.1111/j.1460-9568.1995.tb01108.x.

Wachowiak, M., and Cohen, L. B. (2001). Representation of odorants by receptor neuron input to the mouse olfactory bulb. Neuron 32, 723-35. doi:10.1016/S08966273(01)00506-2.

Wachowiak, M., Economo, M. N., Díaz-Quesada, M., Brunert, D., Wesson, D. W., White, J. A., and Rothermel, M. (2013). Optical dissection of odor information processing in vivo using GCaMPs expressed in specified cell types of the olfactory bulb. J. Neurosci. 33, 5285-300. doi:10.1523/JNEUROSCI.482412.2013.

Wachowiak, M., and Shipley, M. T. (2006). Coding and synaptic processing of sensory information in the glomerular layer of the olfactory bulb. Semin. Cell Dev. Biol. 17, 411-23. doi:10.1016/j.semcdb.2006.04.007.

Wesson, D. W., and Wilson, D. A. (2011). Sniffing out the contributions of the olfactory tubercle to the sense of smell: hedonics, sensory integration, and more? Neurosci. Biobehav. Rev. 35, 655-68. doi:10.1016/j.neubiorev.2010.08.004.

Wilson, D. A. (1998a). Synaptic correlates of odor habituation in the rat anterior piriform cortex. J. Neurophysiol. 80, 998-1001. doi:10.1101/1m.42601.LEARNING.

Wilson, D. A. (2000). Comparison of odor receptive field plasticity in the rat olfactory bulb and anterior piriform cortex. J. Neurophysiol. 84, 3036-3042.

Wilson, D. A. (1998b). Habituation of odor responses in the rat anterior piriform cortex. J. Neurophysiol. 79, 1425-40.

Wilson, D. A., Fletcher, M. L., and Sullivan, R. M. (2004). Acetylcholine and olfactory perceptual learning. Learn. Mem. 11, 28-34. doi:10.1101/1m.66404.

Wilson, D. A., and Linster, C. (2008). Neurobiology of a Simple Memory. J. Neurophysiol. 100, 2-7. doi:10.1152/jn.90479.2008.

Záborszky, L., Carlsen, J., Brashear, H. R., and Heimer, L. (1986). Cholinergic and GABAergic afferents to the olfactory bulb in the rat with special emphasis on the projection neurons in the nucleus of the horizontal limb of the diagonal band. $J$. Comp. Neurol. 243, 488-509. doi:10.1002/cne.902430405.

Zufall, F., and Leinders-Zufall, T. (1997). Identification of a long-lasting form of odor adaptation that depends on the carbon monoxide/cGMP second-messenger system. J. Neurosci. 17, 2703-2712.

Zufall, F., and Leinders-Zufall, T. (1998). Role of cyclic GMP in olfactory transduction and adaptation. Ann. N. Y. Acad. Sci. 855, 199-204.

Zufall, F., and Leinders-Zufall, T. (2000). The cellular and molecular basis of odor adaptation. Chem. Senses 25, 473-481. doi:10.1093/chemse/25.4.473. 


\section{VITA}

Cameron Ogg was born in Charlottesville, VA in 1988 and grew up in Memphis, TN. She completed her undergraduate studies at Bard College in Annandale-on-Hudson, $\mathrm{NY}$ and received a Bachelor of Arts in Biology with a concentration in Global Public Health in 2011. She returned to Memphis and began graduate school in the College of Graduate Health Sciences at the University of Tennessee Health Science Center in 2012. She will receive her Ph.D., with a major in Biomedical Sciences and a concentration in Neuroscience, in December 2017 and will begin her postdoctoral work at St. Jude Children's Research Hospital. 